\title{
Promising Natural Products in New Drug Design, Development, and Therapy for Skin Disorders: An Overview of Scientific Evidence and Understanding Their Mechanism of Action
}

\author{
Nurul Amirah Mohd Zaid, ',* \\ Mahendran Sekar, (iD ${ }^{1, *}$ \\ Srinivasa Reddy Bonam, (iD ${ }^{2, *}$ \\ Siew Hua Gan, (iD ${ }^{3}$ Pei Teng Lum,' \\ $M$ Yasmin Begum, ${ }^{4}$ \\ Nur Najihah Izzati Mat Rani, ${ }^{5}$ \\ Jaishree Vaijanathappa, ${ }^{6}$ \\ Yuan Seng Wu, (iD) \\ Vetriselvan Subramaniyan, ${ }^{9}$ \\ Neeraj Kumar Fuloria, ${ }^{10}$ \\ Shivkanya Fuloria ${ }^{10}$
}

'Department of Pharmaceutical Chemistry, Faculty of Pharmacy and Health Sciences, Royal College of Medicine Perak, Universiti Kuala Lumpur, Ipoh, 30450, Malaysia; ${ }^{2}$ Institut National de la Santé et de la Recherche Médicale; Centre de Recherche des Cordeliers, Equipe-

Immunopathologie et Immunointervention

Thérapeutique, Sorbonne Université, Université de Paris, Paris, France; ${ }^{3}$ School of Pharmacy,

Monash University Malaysia, Selangor Darul

Ehsan, 47500, Malaysia; ${ }^{4}$ Department of

Pharmaceutics, College of Pharmacy, King Khalid University (KKU), Asir-Abha, 6I42I, Saudi

Arabia; ${ }^{5}$ Faculty of Pharmacy and Health Sciences, Royal College of Medicine Perak, Universiti Kuala Lumpur, Ipoh, 30450, Malaysia; ${ }^{6}$ Faculty of Life Sciences, JSS Academy of Higher Education and Research Mauritius, Vacoas-Phoenix, Mauritius; ${ }^{7}$ Centre for Virus and Vaccine Research, School of Medical and Life Sciences, Sunway University, Selangor, 47500, Malaysia; ${ }^{8}$ Department of Biological Sciences, School of Medical and Life Sciences, Sunway University, Selangor, 47500,

Malaysia; ${ }^{9}$ Faculty of Medicine, Bioscience and Nursing, MAHSA University, Selangor, 42610, Malaysia; ${ }^{10}$ Faculty of Pharmacy, AIMST

University, Kedah, 08100, Malaysia

*These authors contributed equally to this work

Correspondence: Mahendran Sekar Department of Pharmaceutical

Chemistry, Faculty of Pharmacy and Health Sciences, Royal College of

Medicine Perak, Universiti Kuala Lumpur, Ipoh, 30450, Perak, Malaysia

Tel $+6016-3346653$

Fax $+605-2536634$

Email mahendransekar@unikl.edu.my

\begin{abstract}
The skin is the largest organ in the human body, composed of the epidermis and the dermis. It provides protection and acts as a barrier against external menaces like allergens, chemicals, systemic toxicity, and infectious organisms. Skin disorders like cancer, dermatitis, psoriasis, wounds, skin aging, acne, and skin infection occur frequently and can impact human life. According to a growing body of evidence, several studies have reported that natural products have the potential for treating skin disorders. Building on this information, this review provides brief information about the action of the most important in vitro and in vivo research on the use of ten selected natural products in inflammatory, neoplastic, and infectious skin disorders and their mechanisms that have been reported to date. The related studies and articles were searched from several databases, including PubMed, Google, Google Scholar, and ScienceDirect. Ten natural products that have been reported widely on skin disorders were reviewed in this study, with most showing anti-inflammatory, antioxidant, anti-microbial, and anti-cancer effects as the main therapeutic actions. Overall, most of the natural products reported in this review can reduce and suppress inflammatory markers, like tumor necrosis factor-alpha (TNF- $\alpha$ ), scavenge reactive oxygen species (ROS), induce cancer cell death through apoptosis, and prevent bacteria, fungal, and virus infections indicating their potentials. This review also highlighted the challenges and opportunities of natural products in transdermal/topical delivery systems and their safety considerations for skin disorders. Our findings indicated that natural products might be a low-cost, welltolerated, and safe treatment for skin diseases. However, a larger number of clinical trials are required to validate these findings. Natural products in combination with modern drugs, as well as the development of novel delivery mechanisms, represent a very promising area for future drug discovery of these natural leads against skin disorders.
\end{abstract}

Keywords: natural products, skin disorder, dermatitis, psoriasis, skin cancer, antiinflammatory, drug delivery

\section{Introduction}

The skin, which is the largest organ in the body, consists of several layers, including the epidermis, dermis, and hypodermis. The skin plays an important role by conferring protection and acting as a barrier to the body. It also regulates body temperature and facilitates sensation. The most common concern with regards to the skin is skin disorders or skin disease. In fact, $50 \%$ of the adult population have suffered from some type of skin disorder at one point in their lives, with one in 


\section{Graphical Abstract}

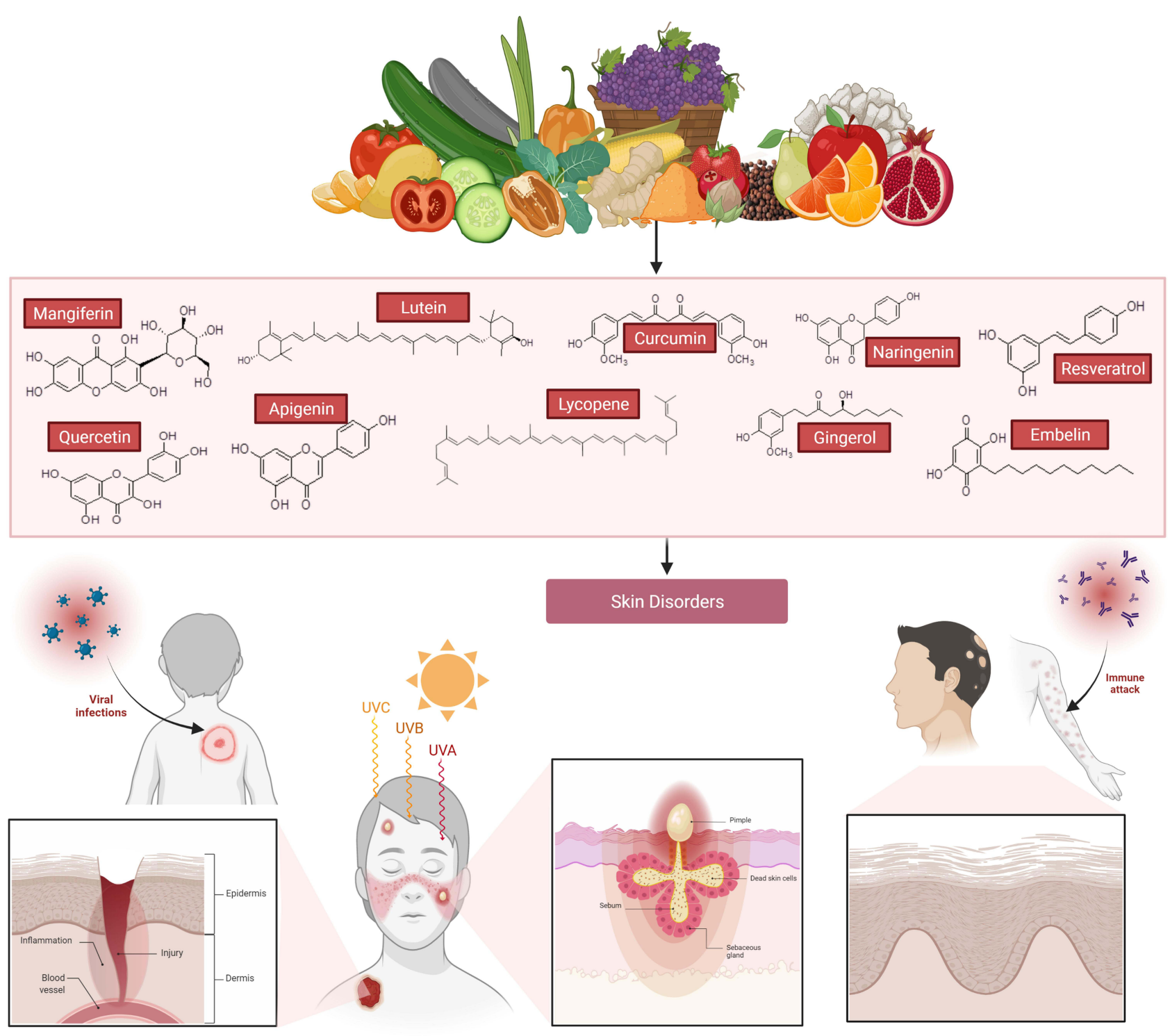

three having the chronic or mild condition. ${ }^{1}$ According to Kassab et al, ${ }^{2}$ skin disorders remain one of the biggest challenges that affect the quality-of-life of adults and teenagers alike.

\section{Skin}

Being the largest organ in the body, skin protects the internal organs from various external insults, such as invading pathogens (bacteria, fungi, viruses, parasites, and mites), exogenous physical stresses, chemicals, and others. Besides, it has an essential role in regulating temperature, electrolytes, water, and others, and providing essential vitamins to the whole body, ie, Vitamin D. Unlike other mucosal epithelia, skin possesses a dry (due to lipids) and a formidable layer of epithelia, which prevent the ease of access of microorganism entry. Despite other routes of pathogen entry, the skin plays an important role in protecting from pathogens. Besides, skin cells also produce many chemicals, such as fatty acids and defensins (antibacterial peptides), to destroy the pathogens. As such, skin is composed of three different major layers, which harbor several types of cells, including immune cells, that perform various functions (Figure 1). ${ }^{3}$ Considering this high amount of immune niches in the skin, it is regarded 


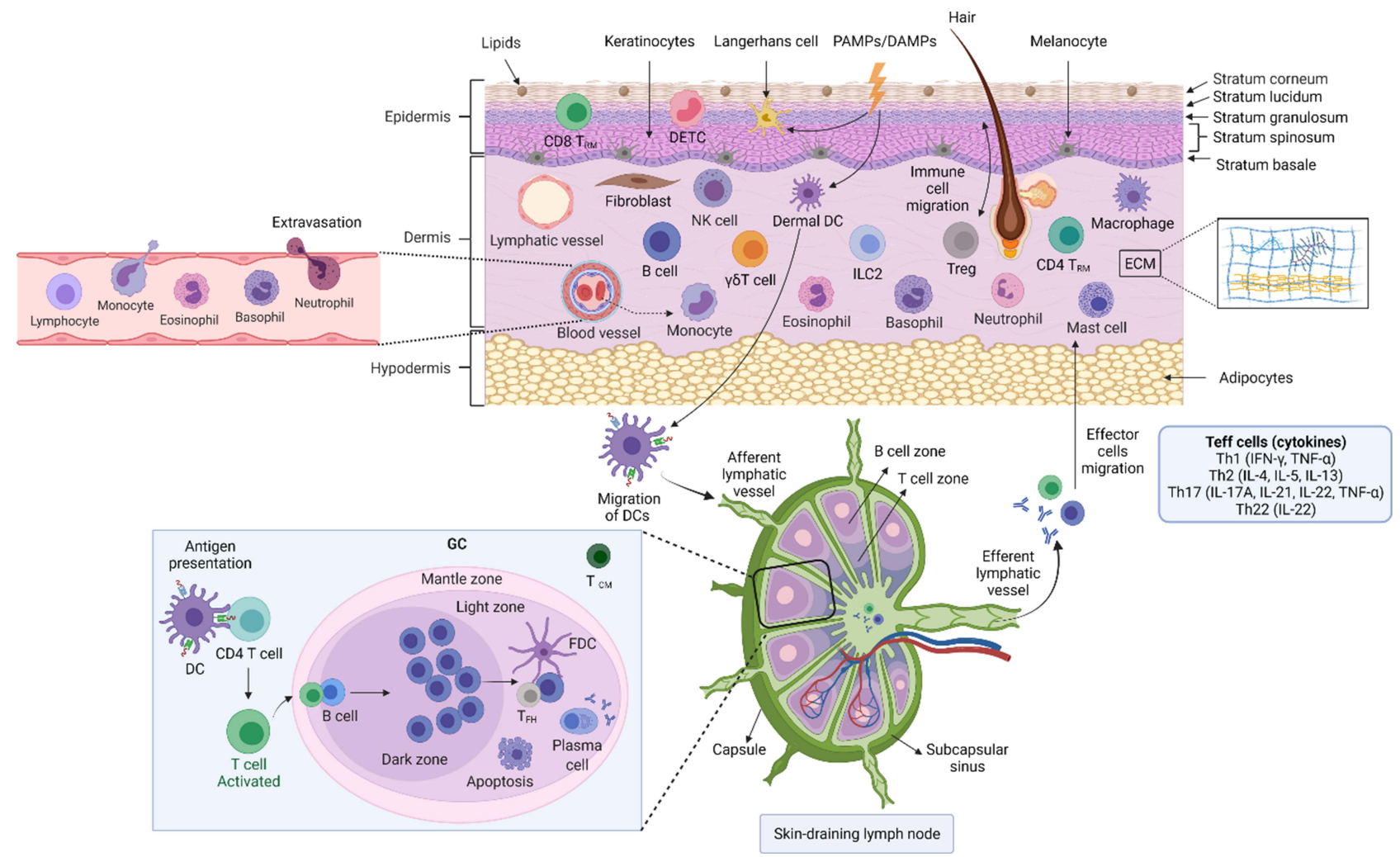

Figure I Skin anatomy in health. The skin structure is mainly divided into the epidermis, dermis, and subcutaneous/hypodermis. The epidermis is further divided into the stratum corneum, stratum lucidum, stratum granulosum, stratum spinosum, and stratum basale. The epidermis contains specialized cells, such as Langerhans cells (LCs), $\mathrm{CD}^{+}$T-cells, melanocytes, and others. Although skin appendages (hair, hair follicles, sweat glands, and sebaceous glands) are the main entry points for microorganisms, they are useful in transportation (from outside to inside and vice versa), prevention from mechanical damage, keeping skin dry, regulating temperature changes, protecting from ultraviolet light, and other. The dermis is the place where the majority of skin immunological interventions take place. The dermis is composed of fibroblasts, tissue-resident T-cells ( $\mathrm{T}_{\mathrm{RM}}$; including CD4 ${ }^{+} \mathrm{T}$-cells [ThI, Th2, and ThI7 cells] CD8 ${ }^{+}$T-cells, $\gamma \delta \mathrm{T}$ cells, NKT cells), dendritic cells (including plasmacytoid DCs, tissue-resident DCs), tissueresident macrophages, mast cells and others, and dense extracellular matrix (ECM). ECM is composed of collagen and elastin fibres, which occupies the extracellular space. The ECM provides a basement structure for the blood vessels, lymphatic vessel, and neurons through which transportation of immune cells and sensory functions are carried out, respectively. Beneath the dermis, a fatty layer which protects the host is the subcutaneous layer, also called subcutaneous adipose tissue. Along with the dermis, the subcutaneous layer also harbors a variety of immune cells, including T-cells, B-cells, macrophages, and others, and thus is collectively called the stromal vascular fraction (SVF). Despite immune cells function, adipocytes tissue secretes several bioactive proteins, collectively called adipokines (such as leptin, resistin, and adiponectin). These adipokines have various functions, including metabolic, inflammation, coagulation, vascular homeostasis, and others. Besides adipokines, adipocytes also secrete other molecules, such as IL-6, TGF- $\beta$, IGF-I, and others. Dermal DCs and LCs, which carry self/non-self-antigens (from PAMPs or DAMPs), migrate to lymph nodes and become antigen-presenting cells and present the antigens to the lymph node resident T-cells. The antigen-experienced T-cells differentiated into T-helper cells and migrate to the injured skin scite. Similarly, B-cells produce antibodies against self/non-self-antigens. The stratum corneum is the outermost layer (I0-30 $\mu \mathrm{m})$ in the skin, which is formed majorly from dead keratinocytes (also called denucleated keratinocytes; corneocytes), intracellular lipids (providing the hydrophobic nature to the skin), and others. The stratum lucidum is a very thin layer of dead cells in the skin after the stratum corneum that can appear as a translucent layer under a microscope. The stratum granulosumis composed of 3-5 layers of cells, which are composed of dark clumps of cytoplasmic granules. The stratum spinosum,also known as the prickle cell layer, originated from the keratinocytes that were differentiated and moved from the stratum basale. The stratum basale is a single layer of undifferentiated keratinocytes, which is the source of the stratum spinosum, and composed of melanocytes (Pigment melanin secreting cells). More information on skin anatomy can be found in excellent reviews. ${ }^{3,10,11,210}$ Created with BioRender.com.

Abbreviations: DAMPs, damage-associated molecular patterns; IGF, Insulin-like growth factor; NKT, natural killer T-cells; PAMPs, pathogen-associated molecular pattern; TGF, transforming growth factor, IL, interleukin.

as "skin immune system" or "tertiary lymphoid structures" (TLS) or "tertiary lymphoid organs" (TLO).,

Dysregulations in the skin-associated lymphoid system lead to chronic, inflammatory, and hyperproliferative skin diseases (Table 1). In addition, damaged or tender skin is the best route of entry for many microorganisms. Therefore, regulation of immune responses in the skin is at most important. The skin-associated lymphoid system is composed of tightly coordinated innate and adaptive arms of the immune system. Despite the innate immune system, humoral immunity (also called antibody-mediated immunity) in the adaptive immune system is also critical for regulating immune homeostasis in the skin. B-cells and their subtypes in the skin have been implicated in antibody-mediated protective immunity. However, the type of antibody production (either self-reactive or non-self-reactive) depends on the type of antigen (self or foreign) exposed, and may drive or suppress the inflammatory 
Table I List of Skin Diseases or Disorders

\begin{tabular}{|c|c|c|c|}
\hline Disease & Characteristics & Causative Factor & References \\
\hline \multicolumn{4}{|c|}{ Autoimmune disorders } \\
\hline $\begin{array}{l}\text { Systemic lupus erythematosus } \\
\text { (SLE) }\end{array}$ & $\begin{array}{l}\text { Antigen-antibody complexes deposition at the } \\
\text { basement membrane region (place where } \\
\text { dermis and epidermis separated) }\end{array}$ & Autoantibodies & Pires et $\mathrm{al}^{224}$ \\
\hline $\begin{array}{l}\text { Scleroderma and morphea } \\
\text { (localized scleroderma) }\end{array}$ & Collagen overproduction in the dermis & - & $\begin{array}{l}\text { Careta and } \\
\text { Romiti }\end{array}$ \\
\hline Mixed connective tissue disease & $\begin{array}{l}\text { Elevated blood levels of anti-UI- } \\
\text { ribonucleoprotein in at least two connective } \\
\text { tissue diseases }\end{array}$ & - & $\begin{array}{l}\text { Sapkota and Al } \\
\text { Khalili }^{226}\end{array}$ \\
\hline Dermatomyositis & $\begin{array}{l}\text { Symmetrical proximal muscle weakness, } \\
\text { elevated serum muscle enzymes, and muscle } \\
\text { biopsy and electromyography findings consistent } \\
\text { with myositis }\end{array}$ & $\begin{array}{l}\text { Immune system activation that causes } \\
\text { immunologic attacks on muscle fibers and } \\
\text { endomysial capillaries }\end{array}$ & $\begin{array}{l}\text { Cheeti et } \mathrm{al}^{227} \\
\text { Koler and } \\
\text { Montemarano } \\
\end{array}$ \\
\hline \multicolumn{4}{|c|}{ Eczematous disorders } \\
\hline Atopic dermatitis & $\begin{array}{l}\text { Genetic, environmental, and immunologic } \\
\text { mechanisms play a role in this inflammatory } \\
\text { disorder. Pro-inflammatory cytokines are } \\
\text { released by keratinocytes in response to } \\
\text { neuropeptides, irritation, or pruritus-induced } \\
\text { scratching }\end{array}$ & $\begin{array}{l}\text { Defects in skin barrier function, immune } \\
\text { dysregulation, and exposure to infectious agents }\end{array}$ & $\begin{array}{l}\text { Siiskonen and } \\
\text { Harvima }^{229} ; \\
\text { Umehara et } \text { al }^{230}\end{array}$ \\
\hline Allergic contact dermatitis & $\begin{array}{l}\text { An antigenic agent triggers an immunologic } \\
\text { reaction in the skin, which may take several days } \\
\text { to occur }\end{array}$ & Antigenic substance & $\begin{array}{l}\text { Corsini et } \mathrm{al}^{231} \\
\text { Kaplan et } \mathrm{al}^{232}\end{array}$ \\
\hline \multicolumn{4}{|c|}{ Hair loss associated skin disorder } \\
\hline Alopecia areata & $\begin{array}{l}\text { Hair loss on the scalp, face, and other parts of } \\
\text { the body is caused by an autoimmune skin } \\
\text { disease. }\end{array}$ & Abnormality in the immune system & Pratt et $\mathrm{al}^{233}$ \\
\hline \multicolumn{4}{|c|}{ Immunodeficiencies } \\
\hline Ataxia telangiectasia & $\begin{array}{l}\text { Development of reddish lesions of the skin and } \\
\text { mucous membranes (Ataxia) due to permanent } \\
\text { widening of groups of blood vessels } \\
\text { (telangiectasia), and impaired immune system } \\
\text { functioning }\end{array}$ & $\begin{array}{l}\text { Mutations in a gene on chromosome II (ATM } \\
\text { gene) }\end{array}$ & $\begin{array}{l}\text { Folgori et a }\left.\right|^{234} \\
\text { Goldman }^{235}\end{array}$ \\
\hline $\begin{array}{l}\text { Chronic mucocutaneous } \\
\text { candidiasis }\end{array}$ & $\begin{array}{l}\text { Candida spp., primarily Candida albicans, cause } \\
\text { recurrent or chronic infections of the nails, skin, } \\
\text { and oral and genital mucosae }\end{array}$ & Primary immune deficiency & Beenhouwer ${ }^{236}$ \\
\hline Chronic granulomatous disease & $\begin{array}{l}\text { Recurrent, life-threatening bacterial and fungal } \\
\text { infections as well as granuloma formation }\end{array}$ & $\begin{array}{l}\text { Defects in an essential enzyme in white blood } \\
\text { cells that produce oxidants for microbial killing } \\
\text { are inherited }\end{array}$ & Song et $\mathrm{al}^{237}$ \\
\hline $\begin{array}{l}\text { Hyper-Immunoglobulin E } \\
\text { syndrome }\end{array}$ & $\begin{array}{l}\text { Recurrent eczema, skin abscesses, lung } \\
\text { infections, eosinophilia, and elevated lgE levels in } \\
\text { the blood }\end{array}$ & Genetic mutation in either STAT3 or DOCK8 & $\begin{array}{l}\text { Freeman and } \\
\text { Holland }^{238} ; \\
\text { Freeman and } \\
\text { Olivier } \\
239\end{array}$ \\
\hline $\begin{array}{l}\text { Leukocyte adhesion molecule } \\
\text { deficiency }\end{array}$ & $\begin{array}{l}\text { Inability of leukocytes to migrate from } \\
\text { circulation into sites of inflammation, resulting in } \\
\text { recurrent bacterial infections }\end{array}$ & $\begin{array}{l}\text { Deficiency of adhesive glycoproteins on the } \\
\text { surfaces of white blood cells }\end{array}$ & $\begin{array}{l}\text { Snyder }{ }^{240} ; \text { Justiz } \\
\text { Vaillant and } \\
\text { Ahmad } \\
\text { 24l }\end{array}$ \\
\hline
\end{tabular}

(Continued) 
Table I (Continued).

\begin{tabular}{|c|c|c|c|}
\hline Disease & Characteristics & Causative Factor & References \\
\hline $\begin{array}{l}\text { Severe combined } \\
\text { immunodeficiency }\end{array}$ & $\begin{array}{l}\text { Numerous genetic mutations disrupt the } \\
\text { production of functional T- and B-cells, resulting } \\
\text { in a wide range of clinical signs }\end{array}$ & $\begin{array}{l}\text { X-linked trait disorder or inherited autosomal } \\
\text { recessive genetic trait }\end{array}$ & $\begin{array}{l}\text { Fischer }^{242} \\
\text { Tasher and } \\
\text { Dalal }^{243}\end{array}$ \\
\hline $\begin{array}{l}\text { Warts- } \\
\text { hypogammaglobulinemia- } \\
\text { infections-myelokathexis } \\
\text { syndrome (WHIM syndrome) }\end{array}$ & $\begin{array}{l}\text { Neutropenia, lymphopenia, infection } \\
\text { susceptibility, and myelokathexis which } \\
\text { describes degenerative changes in mature } \\
\text { neutrophils and hyperplasia of bone marrow } \\
\text { myeloid cells }\end{array}$ & $\begin{array}{l}\text { Primary immunodeficiency caused by } \\
\text { heterozygous mutations in the CXCR } 4\end{array}$ & Badolato et $\mathrm{al}^{244}$ \\
\hline Wiskott-Aldrich syndrome & $\begin{array}{l}\text { Rare X-linked disorder that usually includes the } \\
\text { triad of immunodeficiency, thrombocytopenia, } \\
\text { and eczema }\end{array}$ & $\begin{array}{l}\text { Mutations in the gene encoding for WASP, a key } \\
\text { regulator of signaling and cytoskeletal } \\
\text { reorganization in hematopoietic cells }\end{array}$ & $\begin{array}{l}\text { Baharin et al }{ }^{245} \text {; } \\
\text { Malik and } \\
\text { Masab }^{246}\end{array}$ \\
\hline Papulosquamous disorders & $\begin{array}{l}\text { Well-demarcated areas of papules and scale, } \\
\text { typically on an erythematous background }\end{array}$ & - & $\begin{array}{l}\text { Errichetti and } \\
\text { Stinco } 247 \text {; Langley } \\
\text { et } \mathrm{al}^{248}\end{array}$ \\
\hline Psoriasis & $\begin{array}{l}\text { Skin disease that produces plaques of thickened, } \\
\text { scaly skin }\end{array}$ & THI-type cytokines & Armstrong ${ }^{249}$ \\
\hline Lichen planus & Itchy, non-infectious rash on the arms and legs & $\begin{array}{l}\text { Stress, anxiety, and other factors in relation with } \\
\text { the immune system }\end{array}$ & $\begin{array}{l}\text { Arnold and } \\
\text { Krishnamurthy }\end{array}$ \\
\hline Cutaneous graft vs host disease & $\begin{array}{l}\text { Maculopapular rash that can begin anywhere in } \\
\text { the body but often starts with palm and sole } \\
\text { involvement }\end{array}$ & Immune response against tissue and organ & Villarreal et $\mathrm{al}^{251}$ \\
\hline \multicolumn{4}{|c|}{ Photodermatoses } \\
\hline Polymorphous light eruption & $\begin{array}{l}\text { Recurrent, abnormal, delayed reactions to } \\
\text { sunlight on sunlight-exposed surfaces, ranging } \\
\text { from erythematous papules, papulovesicles, and } \\
\text { plaques to erythema multiforme-like lesions }\end{array}$ & UVA light spectrum, UVB and visible light & $\begin{array}{l}\text { Plaza and } \\
\text { Prieto }\end{array}$ \\
\hline Solar urticaria & $\begin{array}{l}\text { Recurrent episodes of urticaria overlying } \\
\text { regions of the skin that are exposed to sunlight }\end{array}$ & Antigen-antibody reaction & Harris et $\mathrm{al}^{253}$ \\
\hline Chronic actinic dermatitis & $\begin{array}{l}\text { Persistent eczematous eruption, occasionally } \\
\text { associated with infiltrated papules and plaques } \\
\text { due to a reaction to sunlight or artificial light }\end{array}$ & Extrinsic chemicals and intrinsic factors & Smith et $\mathrm{al}^{254}$ \\
\hline Photoallergic contact dermatitis & $\begin{array}{l}\text { Delayed-type hypersensitivity cutaneous } \\
\text { reaction in response to a photoantigen applied } \\
\text { to the skin in subjects previously sensitized to } \\
\text { the same substance }\end{array}$ & Photoallergen & Foti et al ${ }^{255}$ \\
\hline \multicolumn{4}{|c|}{ Pigmentary disorders } \\
\hline Vitiligo & Patches of the skin losing their pigment or color & $\begin{array}{l}\text { Loss or destruction of melanocytes, which are } \\
\text { the cells that produce melanin }\end{array}$ & $\begin{array}{l}\text { Bergqvist and } \\
\text { Ezzedine }^{256}\end{array}$ \\
\hline Purpuric disorders & $\begin{array}{l}\text { Small bleeding vessels near the surface produce } \\
\text { a purplish discoloration of the skin }\end{array}$ & $\begin{array}{l}\text { Deficiency of the anticoagulants protein } \mathrm{C} \text {, } \\
\text { protein } \mathrm{S} \text {, and antithrombin III }\end{array}$ & $\begin{array}{l}\text { Marks and } \\
\text { Miller }{ }^{257} \text {; Reamy } \\
\text { et } \mathrm{a}^{258}\end{array}$ \\
\hline Leukocytoclastic vasculitis & $\begin{array}{l}\text { Inflammation of small blood vessels presenting } \\
\text { with petechiae and palpable purpura }\end{array}$ & $\begin{array}{l}\text { Allergic reaction via mechanism like injury by } \\
\text { bacteria or viruses, activation of antibodies, and } \\
\text { activation of complement }\end{array}$ & $\begin{array}{l}\text { Azanza et } \mathrm{al}^{259} \\
\text { Baigrie et } \mathrm{al}^{260}\end{array}$ \\
\hline
\end{tabular}

(Continued) 
Table I (Continued).

\begin{tabular}{|c|c|c|c|}
\hline Disease & Characteristics & Causative Factor & References \\
\hline $\begin{array}{l}\text { Medium vessel vasculitides } \\
\text { (polyarteritis nodosa, } \\
\text { Wegener's Granulomatosis, and } \\
\text { Churg-Strauss vasculitis) }\end{array}$ & $\begin{array}{l}\text { Inflammation and necrosis on the walls of } \\
\text { medium blood vessels, resulting in lumen } \\
\text { occlusion }\end{array}$ & $\begin{array}{l}\text { Infectious agent or medication such as those } \\
\text { associated with hepatitis B or } C \text { viruses (HBV or } \\
H C V \text {, respectively), cryoglobulinaemic vasculitis, } \\
\text { or cutaneous leucocytoclastic vasculitis, } \\
\text { preceded by an infection or the use of certain } \\
\text { medicine }\end{array}$ & $\begin{array}{l}\text { Baigrie et } \mathrm{al}^{260} \\
\text { Hunder }\end{array}$ \\
\hline \multicolumn{4}{|c|}{ Urticarial disorders } \\
\hline Urticaria and angioedema & $\begin{array}{l}\text { Maculae, papules, and edematous, pruriginous } \\
\text { erythematous plaques that appear unexpectedly } \\
\text { and disappear spontaneously in minutes, hours, } \\
\text { or days }\end{array}$ & $\begin{array}{l}\text { Autoantibodies to the alpha subunit of the high- } \\
\text { affinity lgE receptor on dermal mast cells and } \\
\text { basophils respond with circulating } \\
\text { immunoglobulin G (lgG) autoantibodies, } \\
\text { prompting chronic activation of these cells and } \\
\text { the release of histamine and other inflammatory } \\
\text { mediators }\end{array}$ & $\begin{array}{l}\text { Deacock }^{262} ; \\
\text { Engin et } \mathrm{al}^{263}\end{array}$ \\
\hline Erythema multiforme & $\begin{array}{l}\text { Rash with papular (small raised bumps) or } \\
\text { vesicular lesions (blisters) and skin reddening or } \\
\text { discoloration, usually in concentric zones } \\
\text { around the lesion }\end{array}$ & $\begin{array}{l}\text { Allergic reaction usually due to Herpes virus } \\
\text { (HSV) }\end{array}$ & $\begin{array}{l}\text { Ely and Stone } \mathrm{e}^{264} \text {; } \\
\text { Hafsi and } \\
\text { Badri' } \\
\text { et } \mathrm{al}^{265} ; \text { Paulino }\end{array}$ \\
\hline Stevens Johnson syndrome & $\begin{array}{l}\text { Rare but extreme and life-threatening blistering } \\
\text { eruptions }\end{array}$ & Drug-specific CD8+ cytotoxic lymphocytes & Klimas et $\mathrm{a}^{267}$ \\
\hline Toxic epidermal necrolysis & Blisters and peels of the top layer of skin & Drug-specific CD8+ cytotoxic lymphocytes & Mawson et $\mathrm{al}^{268}$ \\
\hline $\begin{array}{l}\text { Cryopyrin-associated periodic } \\
\text { syndromes (Muckle Wells } \\
\text { syndrome and Familial cold } \\
\text { urticaria) }\end{array}$ & $\begin{array}{l}\text { Recurrent flares or mild to severe systemic } \\
\text { inflammation and fever including episodic fever, } \\
\text { urticaria-like rash, and joint involvement }\end{array}$ & $\begin{array}{l}\text { Increased activation of the NLRP3- } \\
\text { inflammasome and overproduction of IL-I } \beta \text { was } \\
\text { associated with mutations in the NLRP3 gene }\end{array}$ & Azizi et $\mathrm{al}^{269}$ \\
\hline $\begin{array}{l}\text { Neonatal onset multisystem } \\
\text { inflammatory disease (NOMID) }\end{array}$ & $\begin{array}{l}\text { Fever, rash, and tissue damage of the nervous } \\
\text { system, skin, and joints }\end{array}$ & Mutations in the CIASI/NLRP3 gene & $\begin{array}{l}\text { Alsharief et } \mathrm{al}^{270} \text {; } \\
\text { Huttenlocher } \\
\text { et } \mathrm{al}^{271}\end{array}$ \\
\hline $\begin{array}{l}\text { Deficiency of the interleukin-I- } \\
\text { receptor antagonist (DIRA) }\end{array}$ & $\begin{array}{l}\text { The neonatal onset of a pustular skin rash, } \\
\text { multifocal osteomyelitis, periostitis, and, } \\
\text { occasionally, vasculitis }\end{array}$ & Autosomal recessive mutations in ILIRN & $\begin{array}{l}\text { Kutukculer } \\
\text { et al }{ }^{272} ; \\
\text { Schnellbacher } \\
\text { et al }\left.\right|^{273}\end{array}$ \\
\hline \multicolumn{4}{|c|}{ Vesiculobullous diseases } \\
\hline Pemphigus Vulgaris & $\begin{array}{l}\text { The appearance of blisters that originate in the } \\
\text { epidermis suprabasal layer }\end{array}$ & Anti-desmoglein I and 3 antibodies & $\begin{array}{l}\text { Kasperkiewicz } \\
\text { et } \mathrm{al}^{274}\end{array}$ \\
\hline Pemphigus Foliaceus & Blisters in the upper epidermis & Anti-desmoglein I antibodies & James et al ${ }^{275}$ \\
\hline Bullous pemphigoid & $\begin{array}{l}\text { Itching, blistering, and urticarial lesions (hives) } \\
\text { that affect a small area of the body or are } \\
\text { widespread }\end{array}$ & Autoantibodies & Bakker et $\mathrm{al}^{276}$ \\
\hline Paraneoplastic pemphigus & $\begin{array}{l}\text { Ulcerated lesions and vesicular eruptions in the } \\
\text { mucocutaneous regions }\end{array}$ & $\begin{array}{l}\text { Autoantibodies that target desmoglein I and 3; } \\
\text { desmocollins I, 2, and 3; desmoplakins I and 2; } \\
\text { BP230; BPI30; and envoplakin }\end{array}$ & Yatim et al ${ }^{277}$ \\
\hline
\end{tabular}

(Continued) 
Table I (Continued).

\begin{tabular}{|c|c|c|c|}
\hline Disease & Characteristics & Causative Factor & References \\
\hline Epidermolysis bullosa acquisita & $\begin{array}{l}\text { Skin fragility, noninflammatory tense bullae, } \\
\text { milia, and scarring are all indications of } \\
\text { subepidermal blistering disease of the skin and } \\
\text { mucus membranes. }\end{array}$ & Anti-type VII collagen autoantibodies & Gupta et $\mathrm{al}^{278}$ \\
\hline Dermatitis herpetiformis & $\begin{array}{l}\text { Groups of extremely itchy blisters and raised } \\
\text { red skin lesions are present }\end{array}$ & IgA antibodies & Criado et $\mathrm{al}^{279}$ \\
\hline Linear IgA bullous dermatoses & $\begin{array}{l}\text { Blisters with a tense clinical appearance are } \\
\text { produced by linear deposition of } \lg A \text { and } \\
\text { disturbance of the dermoepidermal junction }\end{array}$ & IgA autoantibodies & Chen et $\mathrm{al}^{280}$ \\
\hline Pemphigus gestationis & $\begin{array}{l}\text { Appearance of very itchy red bumps or blisters } \\
\text { on the abdomen and trunk, and other parts of } \\
\text { the body during second and third trimesters of } \\
\text { pregnancy }\end{array}$ & IgG autoantibodies & $\begin{array}{l}\text { Șentürk et } \mathrm{al}^{281} \\
\text { Snarskaya et } \mathrm{al}^{282}\end{array}$ \\
\hline
\end{tabular}

Notes: The main body text contains all of the abbreviations.

response. Therefore, B-cells are implicated in both homeostatic and pathogenic mechanisms in the skin. Although information about localized skin-resident B-cells is inadequate, their migration, via expressing cutaneous lymphocyte-associated antigen (CLA) and chemokine receptors, to the skin during the inflammatory diseases is well established. ${ }^{6}$

Several autoimmune skin diseases are positively correlated with the infiltrating B-cell subsets. ${ }^{6-9}$ Moreover, the skin-homing B-cells respond to local antigens and produce antibodies, which is devoid of primary and secondary lymphoid organs. These antibodies play a crucial role in autoimmune diseases. Some B-cell-mediated autoimmune diseases are mostly by autoreactive B-cells that are possibly devoid of T-cell involvement. The precise source of the autoreactive B-cells in the skin is unknown and is debatable. It is assumed that autoreactive B-cells are generated from either bone marrow or secondary lymphoid organs. However, how these cells are produced by escaping the central or peripheral tolerance checkpoints is still an unanswered question. Once autoreactive B-cells differentiate into memory B-cells and plasma cells in the germinal centers, they become culprits for systemic secretion of autoantibodies. Once the plasma cells are generated, it's their innate nature to reach bone marrow and become a reservoir for a long time (even lifelong) of autoantibody secretion, upon antigen encounter. In skin-associated or cutaneous autoimmune diseases, the presence of autoantibodies is considered a unique diagnostic method. The skin resident autoreactive Bcells amplify or aggravate the autoimmune disease via antibody secretion (IgM, IgG, and $\operatorname{IgA})$, antigen-presentation, T-cell stimulation, pro- and anti-inflammatory cytokine secretion (IL-6, IL-10, and TGF- $\beta$ ), and growth factors secretion (platelet-derived growth factor, basic fibroblast growth factor) in the microenvironment.

\section{Innate and Adaptive Immune System of the Skin}

Skin-associated lymphoid tissue contains both innate and adaptive immune systems, which confer protection locally and systemically. ${ }^{10,11}$ Disturbance in the above system leads to episodes of opportunistic infections and the development of tumors or other immunological diseases. The skin protects the host from most infectious agents by two mechanisms; antigennonspecific and antigen-specific. ${ }^{10,12}$ If a physical barrier (stratum corneum or sebaceous gland secretions) is breached, the innate immune system comes into action. Like other parts of the body, the innate immune system is the first-line defence in the skin, and keratinocytes, monocytes, macrophages, Langerhans cells, dendritic cells, mast cells, and complement components are the innate components of the skin. Among them, keratinocytes are the first responders against any insults. ${ }^{10,11}$ These innate cells possess a high level of patternrecognition receptors (PRRs), which sense pathogen-associated molecular pattern molecules (from pathogen)/damageassociated molecular patterns (from UV radiation or physical damage) (Figure 1) followed by the induction of downstream signaling via NF-kB or inflammasome to produce signaling molecules, such as cytokines, chemokines, and others. Specifically, keratinocytes and mast cells secrete antimicrobial peptides, cathelicidins, and $\beta$-defensins, which also initiate the 
inflammatory response. ${ }^{3,10,11}$ Although the above-mentioned antigen-nonspecific mechanism is wise enough to prevent the spread of pathogens, the innate system alone is not enough to protect the host from reinfection. Nevertheless, the secreted mediators from the innate immune system activate other bystander cells and tissue-resident lymphocytes, particularly T-cells. Besides cytokines and chemokines secreted by melanocytes, fibroblasts also influence the $\mathrm{T}$ lymphocytes.

Innate immune system functions are synergized by the adaptive immune system, composed of T-cells, B-cells, and NK cells. Figure 2 depicts the interactions of the innate and acquired immune systems in cutaneous bacterial infection. Although B-cells have a very limited direct role in protection, T-cells-mediated immunity is well documented in skin diseases. Interestingly, a high amount of Tcells reside in the healthy dermal tissue, which is 2-fold higher than circulating T-cells. ${ }^{10,11}$ LCs and DCs in the innate system present the self and non-self-antigens to the T-cells in the skin-draining lymph nodes (Figure 1). The antigen educated T-cells in the lymph nodes become $\mathrm{T}$ effector cells ( $\mathrm{T}_{\mathrm{EM}}$, effector memory T-cells) and migrate to the site of infection/damage. Some $\mathrm{T}$-cells $\left(\mathrm{T}_{\mathrm{CM}}\right.$, Central memory T-cells) reside in the lymph nodes, and act as a reservoir of skin T-cells. Upon reaching the skin, T-cells proliferate and expand into different subsets, such as Th1, Th2, Th17, Th22, and Treg cells, and each subset has its role in maintaining homeostasis. ${ }^{10-12}$ Further, $\mathrm{T}$ helper cells aid in the induction of activation of B-cells and B-cell mediated protection (Figure 2).

Once the defence task is completed, either by clearing pathogens or removing damaged cells, the innate cells initiate the resolution phase by producing various immunosuppressive signals, including immunomodulatory cytokines (IL-10, TGF- $\beta$ ) or immunosuppressive mediators (indoleamine 2,3 dioxygenase), selective receptor antagonists (Interleukin-1 receptor antagonist), activating Tregs, and others. ${ }^{3}$ Functionally, the aforementioned factors regulate the inflammatory cellular response and establish preinflammatory/homeostatic conditions in the skin.

In contrast, the aberrations/excessive immune response, such as the antigen-presentation, cytokine secretion, differences in distinguishing self and non-self leads to various disease, including autoimmune diseases. On the other hand, inadequate immune response in the skin is more prone to infectious diseases and tumors. This impairment of immune surveillance can occur by a variety of agents, such as chemicals, microorganisms, radiation, and others. ${ }^{12}$
Skin disorders or diseases may include eczema, fungal infections, benign tumors, and viral warts. ${ }^{1}$ Other skin conditions, including acne, atopic dermatitis, wound, skin cancer, psoriasis, iatrogenic dermatitis, infection, and inflammation, may be age-related. ${ }^{13}$ Humans are affected by hundreds of skin disorders. Because some of the symptoms of the most common skin infections are similar, it is essential to know the differences between them. The most common skin diseases are listed in Table 1, which are separated by types. Some other influencing factors include lifestyle, such as diet. For example, high dietary consumption of oily or fatty food, sweet food, chocolates, dairy products, and nuts is related with facial acne or acne worsening. ${ }^{2}$ Other risk factors contributing to a worsening of skin disease include the socioeconomic status of the population. Lower socioeconomic status may have an impact on access to healthcare, ${ }^{14}$ resulting in a higher demand for skin infection and eczema treatment in this population group. ${ }^{1}$ Skin disorders generally have a greater effect on patients as they mostly affect the quality-of-life. Kassab et $\mathrm{al}^{2}$ reported that skin disorders impact the daily physical, social, and psychological features of patients. Physical impact is the severity of the rash and the area which may contribute to itching and flaking. Psoriasis is another important skin condition that leads to severe itching if not carefully treated. ${ }^{2}$ Meanwhile, social impact is the relationship between humans in which an individual with skin disease may isolate himself. Finally, anxiety and depression are two psychological impacts of skin disorders incurred as a result of frustration and embarrassment. ${ }^{2}$

\section{Role and Importance of Natural Products in Drug Development Against Skin Disorders}

Contemporary medicine is a therapy that uses biomedical research, health sciences, genetics, and medical technology to detect, cure, and prevent disease and injury by using pharmacological and non-pharmacological approaches. In addition to that, it also involves ionizing radiation, psychotherapy, and biologics. Natural products or specifically botanicals are very important as a therapeutic approach in contemporary medicine when designed in suitable dosage as they can become an effective therapy to treat the disease, have less side-effects compared to most pharmaceutical drugs, and are not so expensive compared to modern pharmaceutical drugs if these botanicals are used and administered wisely, properly, and rationally. Malik et $\mathrm{al}^{15}$ reported that herbal medicine is essential 

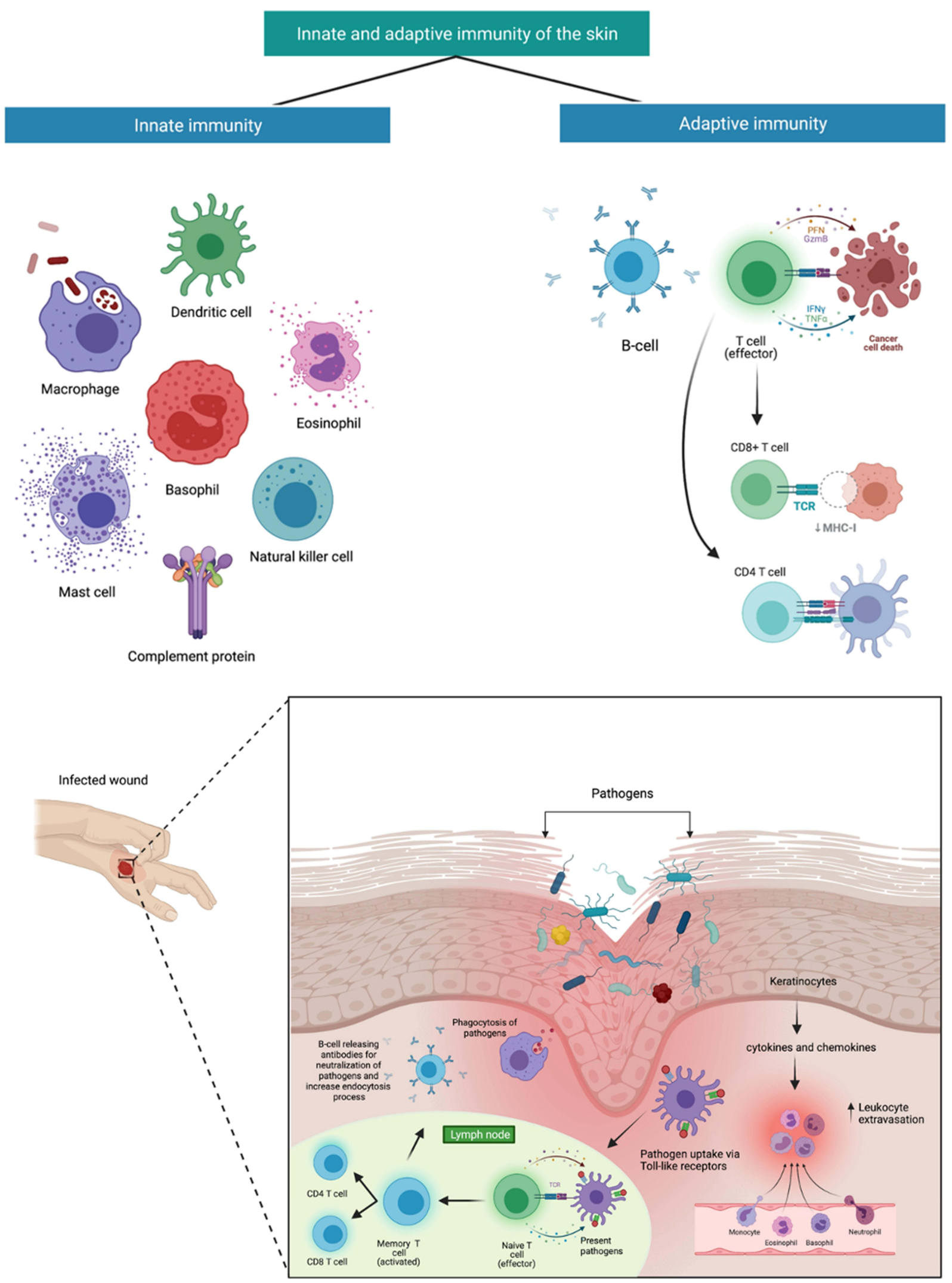

Figure 2 Innate and acquired immune systems interactions in cutaneous bacterial infection. Disruption in the aforementioned barrier leads directly to occasional infections. In reaction to bacteria infringing the epithelial barrier, keratinocytes will produce chemokines, antimicrobial peptides, and cytokine,s which leads to an increase in leukocyte extravasation stimulating the migration into the skin and guiding these cells via chemotactic gradients. Dendritic cells convey bacterial antigens to naïe and central T-cells, contributing to pathogen-specific cells being activated producing CD4 and CD8 T-cells which increased targeting of innate responses. Created with BioRender.com. 
and has become the alternative treatment to cure and control skin disorders due to its fewer side-effects and the cost of treatment with high efficacy. In developing countries, the local public usually depend on natural products or traditional drugs to manage their skin conditions and healthcare. Although theories have speculated that natural products give a slower effect compared to modern pharmaceutical drugs, generally, the natural products help to cure acute and chronic ongoing symptoms as they will work slowly and give a cumulative effect. ${ }^{16}$ Furthermore, natural products can cover the different targets with multiple active principles in a balanced manner when treating chronic complex disease as they have fewer side-effects. ${ }^{17}$ Previous studies stated that natural products had many uses and benefits, like antimicrobial, wound healing, treating burn injuries, and acting as an anti-inflammatory against various skin disorders. ${ }^{18}$ According to Malik et al ${ }^{15}$ the natural products were usually prepared from the paste of the plant parts, like leaves, roots, and others, with other ingredients.

In drug development, the researchers usually do studies about natural products, especially plants with few constituents. The plant constituents or phytoconstituents are categorised based on their function in a basic metabolic process, into primary and secondary metabolites. Generally, primary metabolites imply the basic life functions, which make them much alike in all living cells, meanwhile secondary metabolites are the product of secondary pathways that can be the lead compounds in the manufacturing of medication. ${ }^{19}$ The primary metabolite includes amino acids, nucleic acids, sugars, tricarboxylic acids, polysaccharides, and protein. On the other hand, secondary metabolite classes include phenolics, lipids, saponins, carbohydrate, alkaloids, and terpenes, classed according to their chemical structures. ${ }^{19}$ These phytoconstituents have their different therapeutic role. Among the above-mentioned secondary metabolites, the phenolics had a protective role against oxidative damage illness as they usually act as the protector of the plant against pathogens and are also responsible for growth and reproduction of plants. Meanwhile, alkaloids, a nitrogen-containing constituent, are also beneficial as drugs, especially psychoactive drugs, medicine, and poison, as they can be used as a muscle relaxant, to relieve pain, and as an anesthetic. ${ }^{20}$ Saponins are useful in treating cancer, bone health, blood cholesterol level, and stimulating the immune system. ${ }^{20}$ Other constituents like terpenes were beneficial for the taste, fragrance, pigment of the plant, thermoprotectant, and signaling functions in the plant, and also therapeutic uses like being an anti-inflammatory, wound healing, and anti-bacteria. ${ }^{21}$ Due to this action of phytoconstituents, the researchers were interested in developing natural products or herbal medicine to treat various diseases, especially skin disorders.

Patients may consume supplements to treat skin problems and improve their conditions. Supplements like vitamins, such as vitamins $\mathrm{C}$ and $\mathrm{E}$, honey, and tea tree oil can improve skin condition and decrease the symptoms of skin disease. ${ }^{2}$ Another product commonly used in the treatment of skin diseases like acne is Aloe vera, which has an anti-inflammatory effect and is a good antioxidant. $^{22}$ Overall, due to the wide range of benefits and versatility, natural products are commonly applied in treating various skin disorders as, besides being safe, they are derived from natural sources such as fruits and vegetables. This review aims to provide an overview of existing knowledge about the effects of natural products such as mangiferin, lutein, curcumin, resveratrol, embelin, naringenin, quercetin, lycopene, gingerol, and apigenin (Figure 3 ) on skin conditions through an analysis of the most important studies conducted to date, as well as recommendations for future research.

\section{Methods}

To complete the review, relevant studies and literature were searched from several scientific databases, including PubMed, Google, Google Scholar, and ScienceDirect. The categories of keywords used for the search included "Natural Products" or "Natural Compounds" or "Skin Disorders" or "Skin Disease" or "Mangiferin" and "skin" or "Lutein" and "skin" or "Resveratrol" and "skin" or "Curcumin" and "skin" or "Embelin" and "skin" or "Naringenin" and "skin" or "Quercetin" and "skin" or "Lycopene" and "skin" or "Gingerol" and "skin" or "Apigenin" and "skin". After screening the literature, ten naturally isolated compounds, which have been investigated widely for the effects against various skin disorders, including in vitro and in vivo models, were included.

\section{The Effect of Natural Products Against Skin Disorders Mangiferin}

Mangiferin is a well-known compound obtained mainly from Mangifera indica (Mango), which belongs to the 


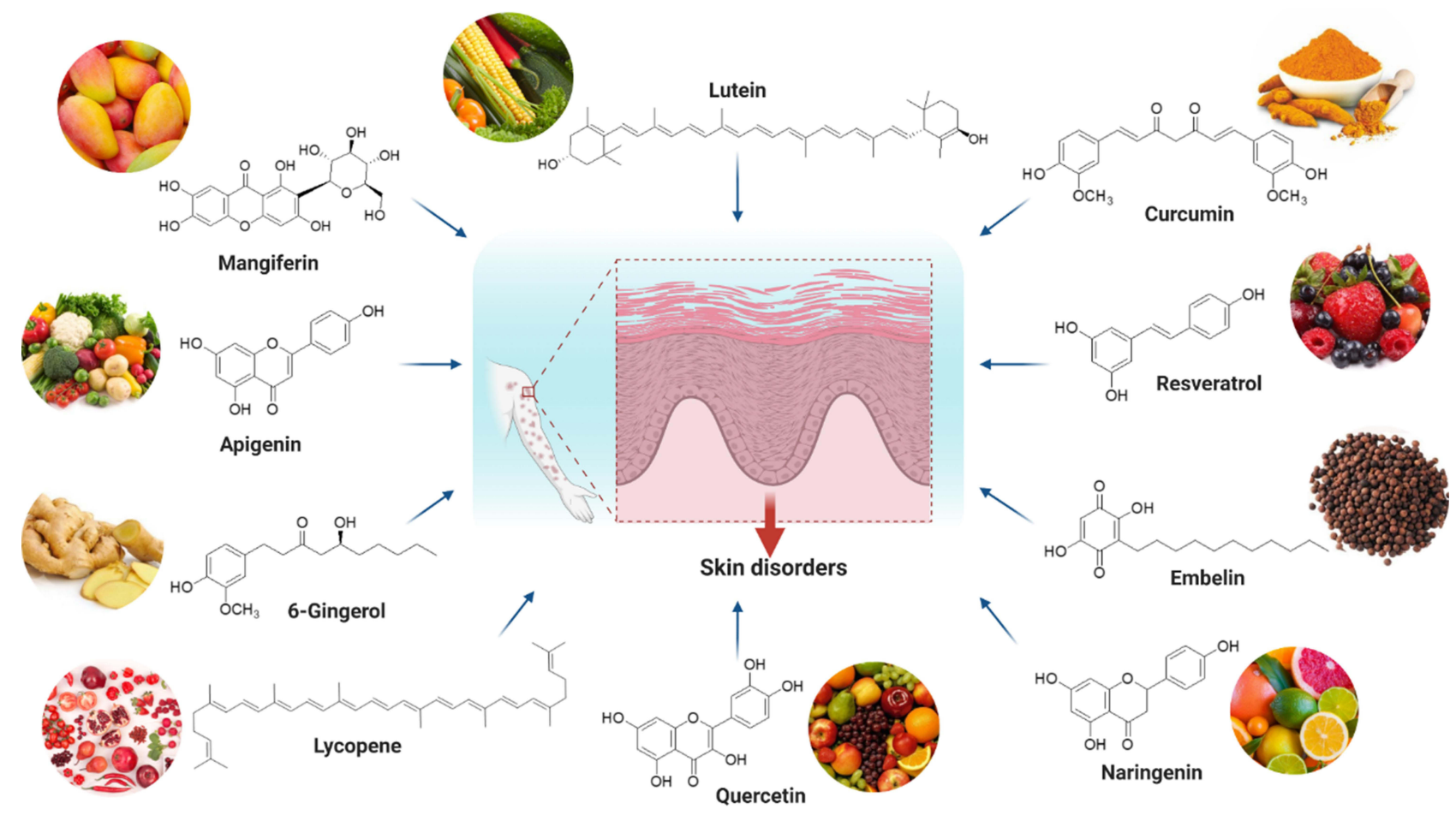

Figure 3 Chemical structure and source of natural products reported against skin disorders. Created with BioRender.com.

family of Anacardiaceae. It is also obtained from honeybush (Cyclopia sp). Mangiferin, chemically known as 2-C$\beta$-D-glucopyranosyl-1,3,6,7-tetrahydroxyxanthone, has various pharmacological and biological properties that have been confirmed in many past studies. It is a strong antioxidant, chemopreventive, and anti-inflammatory agent. $^{23}$ Notably, it has cytotoxic properties where there is apoptosis against tumor cells. Coupled with the antioxidant effect, it confers immense benefits to the skin by being absorbed into the deeper skin layers. ${ }^{23}$ Additionally, Navarro et $\mathrm{al}^{24}$ reported that mangiferin has antimicrobial, antipyretic, antiviral, antibacterial activities in addition to having gastroprotective and hepatoprotective effects, as well as being applied as a lipid-lowering agent. Some reports claimed that the antiproliferative properties are dependent on mango cultivar and the type of cancer cell lines. $^{24}$

Mangiferin is used against skin aging as it can preserve the skin and prevent wrinkles by inhibiting elastase and collagenase as well as water loss. ${ }^{25}$ Skin aging is caused by exposure to sunlight containing ultraviolet (UV) B or UV radiation (UVR), also known as photo-aging, besides being caused by the natural aging process or intrinsic aging. ${ }^{26,27}$ Mangiferin can increase the skin collagen bundles, thus protecting it from damaging UVB exposure. ${ }^{26}$
Skin aging is contributed to by a reduction in collagen that is due to oxidative stress. ${ }^{27}$ Collagen degeneration leads to an increased in matrix metalloproteinase (MMP) activity; a matrix-degrading enzyme. The increase in MMP activity contributes to photo-aging, enhancing the skin aging process. ${ }^{26}$ Although there are many types of MMP, Chae et $\mathrm{al}^{27}$ reported that MMP-1 is important and is responsible for collagen reduction due to oxidative stress that is regulated by extracellular signal-regulated (ERK) and JUN-N-terminal kinases (JNK). Mangiferin blocks the MMP-1 expression by suppressing the ERK and JNK pathways and also through inhibition of MEK and SEK pathways as induced by hydrogen peroxide in human epidermal keratinocyte line (HaCat) cells. ${ }^{27}$ However, Kim et $\mathrm{al}^{26}$ stated that mangiferin inhibits MMP-9 activity that is also generated via the MEK and ERK pathways. Additionally, oral administration of mangiferin decreases wrinkle formation due to UVB radiation, leading to skin aging. ${ }^{28,29}$

The inflammatory reaction is one of the conditions associated with a skin disorder. The most common inflammatory skin disease includes contact dermatitis, which causes skin lesions and destruction of the skin barrier, making its treatment challenging. ${ }^{30}$ Currently, different drugs are being used against inflammatory skin disorders 
like atopic dermatitis and psoriasis, which reduce the quality-of-life. $^{31}$ In another recent study, mangiferin formulated with nanoemulsions can reduce skin damage induced by transcutol-P (TPA), while improving skin inflammation and wound healing. ${ }^{32}$ In past studies, mangiferin was reported to inhibit the inflammatory activity caused by macrophages, thus influencing skin inflammation. Inflammatory mediators such as tumor necrosis factor alfa (TNF- $\alpha$ ) and its inflammatory biomarkers like inducible nitric oxide synthase (iNOS), interleukin (IL)-1 $\beta$, and IL-6 that cause skin lesions, eg, psoriasis and dermatitis, are also ameliorated by mangiferin administration. ${ }^{30}$ In addition, mangiferin can inhibit CD68 activity, which is an important macrophage biomarker contributing to dermatitis. $^{30}$

Besides its ability to treat skin disorders like a wound and allowing skin regeneration, mangiferin is a good antioxidant. It improves wound healing closure by stimulating cell proliferation and migration of fibroblasts during the wound healing process while reducing myeloperoxidase (MPO) activity which is an enzyme involved in inflammation. ${ }^{33}$

In another study on diabetic rats, mangiferin caused a reduction in the oxidative damage in skin tissue by increasing the nuclear factor erythroid 2-related factor (Nrf-2), thus maintaining tissue proliferation and growth while boosting wound healing. ${ }^{34}$ Due to its anti-inflammatory and antioxidant properties, mangiferin facilitates skin flap regeneration and reduces inflammation. ${ }^{35,36}$ Furthermore, mangiferin-loaded liposome is an efficient local treatment for skin flap regeneration as it produces several multipotent flap-protective therapeutics effects. ${ }^{37}$ According to Mao et $\mathrm{al}^{38}$ mangiferin formulated as a hydrogel delivery system boosts the development of skin flap regeneration and enhances survival.

Due to its anti-angiogenic effect that can block tumors from developing their own blood cell, mangiferin is useful for skin cancer or melanoma. Mangiferin blocks the basic fibroblast growth factor (bFGF), which is a tumor growth factor and a TNF-dependent-cell migration. Additionally, based on Ingenuity Pathway analysis (IPA) enrichment, mangiferin blocks the expression of IL6, TNF, PLAU, kinase insert domain receptor (KDR), vascular endothelial growth factor receptor 2 (VEGFR2), interferon gamma (IFN- $\gamma$ ), fibroblast growth factor 1 (FGF1), chemokine ligand 2 (CCL2), MMP19, and placental growth factor (PGF) to stop angiogenesis, metastasis-invasion motility, cell number growth, and viability in cancer signaling processes. ${ }^{39}$ Additionally, mangiferin can treat skin infections like bacteria and human herpes viruses, like herpes simplex virus (HSV), although the ideal current drug for $\mathrm{HSV}$ is a nucleoside. Jie et $\mathrm{al}^{40}$ reported that mangiferin, which is also known as chinonin, can reduce the infectivity of HSV infection in vitro where it can act against animal infection caused by HSV. Figure 4 depicts an overview of mangiferin's effect on skin disorders as well as its mechanism of action.

\section{Lutein}

Lutein, with its stereoisomer zeaxanthin, is a lipid-soluble compound from the xanthophyll family of carotenoids. Lutein is an essential component in serum and exists in ocular tissue like lens and macula lutea, important for central vision and visual acuity. ${ }^{41,42}$ Lutein is also present in the diet, including in dark and leafy green vegetables. ${ }^{42}$ Lutein is formed with 40 carbon atoms and is arranged into eight isoprene units with two oxygen atoms. ${ }^{43}$ Although its main function is related to eye health, like in treating age-related macular degeneration (AMD) and cataracts, it also has some beneficial effects on the skin. Furthermore, lutein has shown some anti-inflammatory properties. $^{43}$

Lutein protects the skin by blocking the damaging blue wavelengths or light, thus ameliorating melisma which is a pigmentation disorder that appears as brown patches on the skin, especially on the face. ${ }^{44,45}$ In one study, evaluation on carotenoids with lutein and zeaxanthin oral supplements are being conducted. As a result, these two supplements, lutein (10 $\mathrm{mg}$ ) and zeaxanthin (2 $\mathrm{mg})$, have been shown to have good benefits to the skin, including enhancement of skin tone, luminance, and color. ${ }^{45}$ Furthermore, lutein also protects the skin against skindamaging sunlight due to UV radiation. ${ }^{44}$

Skin disorders, especially skin aging, can be effectively treated by lutein. Lutein can defend against gene expression induced by UVA, UVB, and UVA1 on individual skin. $^{44}$ Although the functions of MMP-1 mRNA, intracellular adhesion molecule 1 (ICAM-1), and heme-oxygenase 1 are signs of premature aging, oxidative stress and photo-dermatoses, which can develop into skin rash, lutein, and tomato nutrient complex (TNC), provide a good barrier to the skin from UVR that causes skin damage. A study conducted by a team of Italian researchers involved the evaluation of the effectiveness of lutein 

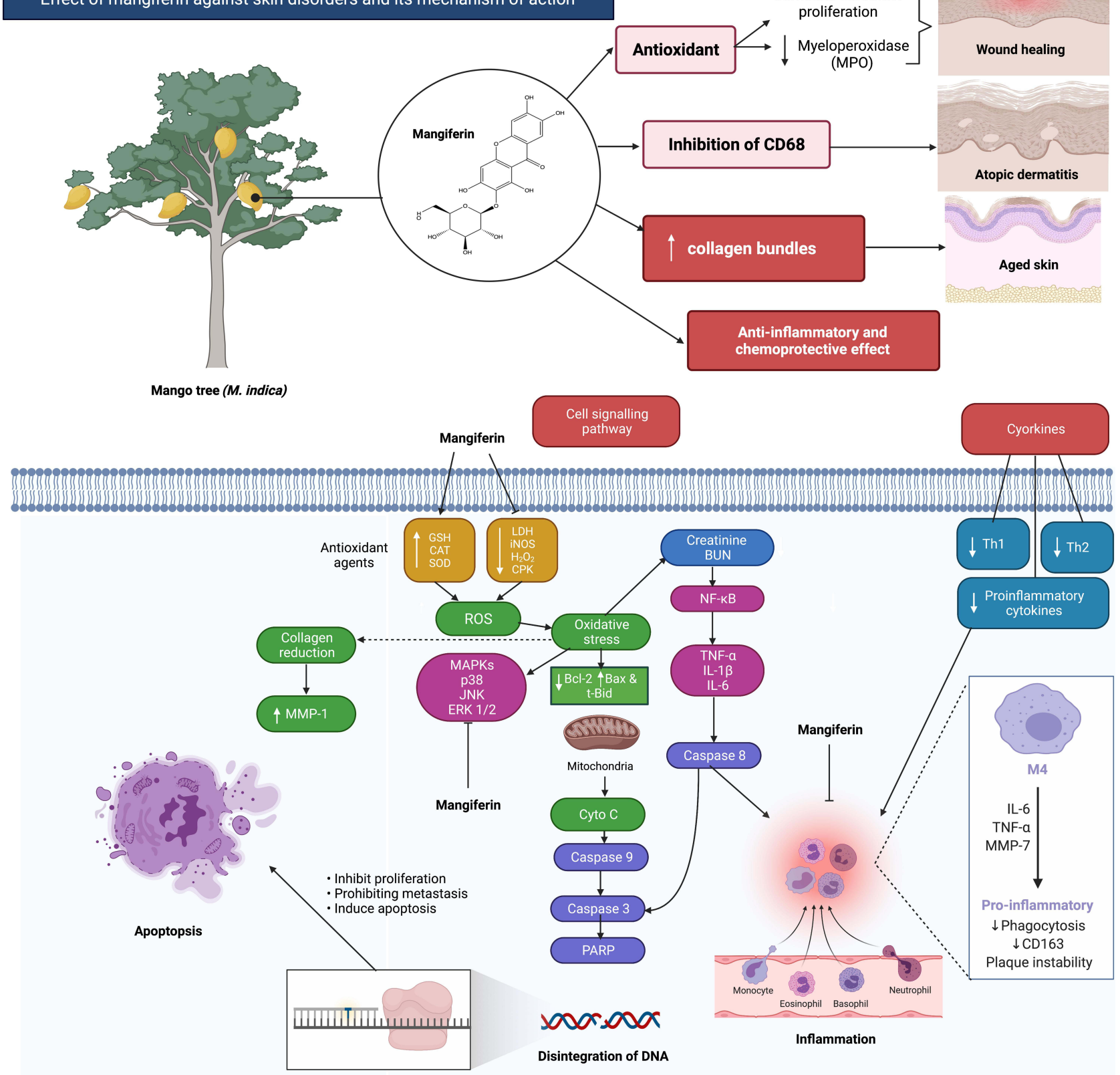

Figure 4 Effect of mangiferin against skin disorders and its mechanism of action. Mangiferin possessed a wide spectrum of pharmacological and biological properties, including antioxidant, chemoprotective, and anti-inflammatory properties. Besides, it can also inhibit elastase and collagenase can also help to preserve the skin and prevent wrinkles. Mangiferin has the ability to suppress CD68 activity, a key macrophage biomarker linked to dermatitis. Created with BioRender.com.

Abbreviations: CD68 and I63, cluster of differentiation 68 and I63; ThI and Th2, Thelper type I and 2; IL-6, IB, Interleukin 6 and I beta; TNF- $\alpha$, tumor Necrosis Factor alpha; MMP-7 and I, matrix metalloproteinase-7 and I; BUN, blood urea nitrogen; NF-kB, nuclear factor kappa-light-chain-enhancer of activated B-cells; Bcl-2, B-cell lymphoma 2; Bax, BCL2 Associated X, Apoptosis Regulator; t-Bid, truncated Bid; Cyto C, cytochrome complex; PARP, Poly (ADP-ribose) polymerase; LDH, lactate dehydrogenase; iNOS, inducible nitric oxide synthase; $\mathrm{H}_{2} \mathrm{O}_{2}$, Hydrogen peroxide; CPK, creatine phosphokinase; GSH, glutathione; SOD, superoxide dismutase; CAT, catalase; ROS, reactive oxygen species; MAPKs, mitogen-activated protein kinases; JNK, c-Jun N-terminal kinase; ERK I/2, extracellular signal-regulated kinases I/2.

and zeaxanthin where healthy middle age women $(\mathrm{n}=40)$ have premature skin aging were administered with topical lutein and oral zeaxanthin. Based on this study, the two carotenoids provide multiple advantages to the skin. The carotenoids block skin damage as induced by UV radiation and can boost skin elasticity, hydration, and elevate surface lipids. Both administration routes (topical and oral) can promote the skin condition, especially in skin aging. ${ }^{44}$ The carotenoid can enhance the collagen I/elastin aging index of the skin layer, as shown in past research. This 
research involved female participants who were given supplements containing $1,650 \mu \mathrm{g}$ carotenoids daily for ten months. ${ }^{44}$

Lutein is useful against skin inflammation, including skin erythema and psoriasis, as confirmed on a mice skin experiment. ${ }^{46}$ Skin inflammation occurs as a result of sun exposure where harmful UVA and UVB can cause oxidative stress and reduce the level of skin and serum carotenoids. In addition, short wavelength UV radiation, like UVA and UVB, causes oxidative stress, while long wavelength UV, such as UVA1, generates gene expression ${ }^{46}$ leading to skin erythema. Lutein can decrease the skin rash (skin erythema) as well as enhance skin health by blocking the UV radiation.

Lutein is also derived from the leafy part of Galittm aparine which can prevent skin disorders like psoriasis and is commonly used in Western countries for this purpose. Lutein has an anti-inflammatory effect due to its antioxidant activity, which is neuroprotective. Another study evaluated the inflammatory activities of lutein and found that both lutein and zeaxanthin can reduce the extent of ear swelling of female mice exposed to UV radiation following the administration of $0.04 / 0.03 \%$ or $0.4 / 0.03 \%$ lutein/zeaxanthin supplement, respectively. The experiment also suggests that lutein and zeaxanthin ameliorate sunburn by blocking the formation of sunburn cells and also decreasing epidermal hyper-proliferation. ${ }^{47}$

Skin cancer is a fatal skin disorder. The two most common ones are 1) squamous cell carcinoma (SCC) and 2) basal cell carcinoma (BCC), which have high incident rates in Australia, Europe, and the US. The causes of skin cancer are usually due to UV radiation where long exposure to sunlight 1) impairs DNA and the immune system and 2) can produce free radicals. Thus, antioxidants can aid in protecting the skin against UV radiation. ${ }^{48}$ Lutein is a strong antioxidant similar to $\beta$-carotene as it can treat the oxidative damage skin caused by UV radiation. ${ }^{46}$ As shown in a community-based study in Australian adults, lutein reduces the risk of SCC by $50 \%$ in individuals with a history of skin cancer where both lutein and zeaxanthin that are present in green leafy vegetables confer some protective effect as well. ${ }^{48}$ The study also concluded that the intake of vitamins $\mathrm{E}, \mathrm{C}$, and $\beta$-carotene cause an increased risk of getting $\mathrm{BCC}$ which has a different risk and causal pathway. ${ }^{48}$ Furthermore, Balić and Mokos ${ }^{44}$ suggested that lutein and zeaxanthin increase the tumorfree survival time, specifically the duration following completion of the first cancer treatment when a patient is free from cancer symptoms with reduced tumor volume and multiplicity).

Finally, lutein ameliorates wound healing as shown in one experiment. According to Aziz et al, ${ }^{46}$ esterified lutein produces a wound healing effect with the development of blood vessels in a chick chorioallantoic model. A hole was created on the model which was loaded with esterified lutein isolated from Tagetes erecta flowers. Non-sulfate glycosaminoglycans that had wound healing properties can hydrate the skin and have high water binding capacity due to a hyaluronan component. Since lutein and zeaxanthin can increase the production of hyaluronan, it is also useful in wound healing. ${ }^{46}$

\section{Curcumin}

Curcumin originates from turmeric or Curcuma longa and belongs to the family of Zingiberaceae or ginger that is usually used as spice for food flavouring. ${ }^{49,50}$ Turmeric is commonly-used in South Asia, India, and Indonesia and is often used as a dye or food color since it exists in bright orange-yellow crystals. ${ }^{51}$ According to Panahi et $\mathrm{al}^{49}$ turmeric contains curcuminoids which include curcumin or specifically, deferuloymethane (75\%), demethoxycurcumin $(20 \%)$, and bisdemethoxycurcumin $(5 \%)$. Curcumin is chemically known as [1, 7-bis (4-hydroxy-3- methoxyphenyl)1,6-heptadiene-3,5-dione]. It is a keto-enol tautomer and is a natural polyphenol that have many important uses. ${ }^{49}$ Additionally, curcumin is used in the treatment of several diseases since the molecule rapidly penetrates the cell membranes and acts on multiple targets in different-cellular pathways. Some studies reported that curcumin is 1) a useful antimicrobial agent, 2) a preservative, and 3) possesses different therapeutic actions against cancer, dyslipidemia, skin diseases, osteoarthritis, diabetes, metabolic syndrome, endothelial dysfunction, autoimmune disease, non-alcoholic fatty liver disease, respiratory disease, depression, premenstrual syndrome, and hyperuricemia. ${ }^{49,51}$ Since curcumin has antioxidant and anti-inflammatory properties, it can be used to treat skin disorders. Panahi et $\mathrm{al}^{49}$ reported that curcumin has minimal toxicity to humans and animals, while Patel et $\mathrm{al}^{51}$ stated that, except for gastrointestinal distress, no major toxicity occurs upon oral administration of curcumin.

A type of skin disorder caused by chronic inflammation is psoriasis, as indicated by the presence of TNF, which is an inflammatory mediator. Current treatment of psoriasis focuses on inhibition of the production and action of TNF such as agents like adalimumab, cyclosporine, infliximab, 
methotrexate, and alefacept, which can cause certain sideeffects if used long-term. ${ }^{52}$ The researchers confirmed that curcumin is a beneficial and effective treatment for psoriasis. A low concentration of curcumin is phototoxic against Escherichia coli and Salmonella typhimurium, which can be used in psoriasis phototherapy. In one experiment, curcumin showed some anti-psoriatic activity when used in an animal model which was a modified mouse tail. Curcumin also inhibits the proliferation of human keratinocytes as it blocks the expression of TNF$\alpha$-induced IL-1 $\beta$, IL- 6 , TNF- $\alpha$, cyclin E, mitogen-activated protein kinase (MAPKs) (JNK, p38 MAPK and ERK), and nuclear factor kappa-light-chain-enhancer of activated Bcells (NF-kB) in HaCaT-cells which will result in reversal of the anti-apoptotic function of TNF- $\alpha$ in the skin cell. ${ }^{52}$ In addition, curcumin is an effective TNF blocker, blocking both the action and production of TNF, and is also a potent inhibitor of phosphorylase kinase (PHK), which is seen in psoriasis. ${ }^{52,53}$

Gupta et $\mathrm{al}^{54}$ indicated that curcumin inhibits inflammation by a direct binding method that perturbs signal transduction between TNF- $\alpha$ and its receptor. Meanwhile, according to Lai et $\mathrm{a}^{55}$ other than inhibition of TNF and certain interleukin (IL) like IL-22, IL-1 $\beta$, IL-17A, and IL$17 \mathrm{~F}$, curcumin gel can also inhibit imiquimod-induce psoriasis-like inflammation. Additionally, curcumin obstructs the endosomal toll-like receptor (TLR) that contributes to psoriatic inflammation by blocking NF- $\mathrm{KB}$ signaling that produce inflammatory cytokines, thus resulting in reduction in IL-17 and IL-22 levels. ${ }^{55}$

Curcumin is also effective against atopic dermatitis or eczema. In a report by Rawal et $a 1,{ }^{56}$ a herbal extract cream containing curcumin $\left(\right.$ Herbavate $^{\circledR}$ ) reduced and improved symptoms of dermatitis including itching, scaling, thickening, and erythema in 150 subjects who suffered from eczema. Nevertheless, it is difficult to evaluate the relevance of the findings due to the small control group, the high dropout rate, and the fact that other components in the cream may also play a role. Another study suggested that curcumin can reduce radiodermatitis when a curcumin cream that contains turmeric oil and sandalwood oil $\left(\right.$ Vicco $\left.^{\circledR}\right)$ is used for radiodermatitis subjects $(n=50)$ compared to baby oil.

A study conducted to evaluate the effect of curcumin in breast cancer patients $(\mathrm{n}=30)$ taking $6 \mathrm{~g} /$ day oral curcumin C3 Complex found that there was a decreased severity score of radiation dermatitis (radiodermatitis) and moist desquamation but no difference in pain, redness, or symptoms of radiodermatitis were seen. ${ }^{57}$ A phytocomponent known as p-hydroxycinnamic acid (HCA) is derived from various plants including Curcuma longa (C. longa) and can modulate the protein kinase $\mathrm{C}-\theta$ (PKC- $\theta$ ) pathway by inhibiting the phosphorylation of PKC- $\theta$ that can have an immunosuppressive effect on T-cells and inhibit the activation of T-cells responsible for the development of various autoimmune disorder including dermatitis. ${ }^{13,58}$ In a different study involving an experiment on a mini-pig model, curcumin reduces the severity of irradiated skin after 2 weeks administration by relieving the skin injury, decreasing the expression of cyclooxygenase-2 (COX-2) and NF- $\mathrm{KB}$ in curcumin-treated irradiated skin when compared to vehicle-treated skin. ${ }^{59}$

Curcumin is useful against wounds caused by oxidative damage and inflammation. ${ }^{60}$ The anti-inflammatory and free-radical scavenging activity of curcumin occur via reduction of lipid peroxidation and reactive oxygen species (ROS). ${ }^{61}$ Curcumin protects the skin from oxidative stress as it regulates lipid peroxidation while its antioxidant effect activates the cytoprotective signaling. Furthermore, curcumin confers some protective activity against hydrogen peroxide in human keratinocytes and fibroblasts. ${ }^{62}$ Additionally, it also suppresses inflammation by reducing the transcription factor protein-1 (AP1) while $\mathrm{NF}-\mathrm{\kappa B}$ reduces the expression of inflammatory cytokines and modulates the pro-inflammatory gene product expression, as shown in a wound model ${ }^{61}$ In an animal study, the anti-inflammatory effect of chrysin-curcumin-loaded nanofibers accelerates wound healing in male rats by decreasing the gene expression for IL-6, TIMP-1, TIMP-2, MMP2, and iNOS. ${ }^{63}$ During proliferation, curcumin activates the growth factors, produces ECM proteins, and helps in collagen synthesis and migration of fibroblasts which aid wound repair. ${ }^{13,64}$ Overall, curcumin acts on inflammatory, proliferative, and remodeling phases which leads to wound healing.

Based on several studies, curcumin is used in skin aging, especially in the elderly. Sommerfeld, ${ }^{65}$ who conducted a study to evaluate the effectiveness of Tricutan (a herbal containing turmeric, rosemary, gotu kola, and dimethylaminoethanol) in women $(\mathrm{n}=28)$, indicated that the formulation enhances the skin firmness and elasticity after 4 weeks as compared to a placebo. Subsequently, a randomized, double-blind, placebo controlled trial in 47 subjects reported that the hot water extract of $C$. longa inhibits the increase in UVB-induced TNF- $\alpha$ and IL-1 $\beta$ and the increased production of hyaluronan occurring with 
age which also contribute to skin dryness. ${ }^{66}$ In fact, increasing the hyaluronan content moisturizes the skin better.

Insulin-like growth factor-1 (IGF-1) can cause cancer, while inhibition of $\mathrm{IGF}-1$ reduces tumors. Kim et $\mathrm{al}^{67}$ demonstrated that curcumin reduces phosphorylation of the IGF-1 receptor, insulin receptor substrate-1 (IRS-1), S6K, AKT, and 4EBP1 in mouse keratinocyte cell lines, indicating that it has an anticarcinogenic effect acting via inhibition of IGF-1 signaling. Other than that, curcumin modulates some pathways like JAK-2/STAT3 which in turn induces apoptosis and inhibition of melanoma cell migration as well as invasion. ${ }^{68}$ Curcumin also upregulates miRNA expression like mmu-miR-205-5p and reduces proliferating cell nuclear antigen (PCNA) and Bcl-2 number, leading to apoptosis and inhibition of proliferation. ${ }^{68}$ In another study, high curcumin concentration decreases the invasion of squamous cell A431 cells by suppressing the signaling pathway and STAT3 expression. ${ }^{69}$ Curcumin also incites mitochondrial permeability transition pore (mPTP) opening, leading to apoptosis/cell death of WM115 melanoma cells since mPTP opening is necessary for curcumin-induced cytochrome $\mathrm{C}$ release. ${ }^{70} \mathrm{~A}$ study indicated that topically applied curcumin on UVB-induced carcinogenesis in mice can delay tumor appearance, multiplicity, and volume hile increasing p53 and p21/Cip1positive cells in the epidermis. $^{71}$

As stated in several studies, curcumin is effective against bacterial and fungi infections. Curcumin has activity against methicillin-resistant Staphylococcus aureus (MRSA) when administered singly and shows some synergistic effects when administered in combination with other antibiotics. $^{72,73}$ Vollono et $\mathrm{al}^{13}$ indicated that vanillin, a curcumin photolytic degradation product in light-irradiated curcumin, interrupts the bacterial cell membrane. Furthermore, curcumin is a photosensitizer and is used in photodynamic therapy against MRSA infection in an intradermal infection model. ${ }^{74}$ According to Vaughn et $\mathrm{al}^{50}$ various mechanisms exists, which include bacterial membrane perturbation, damage to bacteria motility, changes in gene expression, and suppression replication machinery.

Curcumin is effective against acne vulgaris. ${ }^{75}$ It is reported that curcumin microemulsions in combination with myristic acid suppresses $S$. epidermis growth, suggesting that curcumin is effective against acne vulgaris. In another study, curcumin nanoparticles inhibit fungal growth by inducing ROS and reactive nitrogen species (RNS) related to fungal death by apoptosis. ${ }^{76}$

\section{Resveratrol}

Resveratrol, a stilbenoid in a phytoalexin group was first discovered in 1939 and is chemically introduced as 3,5,4'trihydroxy-trans-stilbene. ${ }^{77,78}$ Resveratrol, which was first discovered from the white hellebore, also known as the roots of Veratrum grandiflorum and also available from the root of Polygonum cuspidatum, is usually utilized in Japanese and Chinese medicines. ${ }^{79}$ Interestingly, resveratrol is produced by plants in response to stressors like insects, animals, mechanical injury, UV radiation, and also microorganisms including fungal infection. ${ }^{79,80}$ Resveratrol exists in more than 70 plant species, although it is most abundant in grape skin ${ }^{79}$ besides being present in other foods and beverages including wine. Ruivo et $\mathrm{al}^{77}$ reported that resveratrol is also found in cranberries, peanuts, cocoa, chocolate, and tomatoes.

Resveratrol appears in cis- and trans-isomeric forms with the trans-form being the biologically active version. The cis-form is isomerized from trans-resveratrol via UV irradiation and in the presence of high $\mathrm{pH}$ during grape skin fermentation. ${ }^{80}$ Currently, resveratrol is an important significant nutritional supplement as it has various benefits such as cellular defense against oxidative stress. The pharmacological effects include anti-inflammatory, antimicrobial, anti-cancer, anti-aging, and neuroprotective effects, ${ }^{79}$ making resveratrol a potential natural product for human health. In some reports, resveratrol is useful for amelioration of cardiovascular disease, diabetes, skin disorders, and obesity. It is also high in antioxidants and combats free radical damage by acting as a potent radical scavenger. ${ }^{77}$

Skin aging is classified into either extrinsic or intrinsic. The former is primarily caused by environmental factors like pollutants, lifestyle, and solar radiation, while the latter are changes that progress over time, depending on the anatomy, genetics, hormones, and ethnicity. ${ }^{81}$ An important factor contributing to skin aging is activated MMPs that cause damage to the skin structural integrity, leading to wrinkle formation. TNF- $\alpha$-induced expression of inflammatory cytokines and MMPs is inhibited by resveratrol through a sirtuin 1-dependent mechanism. ${ }^{81}$ According to the same article, $0.8 \%$ of resveratrol analogs, resveratryl triacetate (RTA) confer some anti-aging activity by enhancing sagging, wrinkles, elasticity, and moisture. Furthermore, in a study by Liang et al, ${ }^{82}$ short-term resveratrol injection retards the process of oocytes aging in mice, occurring via 1) enhancement of the expression of the anti-aging molecule sirtuin 1,2) promotion of the 
mitochondria function, and 3) reduction in ROS production.

Resveratrol protects normal human fibroblasts from the damaging effects of hydrogen peroxide by attaching to specific epidermal receptors. ${ }^{83}$ Deloche et $\mathrm{al}^{84}$ demonstrated that skincare products containing resveratrol $(0.25 \%)$ and oligoside $(4 \%)$ can reduce wrinkles and improve skin firmness. Buonocore et $\mathrm{al}^{85}$ investigated a supplement which consisted of dried grape extract containing trans-resveratrol, procyanidin, punicalagin-ellagic acid, and punica granatum, which are strong antioxidants found to enhance skin conditions like a reduction in skin roughness, increased skin moisturization, as well as elasticity. Additionally, resveratrol ameliorates skin inflammation by decreasing the expression of AP-1 and NF- $\kappa$ B transcription factors, collagen breakdown, and inflammation.

Skin cancer occurs due to cell mutation and affects the skin's normal physiology. In a study, resveratrol shows some chemo-preventive effect where it protects against the main factor affecting non-melanoma skin cancer which is UVB radiation by decreasing COX-2 levels. ${ }^{86,87}$ UVB can also elevate the cyclin kinase that enhances growth during the early stage of cancer development. A report demonstrated that resveratrol causes an increase in cyclin kinase inhibitor WAF1/p21 and tumor suppressor p53 which interrupts tumor development. ${ }^{88,89}$ Besides, the anti-proliferative activity of resveratrol may contribute to modulation in the expression and function of cell cycle regulatory protein cyclin-D1 and -D2, cdk-2, -4, and -6, and WAF1/p21, suggesting that the retardation of the MAPK pathway was generated by modulation of the ckicyclin-cdk network. ${ }^{88,89}$

A team of researchers discovered that resveratrol and 5-fluorouracil combination can suppress cell proliferation more effectively than administering the drug alone since resveratrol employs its anti-proliferative activity like reducing tumor growth and angiogenesis in B16 melanoma by altering the expression of vasodilator-stimulated phosphoprotein (VASP), COX-2, AMP-activated protein kinase (AMPK), and vascular endothelial growth factor (VEGF). ${ }^{90}$ Yarla et al ${ }^{91}$ also reported that 1) pterostilbene; a resveratrol analogue or a methoxylated derivative of resveratrol and 2) the combination of resveratrol with ursolic acid can stop the generation of DMBA/TPAinduced skin cancer by obstructing the MAPK/NF- $\mathrm{BB} /$ AP-1/COX-2 pathway.
Herpes simplex virus (HSV) is indicated by a skin lesion affecting several body parts including the nasal cavity, oral, ocular, genital skin, and mucosa. HSV is a double-stranded DNA virus in the Herpesviridae family that can be hidden or latent but it can cause a recurrent infection. ${ }^{92} \mathrm{HSV}$ infection is potentially dangerous and can be fatal. HSV-1 infection causes skin lesions at the nasal, oral, and ocular areas, while HSV-2 infection affects the genital skin and mucosa sites. Based on several studies, resveratrol can potentially be an anti-HSV drug. In an in vivo study by Docherty et al, ${ }^{93}$ topically treated resveratrol cream decreases the development of lesions caused by HSV on SKH1 mice where a $25 \%$ resveratrol cream was more efficient than $12.5 \%$ and resveratrol ameliorates better when the disease had only recently occurred. It was also reported that resveratrol was as efficacious as acyclovir but is more efficient than $10 \%$ of docosanol cream in treating the lesion. ${ }^{93,94}$

For in vitro studies, resveratrol suppresses NF- $\kappa \mathrm{B}$ stimulation which 1) retards the reproduction of HSV and production of DNA virus and 2) changes the gene stimulation. $^{95}$ Furthermore, resveratrol can stimulate the 50 AMPK/Sirtuin 1 (AMPK/Sirt1) axis which decreases viral genes expression leading to HSV infection suppression. ${ }^{96}$ Other than virus infection, Yang et $\mathrm{al}^{97}$ stated that topical application of pterostilbene is useful in the treatment of skin MRSA infection by ameliorating the abscess via reduction in bacteria number and enhancement in the skin structure. ${ }^{97}$

Acne vulgaris is an inflammatory disease affecting all age groups and ethnicities. It occurs due to an imbalance in hormones and some pathogenic factors such as Propionibacterium acnes, increased sebum production, inflammatory mechanism, and unusual follicular hyperkeratinisation. ${ }^{98}$ Nevertheless, a team of researchers have indicated that resveratrol has the potential to exert some antibacterial and anti-inflammatory effects by inhibiting the reproduction process for $P$. acnes and reducing the inflammatory response that is comparable to other acne vulgaris treatment. ${ }^{99}$ Taylor et al $^{100}$ reported that using resveratrol together with benzoyl peroxide can exert a good antibacterial effect by inhibiting bacterial growth since resveratrol can change the surface structure of bacteria with some loss of defined membrane. Additionally, psoriasis can be treated by resveratrol via suppression of imiquimod-induced gene expression of IL-19, IL-17A, IL17F, and IL-23p19 to reduce the psoriasis-like 
inflammation since the genes are mainly involved in the production of psoriatic plaque in both humans and animals. $^{55,101}$

Skin disorders like wounds occur due to tissue injury caused by trauma and other factors. Therefore, factors influencing the healing process like nutrition, drugs, and age are also important in reduction of scarring and shortening of the healing period. ${ }^{83}$ In a previous study, the grape seed extract (GSE) which is a source of resveratrol can heal wounds when topically applied as a $2 \%$ cream. Its antimicrobial, antioxidant, and anti-inflammatory activities cause wound contraction and closure as by 1) forming a protective area in the epithelium and 2) raising the cell density and elevating the displacement of connective tissue at the wound area which enhances the wound cellular construction. $^{102}$

Chloasma or melasma are two other skin diseases that are usually represented by uneven dark to light brown patches on the forehead, chin, cheeks, nose, and upper lip. ${ }^{83}$ Other factors causing chloasma include UV exposure (the most common reason since it affects melanin production), genetic disorders, thyroid disturbance, hormone replacement therapy, and the use of photosensitizer drugs. $^{103}$ In an investigation, the GSE which contains proanthocyanidin can decrease the number of melanocytes that cause a lightening effect on the UV-induced pigmented skin of guinea pigs occurring due to the suppression of melanin production by tyrosinase in melanocytes and ROS activity. ${ }^{104}$ In another study, 12 months of GSE treatment efficiently decreases the hyperpigmentation seen in chloasma in women without conferring adverse effects. Moreira et $\mathrm{al}^{105}$ reported that Skin Whitening Complex (SWC) that consists of ursine grape extract, biofermented aspergillus, grapefruit extract, and rice extract decreased the skin melanin and reduced pigmentation.

\section{Embelin}

Embelin, from the Embelia ribes Burm that belongs to the Myrsinaceae family and Lysimachia punctata, from Primulaceae family with the chemical formula of 2,5dihydroxy-3-undecyl-p-benzoquinone. ${ }^{106}$ The chemical structure of embelin contains a polar dihydroxy-1, 4-benzoquinone ring which is a two carbonyl oxygen atom adjacent to the two vinyl hydroxyl groups. ${ }^{106}$ Embelin, which is frequently referred to as "False Black Pepper", is an Indo-Malaysian species that originates from Malaysia, Singapore, India, Sri Lanka, and South China.
Embelia ribes Burm is also widely used in Tibetan, Folk Indian, Homeopathy, Unani, and Siddha traditional medicinal systems in the treatment of several illnesses including the heart and urinary condition, severe inflammatory disease, tumor, insect, and snake bites. ${ }^{107}$

Embelin has various medicinal and pharmacological activities such as analgesic, anti-inflammatory, antibacterial, antioxidant, anticonvulsant, antidiabetic, anxiolytic, hepatoprotective, and antifertility effects. ${ }^{108}$ Park et al ${ }^{109}$ stated that embelin is a potent inhibitor of $\mathrm{NF}-\kappa \mathrm{B}$ and $\mathrm{X}$-linked inhibitor of apoptosis protein (XIAP) that halted the binding of XIAP to procaspase-9. Kundap et al ${ }^{107}$ also reported that the fruit of Embelia ribes Burm can be used in the treatment of mental disorders, central nervous system (CNS) disease, and as brain tonic in the traditional medicinal system.

Psoriasis is a hyperproliferative skin disorder occurring due to inflammation, as signified by the unusual differentiation and proliferation of keratinocyte, stimulation of T-cells, and polymorphonuclear leukocytes aggregation. ${ }^{110}$ In their investigation on the effect of embelin on skin inflammation in mice, the researchers also confirmed that the pathogenesis of psoriasis is mainly caused by TNF- $\alpha$. There was a dose-dependent decrease in LPS-induced TNF- $\alpha$ level when several concentrations of embelin were used with an effective dose 50\% (ED50) at $9.8 \mathrm{mg} /$ kg. ${ }^{110}$ The researchers also investigated chronic dermatitis inflammation by 12-O-tetradecanoyl-phorbol-13-acetateinduced mice ear. Embelin can reduce edema, decrease the thickness of skin and weight, reduce stimulation of inflammatory cytokines, reduce neutrophil initiation, improve histopathological indicators, and lead to the departure of polymorphonuclear leukocyte. It was concluded that the anti-inflammatory effect of embelin is attributed to the suppression of TNF- $\alpha$ and IL-1 $\beta$ as well as the inhibition of leukocyte aggregation, ${ }^{110}$ overall indicating that embelin is useful against psoriasis and dermatitis.

Swamy et al $^{111}$ reported that embelin extracted from Embelia ribes Burm can treat wounds in a rat model. Wound healing is a process that repairs the damage or injured skin tissue in order to improve tissue integrity and replace damaged tissue. When compared to the control group, embelin accelerated the incision epithelialization, thus contributing to a shorter mean time of epithelialization. ${ }^{111}$ The percentage of wound closure was also high in the embelin-treated group and is comparable with that of a standard drug with reference name 
framycetin. In fact, the incision tensile strength was higher in the group which received topical application of embelin, ${ }^{111}$ indicating its potential in wound healing.

Oral embelin yielded a higher weight of granulation tissue and tensile strength as seen in a dead space wound model indicating 1) that there is improved collagen development through formation of cross-linking between collagen fibres and 2) the existence of high protein content. ${ }^{111}$ In histology of wound tissue in the embelin-treated group, it can be observed that there was a complete healing process, with many fibroblasts having a higher number of blood vessels and collagen tissue, similar to the control group. ${ }^{111}$ All of these findings indicate that embelin confers a good wound healing activity as an alternative for wound healing.

\section{Naringenin}

Naringenin has the IUPAC name 5.7 dihydroxy-2-(hydroxyphenyl) chroman-4-one ${ }^{112}$ or a chemical name 2, 3dihydro-5,7-dihydroxy-2-(4-hydroxyphenyl)-4H-1-benzopyran-4-one. ${ }^{113}$ Naringenin is found in citrus fruits like grapefruits and oranges or in vegetables like tomatoes and figs. ${ }^{113,114}$ According to Salehi et al ${ }^{115}$ its molecular weight is 272.26 , with a chemical formula of $\mathrm{C}_{15} \mathrm{H}_{12} \mathrm{O}_{5}$. Naringenin is a flavonoid that is soluble in organic solvent including alcohol, but is insoluble in water.

Naringenin is a flavone from naringin or the hydrolysis of narirutin (its glycone precursor). ${ }^{115}$ Naringin, which is a bitter principle of grapefruit obtained from the juice, flower, and fruit rind, represents up to $10 \%$ of the fruit's dry weight. Nevertheless, flavonoids including naringenin have some limitations, especially in terms of bioavailability and limited source. Therefore, several efforts aimed at producing naringenin from metabolic engineering of specific pathways in the microbial system like E. coli and Saccharomyces cerevisiae have been made. ${ }^{115}$ Based on previous in vitro and in vivo studies, naringenin confers some pharmacological activities such as anti-inflammatory, anti-microbial, hepatoprotective, anticancer, antiatherogenic, and anti-mutagenic effects. ${ }^{114,115}$ Furthermore, naringenin also exhibits gastrointestinal, rheumatological, cardiovascular effects, and is useful in controlling malignant and infectious diseases. ${ }^{115}$ Venkateswara et $\mathrm{al}^{113}$ reported that naringenin is an antioxidant, is a free radical scavenger, and has the ability to recondition the DNA, indicating that naringenin has many benefits to humans.
A skin disorder that may be impacted by naringenin further is skin cancer. In past studies, high doses of naringenin have been confirmed to decrease the occurrence of papilloma about $20 \%$ in mice. ${ }^{114}$ It also decreases the size and number of papilloma in both pre- and post-treatment groups compared to the control where naringenin suppresses papillomagenesis. $^{114}$ Additionally, naringenin reduces the expression of glyoxalase-1, which is abundantly present in the skin cell carcinoma to cause cancer cell death. ${ }^{116}$ Naringenin also suppresses cancer by elevating carbonyl contents, ${ }^{114}$ indicating that it is a good choice of treatment for skin cancer. Administration of naringenin in combination with curcumin can impede angiogenesis activity since the combination decreases the production of new blood vessels in the peritoneal and inner skin linings of an Ehrlich Ascites Carcinoma (EAC) tumor-bearing mice model. ${ }^{117}$

Naringenin also causes cell death via apoptosis occurring through several mechanisms against skin cancer in humans. Ahamad et $\mathrm{al}^{118}$ reported that naringenin-induces apoptosis by 1) ROS-mediated mitochondrial membrane depolarization, 2) DNA fragmentation which signifies apoptosis that causes damage to cells, 3) induction of nuclear condensation inside human epidermoid carcinoma A431 cells, and 4) obstruction of cells in $G_{0}$ or $G_{1}$ phase of cell cycles leading to apoptosis and initiation of caspase- 3 that is one of the key roles in apoptosis occurring through cellular substrate splitting. Moreover, García-Bores et al ${ }^{119}$ also stated that methanolic extract of Lippia graveolens (MELG), a Mexican oregano containing naringenin, galangin, and pinocembrin, has photochemopreventive effects on a mouse skin model that can prevent tumors as the flavonoids have antineoplastic activity.

Skin aging due to UV light (photo-aging) is identifiable by collagen reduction and also elevation in MMP-1 produced in response to UV irradiation. ${ }^{120}$ Jung et $\mathrm{al}^{121}$ reported that naringenin 1) inhibits the UVB-induced MMP-1 production and the activator protein-1 (AP-1) in a 3D human skin comparable culture and 2) suppresses MMP-13 formation and production of wrinkles in a SKH1 mice model. Additionally, naringenin blocks the UVBinduced extracellular signal regulated kinase 2 (ERK2) and reduces fos-related antigen 1 (FRA1) stability by suppressing its phosphorylation along with inhibiting the transepidermal water loss, overall suggesting that naringenin is useful against photo-aging. ${ }^{121}$ Furthermore, in a study using a nematode model Caenorhabditis elegans, naringenin increases the life span of nematode when 
exposed to UV radiation by downregulating the aging regulated genes (daf-2 and age-1). ${ }^{122}$ Naringenin also accelerates the UVB-induced cyclobutane pyrimidine dimers lesion removal and suppression of excessive apoptosis, thus suggesting that it can prevent UVB-induced aging and cancer. ${ }^{123}$

Naringenin is useful against atopic dermatitis; an inflammatory skin disease. Kim et al $^{124}$ reported that naringenin decreases the atopic dermatitis skin lesion growth in $\mathrm{NC} / \mathrm{Nga}$ mice as initiated by 2,4-dinitrofluorobenzene (DNFB) via 1) inhibition of the formation of interferongamma (IFN- $\gamma$ ) by activated CD4+ T-cells and 2) reduction of the infiltration of skin lesions through CD8+ T-cells, CD4+ T-cells, mast-cells, and eosinophils. There was also improvement in the ear swelling in the naringenin-treated group of mice following a histological analysis on the epidermis thickness. ${ }^{124}$ Besides, an in vivo study of naringenin microsponge gel formulation indicated a reduction in inflammation as confirmed by the decrease in the total white blood count and thickness of the earflap in the dermatitis rat model, ${ }^{125}$ overall highlighting the significance of the microsponge gel carrier system that can enhance its therapeutic effect.

Due to its anti-inflammatory effect, naringenin is also useful against psoriasis. Trombino et al $^{126}$ demonstrated that the solid lipid nanoparticle (SLN) containing naringenin, linolenic acid, and cyclosporine synergistically decrease psoriasis-mediated inflammation. In another study, (R)-naringenin 1) suppresses T-cell proliferation, 2) decreases pro-inflammatory cytokines like TNF- $\alpha$ and IL-6, and 3) caused proliferation of human peripheral blood mononuclear cells (hPBMC). ${ }^{127}$ Since a TNF- $\alpha$ blocker is useful in psoriasis, naringenin, which has antiinflammatory effects, is a good treatment choice. Therefore, naringenin is a good candidate as an anti-psoriatic agent since it inhibits the over-expression of IL-6 and ameliorated psoriasis along with reducing the transepidermal water loss. ${ }^{128}$

Skin allergy, especially type 1 , is a common skin disorder common in industrialized countries due to factors such as allergen exposure, decreased activation of immune system, genetic predisposition, and psychosocial effects. Escribano-Ferrer et $\mathrm{al}^{129}$ reported that topical and intravenous naringenin exhibit a potent anti-allergic activity by inhibiting mast cell degranulation. Additionally, it was demonstrated that naringenin possessed anti-inflammatory activity against ear edema in a mice model. Naringenin present in tomato skin, particularly naringenin chalcone-
2 '-O- $\beta$-D-glucuronide, shows an anti-allergic affect by suppression of histamine release in rat peritoneal mastcells. $^{130,131}$

Terminalia brownii extract, which contains several compounds including naringenin-4'-methoxy-7-pyranoside, shows an antifungal effect against certain fungi that is traditionally-used against fungal infection. ${ }^{132}$ Nevertheless, it is plausible that the antifungal effect is also contributed by $T$. brownii itself. Similarly, Orhan et $\mathrm{al}^{133}$ also demonstrated the antifungal effect of naringenin pyranoside against $C$. krusei and Candida albicans with a minimum inhibitory concentration of 1,600-3,200 $\mu \mathrm{g} / \mathrm{mL}$.

Skin damage such as thermal burns can cause multiple complications if not appropriately treated. Naringenin can treat thermal burn-induced injury in a rat model by suppressing the pro-inflammatory markers like TNF- $\alpha$, interleukin, NF-kB, caspase-3, nitric oxide (NO) level, leukotriene-B4 (LTB4), PGE2, and also through the antioxidant effect. ${ }^{134}$ As for the oxidative parameter, naringenin caused an increase in glutathione (GSH), glutathione-S-transferase (GST), glutathione peroxidase (GPx), catalase, and superoxide dismutase (SOD), while reducing thiobarbituric acid reactive substances (TBARS) after a 7-day treatment.

\section{Quercetin}

Quercetin is a flavonoid that originates from natural products including the vegetables, grapes, apple, brassica, berries, onion, tea, spring onions, ginkgo biloba, and tomatoes. ${ }^{135}$ The word quercetin is derived from the Latin word quercetum (oak forest), with $\mathrm{C}_{15} \mathrm{H}_{10} \mathrm{O}_{7}$ as the molecular formula. ${ }^{135,136}$ Its structure consists of four active groups including the dihydroxy group between the A ring, O-dihydroxy group B, C-ring C2, C3 double bonds, and 4-carbonyl. ${ }^{136}$ According to Basu et al ${ }^{137}$ the chemical name for quercetin is 2-(3,4-dihydroxyphenyl)3,5,7-trihydroxy-4H-chromen-4-one.

Quercetin comes from plants in the form of quercetin3-o-glucoside that can work as a pigment that colors vegetables and fruits. ${ }^{138}$ In addition, rutin is the most common form of quercetin, which is normally glycosylated, while aglycone is a yellow sugar-free structure quercetin. $^{138}$ Quercetin structure usually has an $-\mathrm{OH}$ group while the glycoside structure has a glycosyl group, making its solubility in water higher than the quercetin aglycone. Quercetin has been shown to have anti-inflammatory and antioxidant effects in several studies, besides 
being an anti-tumor, antibacterial, anti-angiogenic, antidiabetes, anti-obesity, and anti-allergic, useful for neurological and cardiovascular diseases. ${ }^{135,136,138}$

Shin et $\mathrm{al}^{139}$ reported that quercetin inhibits UVinduced COX-2, MMP-1, and collagen breakdown in human skin. Furthermore, quercetin protects the skin from UV-induced skin aging by exerting its effect on PKC-delta (PKC $\delta$ ) and Janus kinase-2 (JAK2) to suppress $\mathrm{UV}$-induced skin aging and inflammation since PKC $\delta$ and JAK2 are significant regulators for inflammation. ${ }^{139}$ The researchers also reported that quercetin blocks AP-1 and $\mathrm{NF}-\kappa \mathrm{B}$ stimulation which was key in quercetin's antiaging effects. In another study, quercetin and its derivative quercetin caprylate (QU-CAP) exhibit their anti-aging effects by activating proteasome via the Nrf2 pathway that enhances the antioxidant effect to help protect against skin aging. ${ }^{140}$ Additionally, quercetin also affects the cell's lifespan and growth, as well as fibroblast's survival. ${ }^{141}$

Skin cancer is caused by mutation of cancer-related genes, including the tumor suppressor and protooncogenes. $^{142}$ The major classification of skin cancer includes cutaneous melanoma and non-melanoma that originates from keratinocytes of the epidermis. Quercetin can inhibit the stimulation of signal transducer and activator of transcription (STAT3) via IL-6 by decreasing cyclin D1 and MMP-2 production, leading to suppression of cell proliferation occurring via cell aggregation in particular at the $\mathrm{S}$ and G2/M stages. ${ }^{142}$ Generally, polyphenol that includes flavones, flavonols like quercetin and myricetin, as well as phenolic acid can act on the anti-cancer effect via various mechanisms. According to Shaik et al, ${ }^{143}$ quercetin suppresses the phosphatidylinositol-3-phosphate kinase (P13K) effect by ousting the binding of ATP from P13K and stimulating AMPK. The suppression of the B16-BL6 melanoma cell growth and DNA synthesis, retardation of the development of tumor, and reduction of cell invasion were among its anti-cancer properties mechanisms. ${ }^{144}$ Vargas et al ${ }^{145}$ reported that quercetin is useful in melanoma treatment by exploiting the tyrosinase expression and stimulating the p53 expression as well as ROS regulation, ultimately leading to cell apoptosis and death.

Skin infections such as impetigo, folliculitis, cellulitis, furuncles, and erysipelas may affect the quality-of-life. According to Memariani et al, ${ }^{135}$ quercetin has antimicrobial effects against certain pathogens and can inhibit Staphylococcus aureus, Enterococcus faecalis, Pseudomonas aeruginosa, Streptococcus mutans, and Escherichia coli through several mechanisms. Brown et $\mathrm{al}^{146}$ also suggested that consumption of fruits abundant in quercetin protects against $H$. pylori infection. In fact, an in vitro study suggests that the combination of quercetin with supplements like morin and rutin along with the use of some antibiotics is synergistic against MRSA. $^{147}$

Skin dermatitis is a skin disorder characterized by itching, erythema, rash, blisters, and even crust formation in some cases. Two major types exist: 1) atopic dermatitis (chronic skin damage and inflammation) and 2) contact dermatitis (an allergic reaction on the skin that causes a rash and pain). In vitro and in vivo studies in a rat model indicate that quercetin inhibits atopic dermatitis by blocking the inflammatory cytokines and pro-inflammatory factor. $^{148}$ Additionally, there was upregulation of heme oxygenase that suppress degranulation of mast-cells via the nuclear factor erythroid 2-related factor 2 (Nrf2)mediated pathway, ${ }^{149}$ which contributes to its anti-allergic effect. In a past study, both quercetin and tannic acid 1) reduce the T-helper type 2 ( Th2) polarization and 2 ) inhibit cytokine thymic stromal lymphopoietin (TSLP) as well as thymus activate regulated chemokine (TARC) in atopic dermatitis. ${ }^{150}$ Furthermore, quercetin and tannic acid also suppress the neo-angiogenesis that inhibit the atopic dermatitis inflammation. Quercetin inhibits contact dermatitis and photosensitivity by suppressing IL-6, IL-8, and TNF$\alpha$, where it shows that quercetin is an effective mast-cell inhibitor. ${ }^{151}$ Moreover, quercetin decreases the cytosolic calcium level and blocks NF- $\mathrm{B}$ stimulation.

Quercetin enhances wound healing due to its antiinflammatory and antioxidant activities. ${ }^{152}$ Quercetin penetrates into the fibroblast, a deeper layer of membrane which is the main target for wound healing, making a suitable quercetin formulation that can help enhance skin penetration a necessity. ${ }^{152}$ In a study by Gomathi et al, ${ }^{153}$ quercetin-incorporated collagen (QIC) film heals the wound more effectively than either control or collagentreated groups since it enhances cell proliferation and scavenges free radicals. Additionally, quercetin 1) decreases wound contraction, 2) elevates hydroxyproline to improve collagen, and 3) decreases uronic acid and superoxide dismutase levels. ${ }^{153}$ Moreover, quercetin can treat keloid, an extreme dermal scar due to skin trauma, by suppressing the transforming growth factor-beta (TGF- $\beta$ ) and Smads complex (Smad2/3/4) transfer. ${ }^{154}$

\section{Lycopene}

Lycopene belongs to the plant pigment family (carotenoid) and is found in tomatoes, papaya, pink grapefruit, 
watermelon, cloudberry, cranberry, grape, and peach. ${ }^{155,156}$ Carotenoid gives the color to fruits, including the red color in tomatoes, squash's yellow, and pumpkin's orange, besides yielding a certain smell to some. Lycopene is most abundant in tomatoes, contributing up to $80 \%$ of carotenoid content, and is present at the chromoplasts of plant-cells. ${ }^{156}$ Interestingly, the scientific name for tomato is "Lycopersicon esculentum". ${ }^{157}$

Carotenoid is classified into 1) hydrocarbon carotenoid that consists of only hydrogen and carbon such as in lycopene, and also 2) xanthophylls such as lutein that has the addition of oxygen to hydrogen and carbon. ${ }^{155}$ Lycopene with the molecular formula of $\mathrm{C}_{40} \mathrm{H}_{56}$ has a molecular weight of 536.89 and constituted about $9.49 \%$ of $\mathrm{C}$ and $10.51 \%$ of $\mathrm{H}^{156}$ Its IUPAC name is $2,6,10,14,19,23,27,31$-octamethyl2,6,8,10,12,14,16,18,20,22,24,26,30-dotriacontatridecaene.

Lycopene comes in a variety of cis-configurations while all the transforms are thermodynamically more stable. ${ }^{158}$ Meanwhile, other stable forms include 5-cis isomer, 7-cis, 9-cis, 11-cis, 13-cis, and 15-cis. Lycopene is also present in human plasma, tissue, and breast milk, mostly in the cis-isomer form. ${ }^{155}$ Lycopene's color is believed to indicate the type of isomer, where the alltrans isomer is red and tetra-cis-lycopene is orange. ${ }^{155}$

Lycopene is a good antioxidant, rich in vitamin A. Lycopene is useful in the treatment of asthma, cancer (uterine, prostate, lung, and breast cancers) and cardiovascular diseases (by reducing the possibility of myocardial infarction, blocking oxidation of LDL cholesterol, and lowering blood pressure). ${ }^{155,159}$ It is also believed to have therapeutic effects against Alzheimer's and Parkinson's disease.

Due to its strong antioxidant properties, lycopene can reduce skin aging by decreasing the roughness and scaling in the skin, especially when used in combination with other supplements. ${ }^{160}$ Besides reducing skin roughness, the high lycopene content in the skin can reduce the formation of wrinkles and furrows. ${ }^{161}$ Segger and Schönlau ${ }^{162}$ reported that a nutritional supplement Evelle ${ }^{\circledR}$ that contains various compounds including lycopene improves skin elasticity and decreases skin roughness when compared to placebo. Administration of natural kale extract supplement caused a higher lycopene concentration in the skin as compared to the serum, due to the presence of the antioxidant network in the skin which can help prevent skin aging. ${ }^{163}$ According to Marchena et al ${ }^{164}$ cosmetics consisting of lycopene and melatonin can improve skin hydration and stratum corneum elasticity along with increasing the pigmentation level, all of which can help prevent photo-damage and enhance skin characteristics.

Lycopene also has anti-cancer effects. According to Fazekas et al, ${ }^{165}$ lycopene inhibits UVB irradiation that caused skin damage by $5 \%$. Topical application of lycopene 1) suppresses the activity of ornithine decarboxylase (ODC) which was over-suppressed during cancer development, 2) blocks inflammatory responses like MPO activity and skin thickness, and 3) decreases caspase-3 production related to apoptosis as confirmed by the PCNA staining cell in the epidermis. ${ }^{165}$ Basu and Imrhan ${ }^{166}$ reported that tomato products rich in lycopene have a chemoprotective effect by decreasing the biomarkers for oxidative stress and carcinogenesis. Cooperstone et $\mathrm{al}^{167}$ also suggested that tomatoes with high lycopene content can reduce the tumor number in SKH-1 mice with a UVB-induced skin tumor when compared to control, since lycopene can decrease the possibility of keratinocyte cancer by conferring protection against UVA. In another study, Kopec et al ${ }^{168}$ confirmed that tangerine tomatoes that contain lycopene can reduce the formation of UV-induced cyclobutane pyrimidine dimers, myeloperoxidase activity, and the percentage of $\mathrm{p} 53$ positive epidermal cells in male SKH-1 mice, all of which are attributed to a decrease in inflammation or DNA damage. Antioxidant activity can also contribute to cancer prevention since increased highly reactive free radicals lead to DNA damage which can be neutralized by the antioxidants. Hwang and Bowen ${ }^{169}$ reviewed that in in vivo studies, lycopene can prevent DNA damage by its antioxidant effect by reducing serum thiobarbituric acid reactive substance that ameliorate lipid peroxidation, which may protect against tumor development related to oxidative damage.

Exposure to UV causes photo-oxidative damage to cellular lipids, DNA, and proteins which are related to the formation of erythema and other skin disorders. ${ }^{170}$ In addition, solar erythema, also known as sunburn, is characterized by blister, pain, tenderness, and second degree burns. The damage to the DNA and protein in skin cells alters keratinocytes morphology, which can be ameliorated with products with a photo-protective effect. ${ }^{171}$

Stahl et al $^{170}$ conducted a study involving volunteers on five forms of lycopene (tomato paste, carrot juice, lycopene supplement, tomato extract, and synthetic lycopene) for 10 to 12 weeks an reported that lycopene confers a photo-protective effect by reducing the sensitivity to UV-induced erythema by reducing the chromametry a-values ( $\Delta$ a-values), a measurement for erythema effective as photo-protection since lycopene 
absorbs in the UV-range. Sies and Stahl ${ }^{172}$ suggested the application of lycopene as a sun protectant due to the prevention of UV-induce erythema production. Grether-Beck et $\mathrm{al}^{173}$ stated that lycopene-rich tomato nutrient complex (TNC) suppresses the UVA1- and UVA/B-induced heme-oxygenase 1 (HO1) increase, intercellular adhesion molecule 1 (ICAM-1), and matrix metallopeptidase 1 (MMP-1) mRNA, which protect against sun radiation damage as compared to placebo.

Lycopene also protects against psoriasis. In a previous study, lycopene suppresses the imiquimod (IMQ)-induced psoriasis-like inflammation in keratinocyte, a type of epidermis by inhibiting monocyte adhesion in a mice model. ${ }^{174}$ The adhesion molecules include intercellular adhesion molecules (ICAMs) and vascular cell adhesion molecule-1 (VCAM-1), which are significant in inflammatory response. ${ }^{174}$ Atopy is associated with an allergic reaction that produces an exaggerated immune response such as eczema, asthma, and allergic rhinitis. Lycopene is useful against atopy occurring in the skin, lungs, and immune-competent cells. Carotenoids like lycopene can stimulate the retinoic acid receptor (RAR) and retinoid-X receptor (RXR) essential in atopy. ${ }^{175}$ Furthermore, carotenoid is metabolized to be more bioactive under oxidative circumstance; stimulating the RAR- and peroxisome proliferatoractivated receptor (PPAR)-mediated signaling pathways and preventing the NF- $\mathrm{KB}$ signaling that confers the anti-inflammatory effect. ${ }^{175}$ Additionally, carotenoid transporter-proteins, polymorphism, and local carotenoid levels can inhibit atopic development, making carotenoids including lycopene an important strategy in atopy suppression. ${ }^{175}$

\section{Gingerol}

Gingerol, a polyphenol present in ginger, belongs to the Zingiberaceae family. It is widely used as a herbal medicine, a food, and a spice, not only in Asia but globally. ${ }^{176}$ The molecular formula of gingerol is $\mathrm{C}_{17} \mathrm{H}_{26} \mathrm{O}_{4}$ with the IUPAC name (5S)-5-hydroxy-1-(4-hydroxy-3-methoxyphenyl)decan-3-one. ${ }^{177}$ In general, ginger contains many components including volatiles such as camphene, geranyl acetate, $\beta$-phellandrene, curcumene, borneol, cineole, terpineol, limonene, geraniol, $\beta$-elemene, linalool, $\alpha$-zingiberene, zingiberol, zingibereno, $\alpha$-Farnesene, $\beta$ bisabolene, and $\beta$-sesquiphellandrene, and also non-volatiles such as gingerol, zingerone, paradols, and shogaols.178 The main active component of ginger is 6-gingerol (1[4'-hydroxy-3'-methoxyphenyl]-5-hydroxy-3-decanone), while other components include 8-gingerol and 10gingerol. $^{176,179}$
Ginger has a strong flavor and an unpleasant taste to some individuals, especially when used in high concentrations. ${ }^{180}$ Gingerol has various therapeutic effects including amelioration of fever, vomiting, pain, cramps, arthritis, hypertension, and cardiopathy. ${ }^{176}$ Other activities include anti-cancer, anti-inflammatory, antipyretic, decreased blood lipids, anti-angiogenic, anti-aging, improved circulation of blood, cardiotonic, improved digestion, antioxidant, and as an antimicrobial. ${ }^{176,181}$ Additionally, Wang et $\mathrm{al}^{178}$ reported that gingerol has an antifungal effect and anti-platelet aggregation. In Chinese, gingerol is called Shengjiang and ginger is commonly used in traditional Chinese medicine, since it can soothe a cough and overcome phlegm in addition to treating poisons from crab and fish. ${ }^{181}$

Gingerol exhibits anti-cancer and anti-inflammatory effects in various organs including the skin, gastrointestinal, colorectal, and pancreas. ${ }^{91}$ Kim et al ${ }^{182}$ reported that 6-gingerol decreases the UVB-induced ROS since UV is the main factor contributing to skin cancer where UVBinduced ROS stimulates inflammation and increases tumor number by lipid peroxidation, DNA damage, and changes in enzyme activity. Additionally, 6-gingerol also suppresses the UVB-induced COX-2 production by inhibiting ROS and activating $\mathrm{NF}-\kappa \mathrm{B}$ in the HaCat-cell through inhibition of I $\kappa \beta \alpha$ phosphorylation; leading to suppression of the UVB-induced apoptotic pathway. ${ }^{182}$ In fact, COX-2 is the main target involved in reduction of photo-inflammation that causes tumor production and photo-aging. ${ }^{182}$ Yarla et al $^{91}$ reported that 6-gingerol acts as an anti-tumor and possesses some chemoprotective effect by inhibiting the arachidonic acid (AA) pathway significant in carcinogenesis. Additionally, 6-gingerol suppresses melanin formation in murine B16F10 melanoma cells which stimulates the Akt/PKB pathway and also inhibits the melanogenesis development in melanoma cells through reductions in microphthalmia-associated transcription factor (MITF) and tyrosinase activity suppression. ${ }^{183}$ Moreover, 6-gingerol also suppresses the TPA-induced COX-2 synthesis by preventing the p38 mitogen-activated protein (MAP) kinase-NF- $\kappa \mathrm{B}$ signaling pathway, thus confirming the anti-tumor effect of ginger. ${ }^{184}$

\section{Apigenin}

Apigenin is from the flavone class and is an aglycone of several natural occurring glycosides. ${ }^{185}$ Species like Lamiaceae, which includes Sideritis and Teucrium, and Fabaceae, including Genista, haveapigenin existing in the aglycone form and/or 
its C- and O-glucosides, glucuronides, acetylated derivatives, and O-methyl ethers. ${ }^{186}$ Apigenin which has a molecular formula of $\mathrm{C}_{15} \mathrm{H}_{10} \mathrm{O}_{5}$ and molecular weight of 270.24 is also known as $4^{\prime}, 5,7$,-trihydroxyflavone. ${ }^{185,187}$ In the Biopharmaceutics Classification system (BCS), apigenin is classified as a class II drug due to its low solubility and high permeability. $^{187}$

Apigenin is mainly found in Asteraceae species like Artemisia, Matricaria, Achillea, and Tanacetum genera. ${ }^{186}$ In addition, apigenin, which exists as a glycosylated form, is found in 1) herbs like thyme, basil, chamomile, and oregano, 2) vegetables such as celery, parsley, and onion, and 3) plantbased beverages like beer, tea, and wine. ${ }^{186}$ Other sources of apigenin include red and white sorghum, oranges, wheat sprouts, rutabagas, cilantro, and kumquats. ${ }^{187}$

Apigenin is slightly soluble in highly polar solvents like water and non-polar solvents including safflower oil and silicone fluid. However, apigenin is freely soluble in ethanol, dimethylsulfoxide (DMSO), and dimethylformamide (DMF), excluding inert gases at $0.3,15$, and $25 \mathrm{mg}$ / mL, respectively. ${ }^{187}$ Apigenin has low toxicity with good biological activities like antioxidant, anti-tumor, anti-allergic, anti-inflammatory, cardioprotective, neuroprotective, antimicrobial, and anti-genotoxic. ${ }^{185}$ Moreover, it also has anti-hyperglycemic, anti-apoptotic, anti-atherogenic, antiparasitic effects, and can confer protection against hypertension, autoimmune myocarditis, and cardiac hypertrophy. ${ }^{185,187}$

Apigenin inhibits 1) UV-induced skin cancer by stimulating AMPK, leading to inhibition of the mammalian target of rapamycin (mTOR) effect and activation in keratinocytes, and 2) proliferation of cells and development of cell cycles in the mouse model skin and epidermal keratinocyte. $^{188}$ Furthermore, apigenin suppresses Akt (protein kinase B) and mTOR signaling independently, leading to AMPK-dependent inhibition of mTOR that intensifies autophagy along with reducing proliferation in keratinocytes. ${ }^{189}$ Kiraly et al ${ }^{190}$ demonstrated that apigenin inhibits tumorigenesis including tumor multiplicity as well as the incidence of a DMBA/TPA-induced tumor in a SKH-1 mice model by 1) reducing COX-2, EP1, EP2, and PGE2 production, 2) escalating the terminal differentiation, and 3) suppressing cell proliferation that contributes to the blocking of the production of tumors.

Paredes-Gonzalez et $\mathrm{al}^{191}$ concluded that apigenin demethylates the $\mathrm{Nrf} 2$ gene promoter in the $15 \mathrm{CpG}$ site in JB6 P+ cells that 1) initiate the Nrf2 nuclear translocation and protein expression and 2) escalate NQO1, the
Nrf2 downstream target. In addition, apigenin decreases DNA methyltransferase epigenetic proteins and also histone deacetylase (HDAC), indicating that apigenin can be a good chemoprotective agent or adjuvant. The researchers have reported that in UVB-induced skin cancer, thrombospondin-1 (TSP1) is an important element in chemoprotective activities of apigenin since apigenin suppressed the UVB-induced carcinogenesis in wild-type (WT) mice but not in TSP1 KO (TKO) mice. In summary, conserving normal TSP1 production via apigenin application can reduce the inflammatory cytokines in UVB-irradiated WT mice, indicating that TSP1 that has an anti-inflammatory effect is a significant element of the anti-tumor activities of apigenin in the skin. ${ }^{192}$ Overall, the findings indicated that apigenin can treat inflammatory diseases like psoriasis and eczema.

Topical apigenin, which can boost permeability barrier homeostasis, increasethe production of filaggrin, lamellar body, and mRNA levels in lipid synthetic enzymes, is useful in the treatment of skin diseases like atopic dermatitis that is associated with a permeability barrier aa long with decreased degree of filaggrin. ${ }^{193}$ An important source of apigenin includes matricaria chamomile; also known as chamomile. Chamomile ointment can reduce dermatitis or eczema due to its purported anti-inflammatory activities. Topical chamomile extract reduced inflammation in croton oil-induced dermatitis in a rat model. In fact, matricaria ointment that contains apigenin has been reported to be comparable with non-steroidal anti-inflammatory drugs (NSAID) or $0.25 \%$ hydrocortisone, and is even more effective compared to $0.75 \%$ fluocortin butyl ester and $5 \%$ bufexamac against dermatitis. ${ }^{194}$ Additionally, topical apigenin can also reduce acute inflammation and subacute dermatitis. $^{195}$

In a study with murine models that had acute allergic dermatitis and acute irritant contact dermatitis, apigenin 1) can treat both types of dermatitis, 2) decreases transepidermal water loss, 3) improves skin hydration, and 4) reduces the $\mathrm{pH}$ of the skin surface. ${ }^{195}$ Due to its antioxidant activities, apigenin is also useful against skin aging. Topical application of apigenin improves skin aging in female participants $(n=25)$ by ameliorating the skin roughness via 1) reduction of the volume of roughness, 2) improvement of fine lines, 3) reducing class 1 wrinkles (depth from $0-55 \mu \mathrm{m}$ ) to about $10 \%$ following 4 weeks of treatment, and 4) enhancement of skin elasticity, making the skin firmer following 8 weeks of treatment. ${ }^{196}$ Overall, 
Table 2 Overall Mechanism of Action for Natural Products Against Skin Disorders

\begin{tabular}{|c|c|c|}
\hline $\begin{array}{l}\text { Natural } \\
\text { Products }\end{array}$ & Mechanism of Action & References \\
\hline Mangiferin & $\begin{array}{l}\text { Reduce Skin Aging } \\
\text { - By increasing the collagen bundles in skin } \\
\text { - By blocking MMP-I expression by supressing the ERK and JNK pathway and also through inhibition of MEK and } \\
\text { SEK pathways } \\
\text { Inflammation Reduction (dermatitis and psoriasis) } \\
\text { - By inhibiting the inflammatory activity via reduction of inflammatory mediators and inflammatory biomarkers } \\
\text { - By inhibiting the CD68 activity } \\
\text { Wound Healing } \\
\text { - By instigating the cell proliferation and migration of fibroblasts and reducing MPO activity } \\
\text { - By reducing the oxidative damage on skin tissue by increasing the Nrf-2 degree } \\
\text { - Skin flap regeneration } \\
\text { Treat Skin Cancer } \\
\text { - By blocking fibroblast growth factor (bFGF) and expression of IL6, TNF, PLAU, KDR (VEGFR2), IFNG, FGFI, } \\
\text { CCL2, MMPI9, and placental growth factor (PGF) } \\
\text { Treat Skin Infection } \\
\text { - By reducing the infectivity of HSV infection }\end{array}$ & 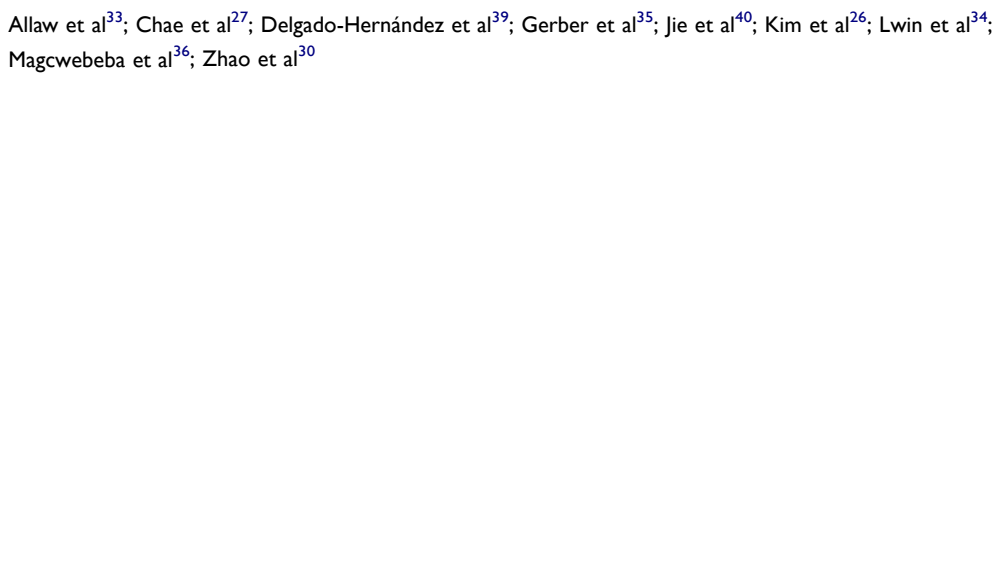 \\
\hline Lutein & $\begin{array}{l}\text { Reduce Melisma } \\
\text { - By enhancing skin tone, luminance and color } \\
\text { Reduce Skin Aging } \\
\text { - By defending from gene expression and providing a barrier to the skin from UVR } \\
\text { - Block the skin damage and promote the skin component } \\
\text { - Enhance the collagen I/elastin aging index } \\
\text { Inflammation Reduction (skin erythema and psoriasis) } \\
\text { - Decrease the skin rash by block UVR } \\
\text { - Due to antioxidant activity } \\
\text { - Decrease the amount of sunburn cells and decrease epidermal hyperproliferation } \\
\text { Treat Skin Cancer } \\
\text { - Due to antioxidant activity } \\
\text { - By decreasing risk of SCC } \\
\text { - Increase the tumor free survival time and reduce the tumor volume and multiplicity } \\
\text { Wound Healing } \\
\text { - By increasing production of hyaluronan }\end{array}$ & Aziz et $\mathrm{al}^{46} ;$ Balić and Mokos $^{44} ;$ Heinen et $\mathrm{al}^{48} ;$ Murillo et $\mathrm{al}^{47}$; Souyoul et $\mathrm{al}^{45}$ \\
\hline
\end{tabular}


Table 2 (Continued).

\begin{tabular}{|c|c|c|}
\hline $\begin{array}{l}\text { Natural } \\
\text { Products }\end{array}$ & Mechanism of Action & References \\
\hline Curcumin & 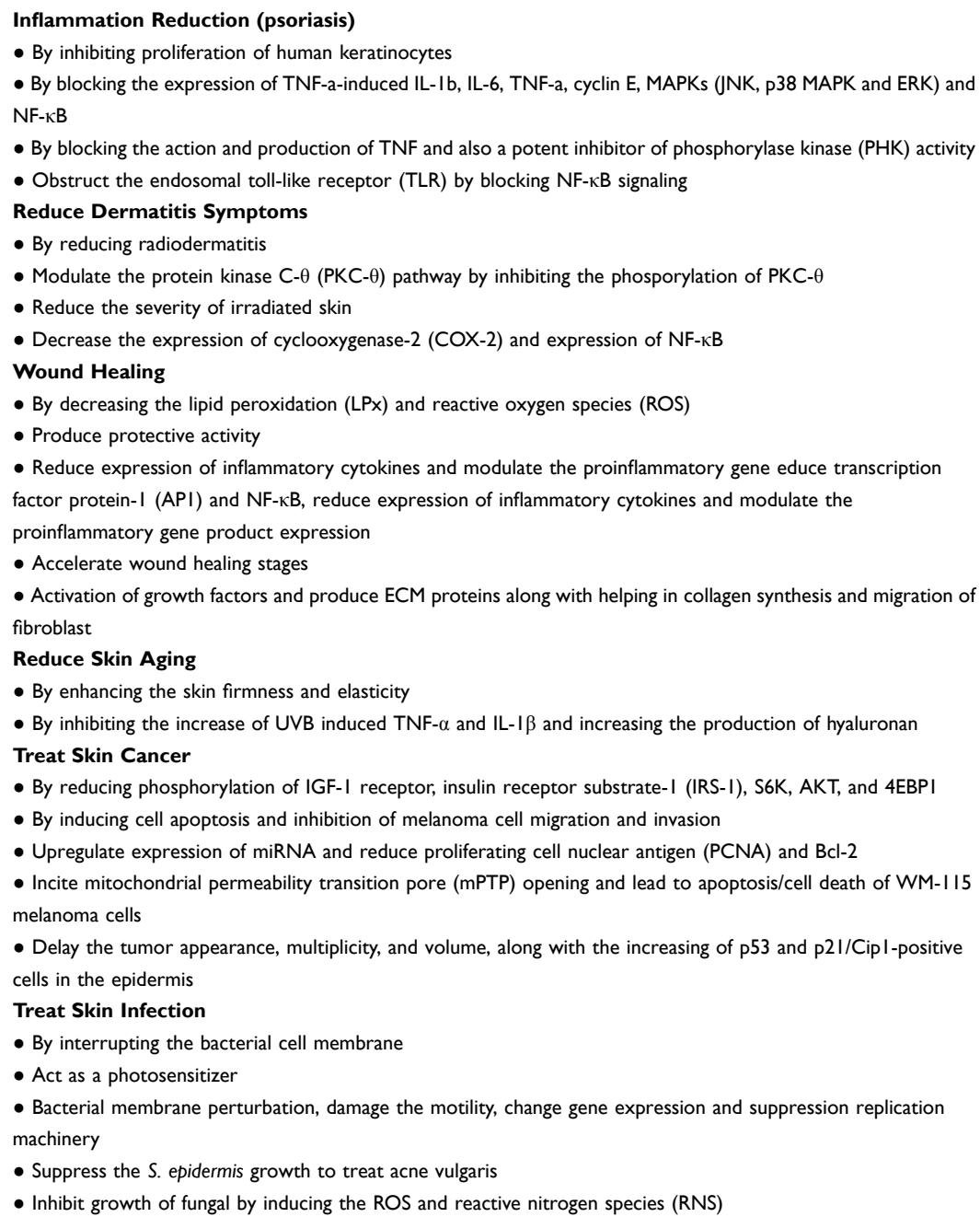 & 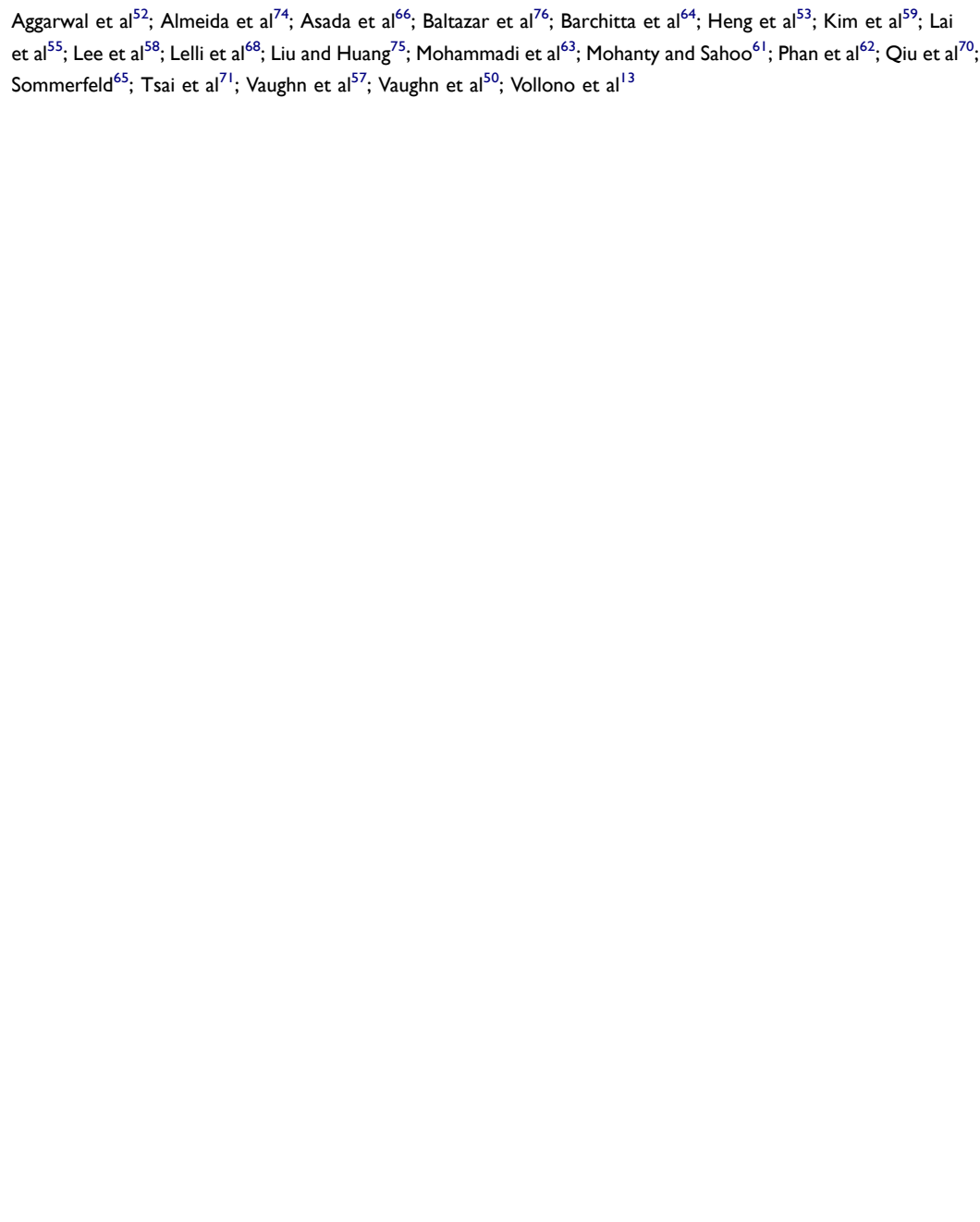 \\
\hline
\end{tabular}


Aziz et $\mathrm{al}^{86} ; \mathrm{Boo}^{81}$; Buonocore et $\mathrm{al}^{85}$; Docherty et al ${ }^{94}$; Docherty et al $\mathrm{a}^{99}$; Docherty et $\mathrm{al}^{93}$; Dybkowska et $\mathrm{al}^{87}$; Faith et $\mathrm{al}^{95}$; Hemmati ${ }^{102}$; Kjær et al ${ }^{101}$; Lai et $\mathrm{al}^{55}$; Lee et $\mathrm{al}^{283}$; Leyton et $\mathrm{al}^{96}$; Liang et $\mathrm{al}^{82}$; Moreira et al ${ }^{105}$; Rauf et $\mathrm{al}^{\mathrm{8}}$; Reagan-Shaw et $\mathrm{al}^{89}$; Soleymani et $\mathrm{al}^{83}$; Taylor et al ${ }^{100}$; Yamakoshi et al ${ }^{104}$; Yarla et al ${ }^{9}$
By inhibiting TNF- $\alpha$-induced expression of inflammatory cytokines and MMPs

- By enhancing the sirtuin I expression, promoting the mitochondria function and decreasing the ROS production

- By protecting from the damaging effects of hydrogen peroxide

- Decrease the AP-I and NF-kB transcription factors expression, collagen breakdown, and inflammation

Treat Skin Cancer

- Has a chemo-preventive effect by decreasing the COX-2 levels

- Increase cyclin kinase inhibitor WAFI/p2I and tumor suppressor p53

- Modulation in the expression and function of cell cycle regulatory protein cyclin-DI and -D2, cdk-2, -4, and -6 and WAFI/p2I

- Alter the expression level of vasodilator-stimulated phosphoprotein (VASP), COX-2, AMP-activated protein

kinase (AMPK), and vascular endothelial growth factor (VEGF)

- Obstruct the MAPK/ NF-KB/AP-I/COX-2 pathway

Reduction of Skin Infection (HSV)

- By decrease the development of lesio

- Suppress the stimulation of NF-KB

- Stimulate the 50 AMP-activated protein kinase/Sirtuin I (AMPK/Sirtl) axis

Treat Acne Vulgaris

Inhibit P.acnes reproduction and reduce the inflammation

- Change the surface structure of bacteria with loss of define membrane

- Suppress imiquimod-induced gene expression of IL-19, IL-17A, IL-17F, and IL-23pI9

Wound Healing

- Cause the growth of a protected area ithe $n$ epithelium, raise the cell density and elevate the displacement of connective tissue at the place of wound

Reduce Chloasma

- Decrease the number of melanocytes

- Decrease in skin melanin and reduce pigmentation

Embelin

Inflammation Reduction (psoriasis)

- By suppression of TNF- $\alpha$ and IL-I $\beta$ and the inhibition of aggregation of leukocyte

- Increase the percentage of wound closure

Wound Healing

- By accelerating the incision epithelialization

- Show the complete healing process 
Table 2 (Continued).

\begin{tabular}{|c|c|c|}
\hline $\begin{array}{l}\text { Natural } \\
\text { Products }\end{array}$ & Mechanism of Action & References \\
\hline Naringenin & 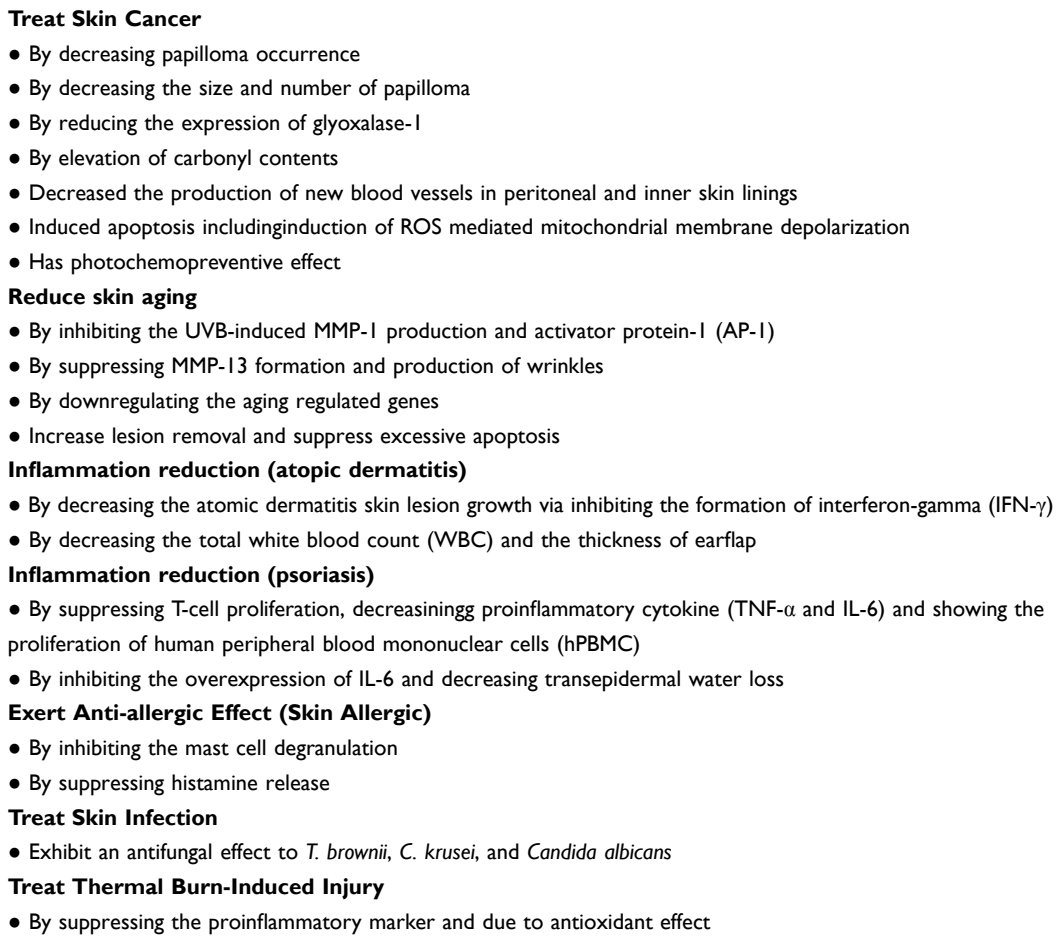 & 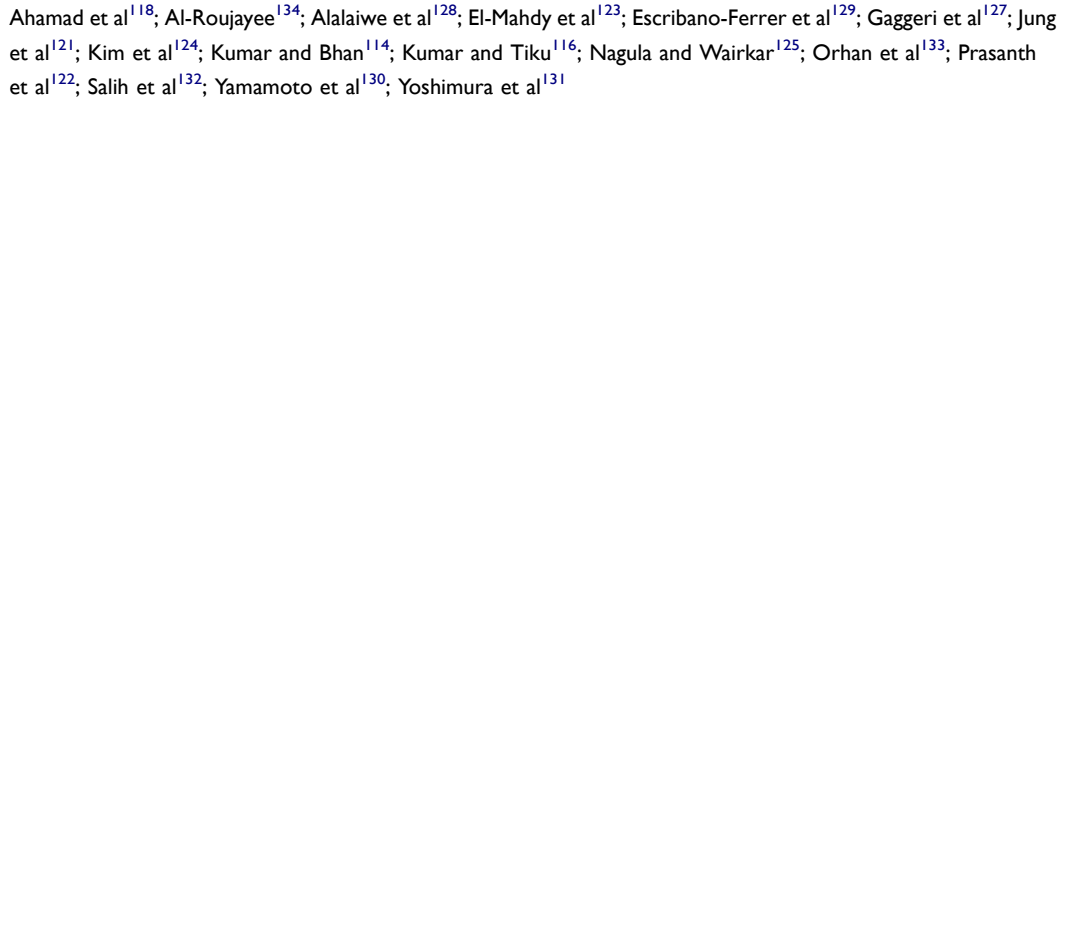 \\
\hline
\end{tabular}


Amin et al ${ }^{147}$; Brown et al $\left.\right|^{146}$; Caltagirone et al $\left.\right|^{144}$; Chondrogianni et al ${ }^{140}$; Gomathi et al ${ }^{153}$; Hatahet et al ${ }^{152}$; Jung et al $\left.\right|^{150}$; Matsushima et al ${ }^{149}$; Sajadimajd et al ${ }^{142}$; Shaik et al ${ }^{143}$; Shin et al ${ }^{139}$; Unahabhokha et al ${ }^{154}$; Vargas et al ${ }^{145}$;

\section{Reduce Skin Aging}

- By inhibited UV-induced COX-2, MMP-I and breakdown of collagen in human skin

et al ${ }^{150}$; Matsus

Weng et al ${ }^{151}$

- By blocking AP-I and NF-KB stimulation

- Activate the proteasome through the Nrf2 pathway

Treat Skin Cancer

- By inhibiting the stimulation of signal transducer and activator of transcription (STAT3) via IL-6 by decreasing the

cyclin DI and MMP-2 production

- Suppressing the phosphatidylinosi-tol-3-phosphate kinase (PI3K) effect

- Suppressing the BI6-BL6 melanoma cell growth and DNA synthesis

- Stimulate the p53 expression and ROS stimulation

Treat Skin Infection

- Can inhibit certain pathogens

- Protect from H. pylori infection and have an effect against MRSA

Inflammation Reduction (dermatitis)

- By blocking the inflammatory cytokines and proinflammatory factor

- Upregulation of heme oxygenase

- By reducing Th2 polarization, inhibiting cytokine TSLP and TARC

- By inhibiting IL-6, IL-8, and TNF- $\alpha$

Wound healing

- By penetrating into the fibroblast

- By elevating the cell proliferation

- By decreasing the wound contraction, elevating the hydroxproline, decreasing uronic acid content and

superoxide dismutase content

Reduction of keloid (dermal scar)

- By suppressing the transforming growth factor-beta (TGF- $\beta$ ) and Smads complex (Smad2/3/4) 
Table 2 (Continued).

\begin{tabular}{|c|c|c|}
\hline $\begin{array}{l}\text { Natural } \\
\text { Products }\end{array}$ & Mechanism of Action & References \\
\hline Lycopene & $\begin{array}{l}\text { Reduce Skin Aging } \\
\text { - By reducing the roughness and scaling in human skin } \\
\text { - By improving the skin elasticity } \\
\text { - By improving the skin hydration and elasticity of stratum corneum } \\
\text { Treat Skin Cancer } \\
\text { - By suppressing ODC activity, blocking inflammatory responses like MPO activity and skin thickness, decreasing } \\
\text { the caspase-3 production and showing a PCNA staining cell } \\
\text { - By decreasing the biomarkers of oxidative stress and carcinogenesis } \\
\text { - Reduction of tumor number } \\
\text { - By reducing the UV-induced cyclobutane pyrimidine dimers formation, myeloperoxidase activity and percentage } \\
\text { of p53 positive epidermal cells } \\
\text { - Due to antioxidant activity - DNA damage and reduction of serum thiorbarbituric acid reactive substance } \\
\text { Inflammation Reduction (Skin erythema) } \\
\text { - By reducing the sensitivity to UV induced erythema } \\
\text { - By suppressing the UVAI- and UVA/B-induced HOI increase, ICAM-I and MMP-I mRNA } \\
\text { - By demonstrating higher phenol content that make it as a good capacity of antioxidant } \\
\text { Inflammation Reduction (psoriasis) } \\
\text { - By suppressing IMQ-induced psoriasis-like inflammation by inhibiting the monocyte adhesion } \\
\text { Reduce Atopy Disease (eczema) } \\
\text { - By stimulating the retinoic acid receptor (RAR) and retinoid-X receptor (RXR)ing } \\
\text { - By block the atopy development }\end{array}$ & 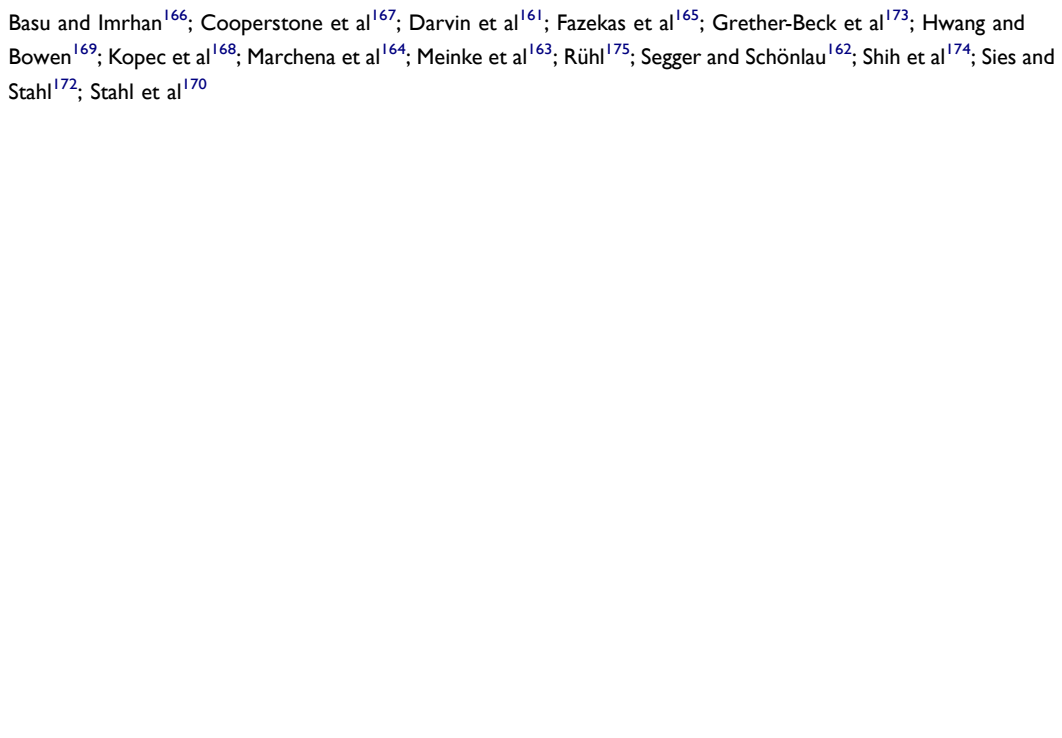 \\
\hline Gingerol & $\begin{array}{l}\text { Treat Skin Cancer } \\
\text { - By decreasing the UVB-induced ROS } \\
\text { - By suppressing the UVB-induced COX-2 production } \\
\text { - Exert chemoprotective effect through targeting the arachidonic acid (AA) pathway } \\
\text { - By suppressing the melanin formation and inhibiting melanogenesis development } \\
\text { - By suppressing the TPA-induced COX-2 synthesis through prevention of p38 mitogen-activated protein (MAP) } \\
\text { kinase- NF-KB signaling pathway }\end{array}$ & Huang et al ${ }^{183} ;$ Kim et al ${ }^{182} ;$ Kim et al ${ }^{184} ;$ Yarla et al ${ }^{91}$ \\
\hline
\end{tabular}




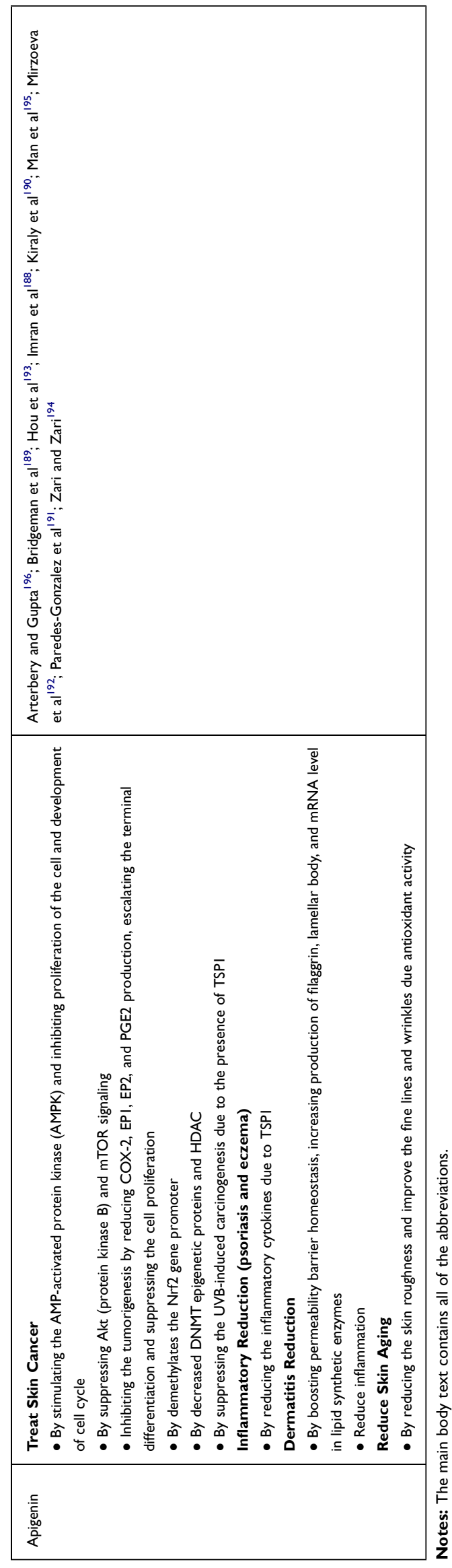

the positive findings indicate that apigenin is a useful antiaging skin product.

\section{Overview of the Mechanisms of Action of Natural Products Reported for the Treatment/Management of Skin Disorders}

The prevalence of skin diseases commonly affects and risks human health of all generations, from children to older people. According to Tabassum and Hamdani, ${ }^{22}$ there are various skin diseases that are associated with humans including rashes and inflammation like psoriasis and dermatitis, infection like bacteria, virus and parasitic infection, tumor or cancer, wrinkles, pigmentary disorder, and skin aging. Therefore, it is essential to keep the skin healthy to get a healthy body. In fact, the skin actually acts as the body's defence against foreign particles, pathogens, and uncontrolled loss of water, and the skin also functions as insulation, regulating temperature, and is related with certain vitamin like vitamin $\mathrm{D}$ and $\mathrm{B}$. According to Wootton et $\mathrm{al}^{14}{ }^{14}$ the most frequent human disease was skin disease, which will affect the human's quality-oflife, mental health, and productivity. Furthermore, the study also highlighted that the use of natural products or herbal medicines that come from natural sources like plants, fruits, and vegetables are getting public attention as they are cheap, have less-side effects, good patient tolerance, and are acceptable as they have been used by our ancestors. ${ }^{22}$

The present review focused on ten natural products or isolated compounds which are well documented for the treatment of inflammation skin disorders like psoriasis and dermatitis, tumor or cancer, skin infection, skin aging, and wounds, based on the in-vitro and in-vivo experiments. The overall mechanism of action of natural products against skin disorders has been summarized in Table 2 and Figure 5. However, these natural compounds need to be further studied to strengthen the claims, although they have potential against skin disorders.

On the one hand, the immune system in the skin is tightly regulated, thus protecting the host from extrinsic insults. On the other hand, when people become old, the immune system functions less actively therefore creating pro-inflammatory pathologies and other diseases. Moreover, any injury or infection in the skin changes its physical appearance. In general homogenous skin is considered as beautiful. Visually unappealing skin would affect the psychological health of the patients. An 

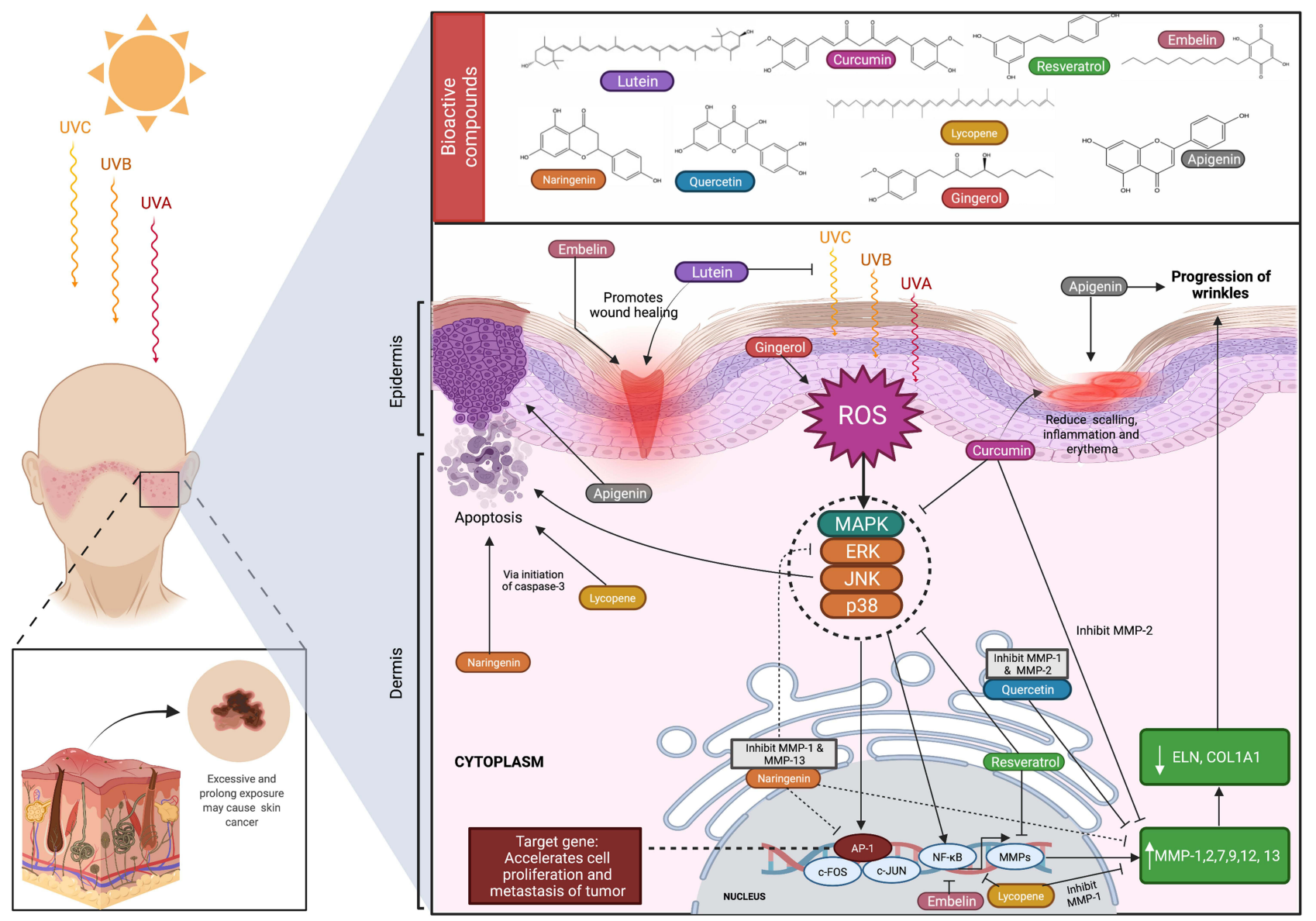

Figure 5 Overview of the mechanisms of action of natural products reported to treat/management of skin disorders. Mangiferin, lutein, curcumin, resveratrol, embelin, naringenin, quercetin, lycopene, gingerol, and apigenin are natural products that are commonly used in the treatment of various skin disorders. Through various pathways, these natural products can aid in wound healing, protect against tumor development due to oxidative damage, prevent further progression of wrinkles from prolonged UV exposure, and reduce atopic dermatitis skin lesion growth. Created with BioRender.com.

Abbreviations: UVA, B and C, ultraviolet A, B and C; AP-I, Activator protein I; c-FOS, proto-oncogene.

improvement in visible skin appearance enhances confidence. Some skin diseases, which spread throughout the body, induce psychological stress. Besides, stress dysregulates the immune homeostasis, which again drives the inflammatory diseases. A vast number of skin diseases are emerging (Figure 6), and each is categorized based on the type of inflammation intervention. Different levels of scaling have been assigned to track the disease status of the skin. The detailed mechanisms of how several skin diseases originated and progress have yet to be elucidated.

\section{Role and Importance of Nanoformulation Development of the Reported Natural Products for Skin Therapy}

Natural products are beneficial due to their low toxicity and high efficiency in delivering a therapeutic effect. ${ }^{197}$
However, their disadvantages include low bioavailability, they are not stable, and their poor solubility, which limit their effect. Previous studies stated that one of the ways to overcome these disadvantages is to develop the product into a nanoformulation, a novel drug delivery system, as it can improve the water solubility and permeability of the products to deliver the drug, thus improving the therapeutic effect. ${ }^{198}$ Furthermore, nanoformulations help the drug reach the epidermis and dermis in dermatological treatment, specifically in psoriasis disease. The nanoformulation helps the drug reach the epidermis that is difficult to reach due to several scales of psoriasis. ${ }^{198}$ According to Taghipour et al, ${ }^{197}$ various phytochemicals like curcumin, naringenin, resveratrol, quercetin, and others have been developed into a nanoformulation. Other studies also demonstrated that nanoformulation increases the efficacy of therapeutics activities of natural products which also 


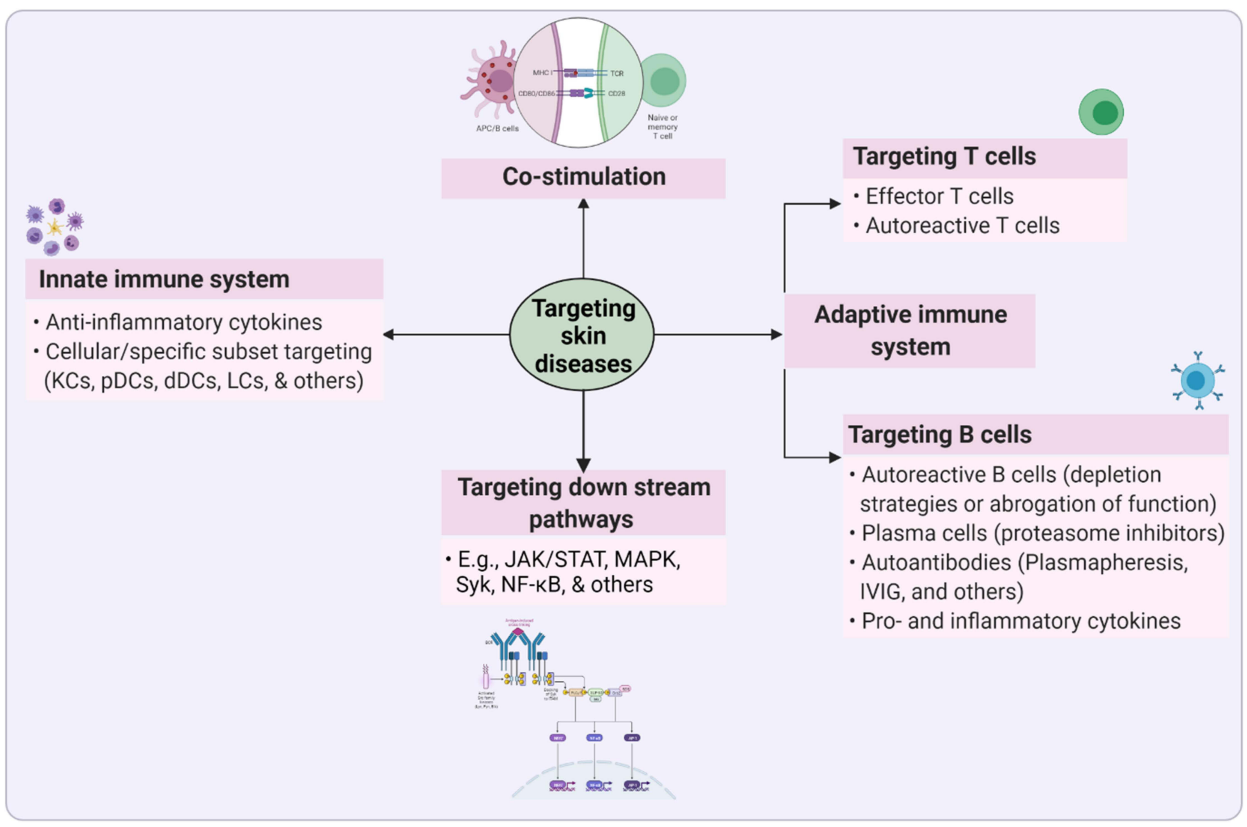

Figure 6 Targets of inflammatory skin diseases. Inflammation is an innate response of the body's initial response against any insults (damage or infection). The hyperimmune response is the seeding point for several inflammatory skin diseases, including autoimmune diseases. The loss of self-tolerance in the skin sequentially develop as autoimmune diseases. Therefore, targeting excess inflammation would serve as a best strategy to restore the skin homeostasis. Several established targets in inflammatory diseases, such as innate immune system, co-stimulation, downstream pathways, adaptive immune system (including T- and B-cells), and others. Created with BioRender.com. Abbreviations: dDCs, dermal dendritic cells; IVIG, intravenous immunoglobulin; JAK, Janus kinase; KCs, keratinocytes; LCs, Langerhans cells; MAPK, mitogen-activated protein kinase; NF-kB, nuclear factor kappa-light-chain-enhancer of activated B-cells; PDCs, plasmacytoid dendritic cells; STAT, signal transducer and activator of transcription; Syk, spleen tyrosine kinase.

contribute to a smart healing process, decreasing the doses required for treatment, and improving the healing process of skin disorders like wound, where herbal-based nanostructures help in decreasing the oxidative factor and block the production of inflammatory cytokines and cascades. ${ }^{198}$

According to Pleguezuelos-Villa et al, ${ }^{32}$ mangiferin nanoemulsions that are produced by hyaluronic acid boost the permeation, where the utilization of a TPAinflamed skin mice model diminished the edema and leucocyte infiltration. Moreover, these nanoformulations show a good anti-inflammatory effect. A previous article also reported that a $\beta$-cyclodextrin-curcumin nanoparticle complex enhances the permeability in tissue of a skin model and encapsulated a nanoparticle formulation able to penetrate into the skin and help decrease the UVBirradiation better than free curcumin. ${ }^{199}$ On the other hand, the nanoformulation of naringenin, a flavonoid also used in treating skin diseases, overcomes the poor bioavailability problem and enhances the naringenin availability that leads to increased efficacy. ${ }^{200}$ Hatahet et al ${ }^{152}$ also investigated that quercetin smartcrystals (also known as quercetin nanocrystals) are able to enhance the saturation solubility and dissolution velocity and, more importantly, can preserve the antioxidative effect which will tolerate well with the skin. Besides, resveratrol nanoformulations like solid-lipid nanoparticles, liposomes, nanostructured lipid carriers, niosomes, and lipid-core nanocapsule have been developed toan achieve effective effect of resveratrol that is used to treat skin diseases including skin aging, acne vulgaris, and chloasma. ${ }^{83}$

\section{Challenges and Opportunities of Natural Products in Transdermal/Topical Delivery Systems and Their Safety Considerations for Skin Disorders}

The skin has proven to be beneficial for both localized and systemic drug deliveries by showing various advantages, including 1) bypassing the hepatic first-pass effect, 2) minimizing changes in drug/natural product plasma levels, 3) allowing selective targ,eting 4) flexibility for controlledrelease profiles, 5) improved patient compliance, and 6) cost-effectiveness. ${ }^{201-203}$ The stratum corneum allows for percutaneous absorption of drugs and natural products. It is $10 \mu \mathrm{m}$ thick, keratinized epidermal cells that act as a rate limiting barrier for drug/natural products permeation, ${ }^{204,205}$ thus restricting the entry of polar, big molecular weight substances. ${ }^{206}$ The movement of lipophilic moieties into the 


\begin{tabular}{|c|c|c|}
\hline & $\frac{5}{\frac{1}{2}}$ & 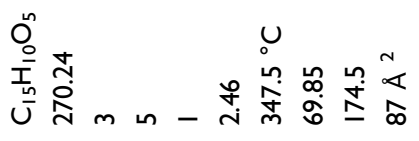 \\
\hline & 恿 & 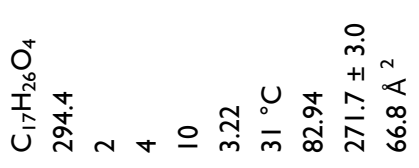 \\
\hline & 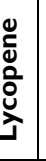 & 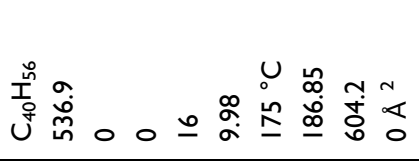 \\
\hline & वे & 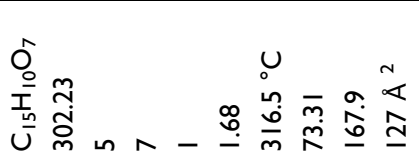 \\
\hline & 空 & 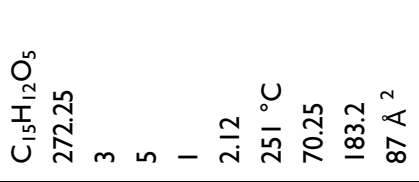 \\
\hline & है & 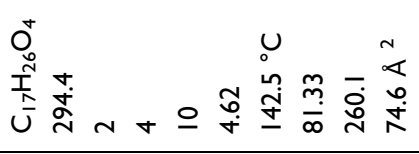 \\
\hline & 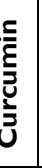 & 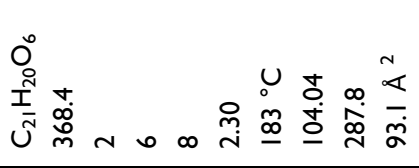 \\
\hline & 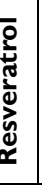 & 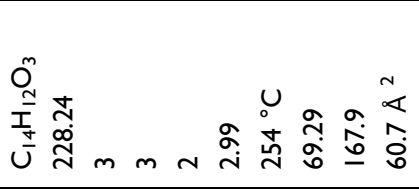 \\
\hline & בְ & 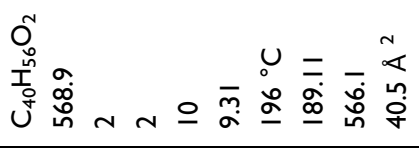 \\
\hline & 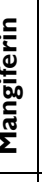 & 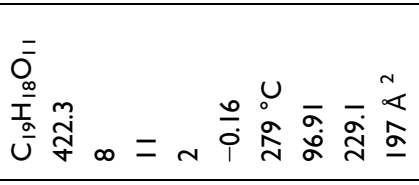 \\
\hline & $\mid$ & 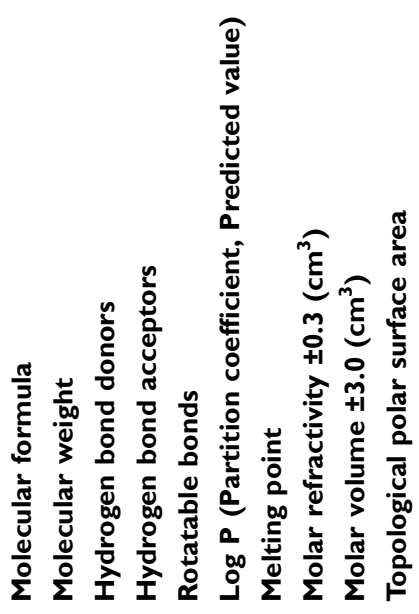 \\
\hline
\end{tabular}

stratum corneum is also limited, although hydrophilic moieties fail to partition. ${ }^{207}$ As for transdermal distribution, ideally, a drug candidate should have 1) moderate lipophilicity $(\log \mathrm{P}<5), 2)$ sufficient solubility in both aqueous and lipophilic phases, 3) low molecular weight: $<500$, 4) high potency, and 5) a low melting point. ${ }^{208,209}$ The natural products described in this review meet almost all of Lipinski's rules, indicating their drug-likeness in nature, and therefore are good candidates for further investigation on the development of different formulations to deliver active constituents into the skin. The physicochemical properties of the natural products reported in this review are summarized in Table 3.

Although traditional transdermal formulations such as ointments, creams, and lotions exist, they have some drawbacks, such as having a lack of spreadability, being of a sticky nature, and having stability issues, overall contributing to non-compliance. ${ }^{210}$ Transdermal distribution has progressed to the point where transparent gels and emulgels have been developed with improved efficacy and patient compliance. Consequently, these formulations are gaining popularity in both the cosmetics and pharmaceutical industries.

Nevertheless, rather the formulation and development of a suitable delivery system, and the delivery of hydrophobic moieties "across" the skin barrier, which is challenging. ${ }^{210}$ According to the literature, nanosized topical formulations can increase the permeability of natural products by breaking the lipid bilayer ${ }^{211}$ and prolonging their retention at the site of action. ${ }^{212}$ Currently, liposomes, lipid nanoparticles, phytosomes, nanoemulsions, transferosomes, ethosomes, niosomes, $\beta$-cyclodextrin complexes, and polymeric nanomicelles are some of the most important nano-formulations used for dermatological and transdermal applications of phytomedicines. ${ }^{213}$

A nanoemulsion is an isotropic, translucent, or transparent heterogeneous mixture made of oil and aqueous phases that is stabilized by the interfacial coating of a surfactant. $^{210}$ Nanoemulsions can improve the solubility of natural products over simple micellar solutions and give higher thermodynamic stability as compared to unstable dispersions like emulsions and suspensions, although they tend to be limited by their low viscosity and spreadability. Nevertheless, a simple change of nanoemulsion to nanoemulgel can be incorporated to tackle the challenges of using a nanoemulsion for transdermal delivery. Nanoemulgels are nanoemulsions that contain a gelling agent and are either water-in-oil (w/o) or oil-in-water $(\mathrm{o} / \mathrm{w})$ in nature. When compared to other carriers such as 


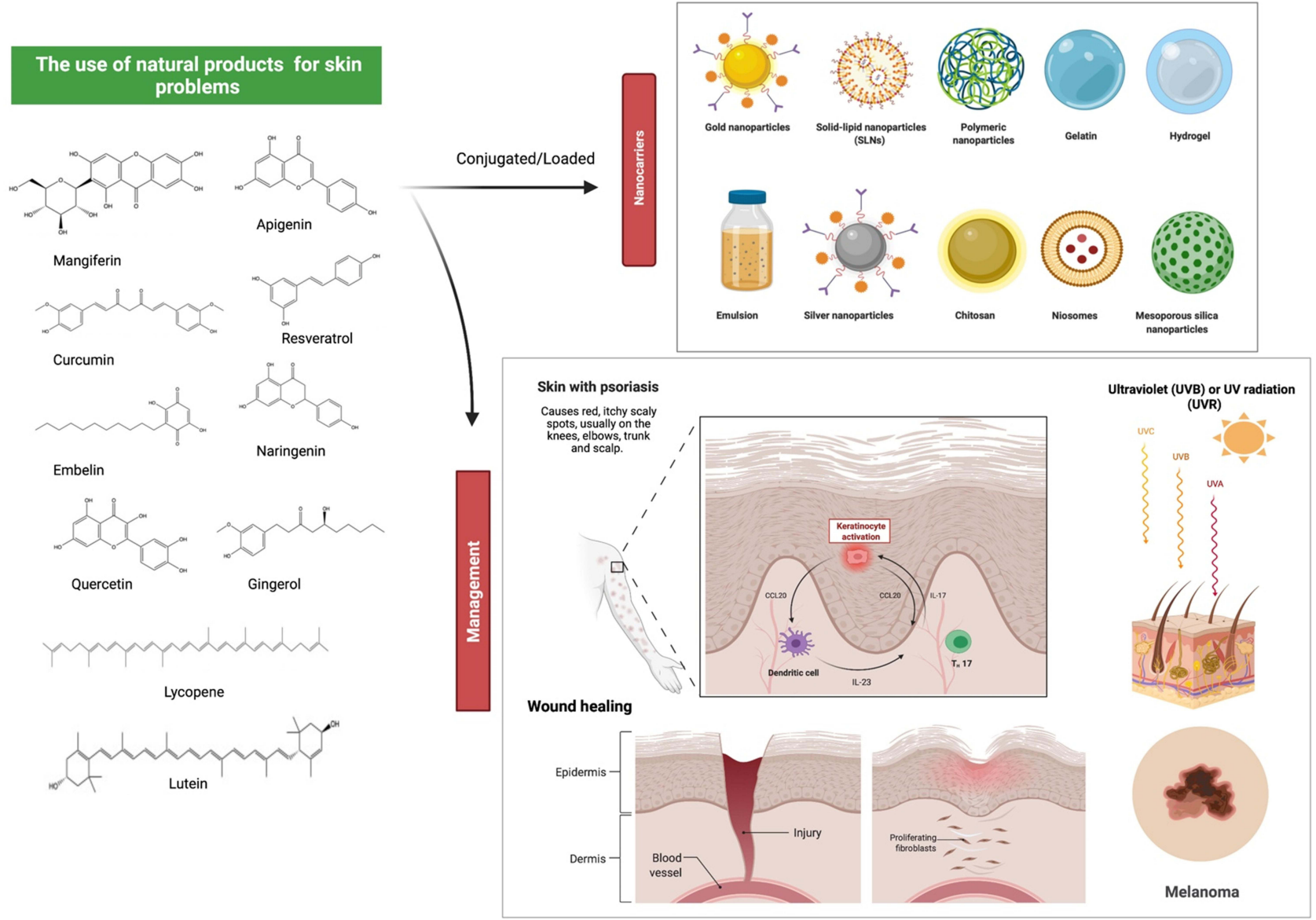

Figure 7 Effects of natural products on numerous skin conditions and possible drug delivery system. Nanocarriers are currently being used as a vehicle to deliver natural products to specific targeted regions in a regulated manner, as well as to overcome some of the drawbacks pertaining to the free compounds, such as poor bioavailability and rapid degradation. Natural products, along with innovative delivery systems, are a very promising area for future drug discovery against skin problems. For example, naringenin is a good candidate as an anti-psoriatic treatment as it inhibits over-expression of interleukin and ameliorated psoriasis and reduces transepidermal water loss. Resveratrol has protection against the main factor affecting non-melanoma skin cancer, which is UVB exposure by reducing COX-2 levels. Some other bioactive substances also exhibited a similar mode of action against various skin conditions including wound healing. Created with BioRender.com.

microemulsions, liposomes, or solid lipid nanoparticles, nanoemulgels have several advantages including increased permeability, better drug-loading capacity, and less skin irritation. $^{210}$

When developing nanophytomedicines, a variety of approaches have been used, as discussed in detail by Sahni et al. ${ }^{214}$ The techniques include nanoprecipitation, co-precipitation, complex coacervation, supercritical fluid method, salting out method, solvent emulsification-diffusion method, and self-assembly methods. ${ }^{214-216}$ Although nanoformulations of natural products have yielded positive outcomes, a thorough assessment of their safety, including toxicity to either the phytomedicine itself or to a component of the nanosystem is of paramount importance. ${ }^{217,218}$

Another exciting new discovery in skin distribution of natural products is the film forming technology, which is a great alternative to traditional transdermal products.
Although it is not a solid dosage form, it can turn into a film in situ, following skin application. Film formation is promoted by the presence of film-producing excipients in the system, allowing a film of excipients and drug/natural products into contact with the skin following solvent evaporation. The resulting film can either be a solid polymeric matrix that maintains active ingredient release into the skin or a residual liquid film that can be quickly absorbed in the stratum corneum. ${ }^{219}$ All of the listed strategies have the potential to overcome the drawbacks of natural products in the development of skin formulations to treat a variety of skin disorders (Figure 7).

\section{Conclusion and Future Perspectives}

Natural products, particularly plant-based medicines, have received a lot of attention in the last decade, due to their efficacy in disease prevention and treatment. ${ }^{220-223}$ In this 
review, we provide a comprehensive review on the effects of various natural products against skin disorders. Ten natural products, mangiferin, lutein, resveratrol, curcumin, embelin, naringenin, quercetin, lycopene, gingerol, and apigenin, from fruits, herbs, and vegetables which can usually be found in our daily lives, have been identified herein to be effective against various types of skin disorder. The skin disorders are widely associated with inflammation and/or tumors caused by several factors like UV radiation since the natural products have anti-inflammatory and antioxidant action.

Skin disease is a very common disease in humans, affecting the quality-of-life, mental health, and productivity. In fact, skin disorders have been reported to be the fourth major factor for a nonfatal burden, as indicated by the disability-adjusted life years (DALYs), besides the fact that the skin is also the 18th main origin of health burden worldwide. Overall, most of the natural compounds act on specific pathways to treat skin disorders where most are useful against more than one skin disease, with skin cancer and inflammatory-related diseases being the common ones. These include skin aging, wound, dermatitis or eczema, and psoriasis. In several studies, the action of all of the natural compounds reported in this review against skin disorders are reduction of inflammatory mediators and biomarkers, as anti-oxidant defence, anti-cancer (like chemoprotective and induction of apoptosis in cancer cell), and protection from UV radiation effect.

Two characteristics that these extracts or phytoconstituents must and should have are antimicrobial and woundhealing properties. In addition, extracts, which inhibits histamine release and pro-inflammatory cytokines release, are additional assets. The advantage of using natural products in cosmetics or skincare products is they offer less toxicity when compared to novel synthetic products. In addition, their absorption and systemic concentration of the active ingredients are significantly less.

Nevertheless, several perspectives on the application of natural products for the treatment and prevention of skin diseases are suggested. Further studies are required to strengthen the claims, especially in clinical trials. Bypassing drawbacks associated with natural products such as poor bioavailability and metabolism, broader clinical trials might be done, offering clinicians trustworthy evidence on the safety and possible clinical benefits of natural products for skin health. Natural products in combination with modern drugs, as well as the development of novel delivery mechanisms, represent a very promising area for future drug discovery of these natural leads against skin disorders.

\section{Consent for Publication}

The final version of the manuscript was reviewed by all the authors, who consented to its submission.

\section{Acknowledgments}

The authors acknowledge Universiti Kuala Lumpur Royal College of Medicine Perak, Ipoh, Perak, Malaysia for providing the facilities and services required to complete the study. Figures were created with the support of https:// biorender.com under a paid subscription. SRB is grateful to Prof. Jagadeesh Bayry (INSERM, Centre de Recherche des Cordeliers, Sorbonne Universités, Université de Paris, France and IIT Palakkad, Palakkad, Kerala, India) for providing a postdoctoral position.

\section{Author Contributions}

All authors made a significant contribution to the work reported, whether that is in the conception, study design, execution, acquisition of data, analysis and interpretation, or in all these areas; took part in drafting, revising, or critically reviewing the article; gave final approval of the version to be published; have agreed on the journal to which the article has been submitted; and agree to be accountable for all aspects of the work.

\section{Funding}

There is no funding to report.

\section{Disclosure}

The authors report no conflicts of interest associated with the publication.

\section{References}

1. Sinikumpu S-P, Huilaja L, Jokelainen J, et al. High prevalence of skin diseases and need for treatment in a middle-aged population. A Northern Finland birth cohort 1966 study. PLoS One. 2014;9(6): e99533. doi:10.1371/journal.pone.0099533

2. Kassab YW, Muhamad SA, Aldahoul H, Mohammed I, Paneerselvam G, Ayad M. The impact of skin disorders on patients' quality of life in Malaysia. J Clin Intensive Care Med. 2019;4:001-009. doi:10.29328/ journal.jcicm. 1001018

3. Xu H, Timares L, Elmets CA. Host defenses in skin. In: Clinical Immunology. Elsevier; 2019.

4. Bos JD, Zonneveld I, Das PK, Krieg SR, van der Loos CM, Kapsenberg ML. The skin immune system (SIS): distribution and immunophenotype of lymphocyte subpopulations in normal human skin. $J$ Investig Dermatol. 1987;88(5):569-573. doi:10.11 11/1523-1747.ep12470172

5. Nguyen AV, Soulika AM. The dynamics of the skin's immune system. Int J Mol Sci. 2019;20(8):1811. doi:10.3390/ijms20081811 
6. Lerman I, Mitchell DC, Richardson CT. Human cutaneous B cells: what do we really know? Ann Transl Med. 2021;9(5):440. doi:10.21037/atm-20-5185

7. Egbuniwe IU, Karagiannis SN, Nestle FO, Lacy KE. Revisiting the role of B cells in skin immune surveillance. Trends Immunol. 2015;36(2):102-111. doi:10.1016/j.it.2014.12.006

8. Debes GF, McGettigan SE. Skin-associated B cells in health and inflammation. J Immunol. 2019;202(6):1659-1666. doi:10.4049/ jimmunol.1801211

9. Fetter T, Niebel D, Braegelmann C, Wenzel J. Skin-associated B cells in the pathogenesis of cutaneous autoimmune diseasesimplications for therapeutic approaches. Cells. 2020;9(12):2627. doi:10.3390/cells9122627

10. Nestle FO, Di Meglio P, Qin J-Z, Nickoloff BJ. Skin immune sentinels in health and disease. Nat Rev Immunol. 2009;9 (10):679-691. doi:10.1038/nri2622

11. Kabashima K, Honda T, Ginhoux F, Egawa G. The immunological anatomy of the skin. Nat Rev Immunol. 2019;19(1):19-30. doi:10.1038/s41577-018-0084-5

12. Stingl G, Steiner G. Immunological host defense of the skin. Curr Probl Dermatol. 1989;18:22-30.

13. Vollono L, Falconi M, Gaziano R, et al. Potential of curcumin in skin disorders. Nutrients. 2019;11(9):2169. doi:10.3390/nu11092169

14. Wootton C, Bell S, Philavanh A, et al. Assessing skin disease and associated health-related quality of life in a rural Lao community. BMC Dermatol. 2018;18(1):1-10. doi:10.1186/s12895-018-0079-8

15. Malik K, Ahmad M, Zafar M, et al. An ethnobotanical study of medicinal plants used to treat skin diseases in northern Pakistan. BMC Complement Altern Med. 2019;19(1):1-38. doi:10.1186/ s12906-018-2420-5

16. Hanrahan C, Odle T, Frey R. Botanical Medicine. Encyclopedia. com. Gale Encyclopedia of Alternative Medicine. [updated cited] Avaiable from: https://www.encyclopedia.com/medicine/drugs/ pharmacology/botanical-medicine. Accessed December 17, 2021.

17. Pelkonen $\mathrm{O}, \mathrm{Xu}$ Q, Fan T-P. Why is research on herbal medicinal products important and how can we improve its quality? J Tradit Complement Med. 2014;4(1):1-7. doi:10.4103/2225-4110.124323

18. Samraj K, Thillaivanan S, Parthiban P. A review of beneficial effects of medicinal plants on skin and skin diseases. Int J Pharm Res Bio Sci. 2014;3(1):93-106.

19. Hussein RA, El-Anssary AA. Plants secondary metabolites: the key drivers of the pharmacological actions of medicinal plants. Herb Med. 2019;1:13.

20. Varma N. Phytoconstituents and their mode of extractions: an overview. Res J Chem Environ Sci. 2016;4(2):8-15.

21. Cox-Georgian D, Ramadoss N, Dona C, Basu C. Therapeutic and medicinal uses of terpenes. In: Medicinal Plants. Springer; 2019.

22. Tabassum N, Hamdani M. Plants used to treat skin diseases. Pharmacogn Rev. 2014;8(15):52. doi:10.4103/0973-7847.125531

23. Ochocka R, Hering A, Stefanowicz-Hajduk J, Cal K, Barańska $\mathrm{H}$. The effect of mangiferin on skin: penetration, permeation and inhibition of ECM enzymes. PLoS One. 2017;12(7):e0181542. doi:10.1371/journal.pone.0181542

24. Navarro M, Arnaez E, Moreira I, et al. Polyphenolic characterization, antioxidant, and cytotoxic activities of Mangifera indica cultivars from Costa Rica. Foods. 2019;8(9):384. doi:10.3390/ foods 8090384

25. Tundis R, Loizzo M, Bonesi M, Menichini F. Potential role of natural compounds against skin aging. Curr Med Chem. 2015;22(12):1515-1538. doi:10.2174/09298673226661502271 51809

26. Kim H-S, Song JH, Youn UJ, et al. Inhibition of UVB-induced wrinkle formation and MMP-9 expression by mangiferin isolated from Anemarrhena asphodeloides. Eur J Pharmacol. 2012;689 (1-3):38-44. doi:10.1016/j.ejphar.2012.05.050
27. Chae S, Piao MJ, Kang KA, et al. Inhibition of matrix metalloproteinase-1 induced by oxidative stress in human keratinocytes by mangiferin isolated from Anemarrhena asphodeloides. Biosci Biotechnol Biochem. 2011;75(12):2321-2325. doi:10.1271/bbb.110465

28. Petrova A, Davids LM, Rautenbach F, Marnewick JL. Photoprotection by honeybush extracts, hesperidin and mangiferin against UVB-induced skin damage in SKH-1 mice. $J$ Photochem Photobiol B. 2011;103(2):126-139. doi:10.1016/j. jphotobiol.2011.02.020

29. Song JH, Bae EY, Choi G, et al. Protective effect of Mango (M angifera indica L.) against UVB-induced skin aging in hairless mice. Photodermatol Photoimmunol Photomed. 2013;29(2):8489. doi:10.1111/phpp.12030

30. Zhao Y, Wang W, Wu X, et al. Mangiferin antagonizes TNF- $\alpha$ mediated inflammatory reaction and protects against dermatitis in a mice model. Int Immunopharmacol. 2017;45:174-179. doi:10.1016/j.intimp.2017.02.014

31. Pleguezuelos-Villa M, Diez-Sales O, Manca ML, et al. Mangiferin glycethosomes as a new potential adjuvant for the treatment of psoriasis. Int $J$ Pharm. 2020;573:118844. doi:10.1016/j.ijpharm.2019.118844

32. Pleguezuelos-Villa M, Nácher A, Hernández M, Buso MOV, Sauri AR, Díez-Sales O. Mangiferin nanoemulsions in treatment of inflammatory disorders and skin regeneration. Int J Pharm. 2019;564:299-307. doi:10.1016/j.ijpharm.2019.04.056

33. Allaw M, Pleguezuelos-Villa M, Manca ML, et al. Innovative strategies to treat skin wounds with mangiferin: fabrication of transfersomes modified with glycols and mucin. Nanomedicine. 2020;15(17):1671-1685. doi:10.2217/nnm-2020-0116

34. Lwin OM, Giribabu N, Kilari EK, Salleh N. Topical administration of mangiferin promotes healing of the wound of streptozotocin-nicotinamide-induced type-2 diabetic male rats. J Dermatol Treat. 2020;1-10. doi:10.1080/09546634.2020.1721419

35. Gerber GS, Fox LT, Gerber M, et al. Stability, clinical efficacy, and antioxidant properties of Honeybush extracts in semi-solid formulations. Pharmacogn Mag. 2015;11(Suppl 2):S337. doi:10.4103/0973-1296.166063

36. Magcwebeba TU, Riedel S, Swanevelder S, et al. The potential role of polyphenols in the modulation of skin cell viability by Aspalathus linearis and Cyclopia spp. herbal tea extracts in vitro. J Pharm Pharmacol. 2016;68(11):1440-1453. doi:10.1111/ jphp. 12629

37. Mao X, Cheng $\mathrm{R}$, Zhang $\mathrm{H}$, et al. Self-healing and injectable hydrogel for matching skin flap regeneration. Adv Sci. 2019;6 (3):1801555. doi:10.1002/advs.201801555

38. Mao X, Liu L, Cheng L, et al. Adhesive nanoparticles with inflammation regulation for promoting skin flap regeneration. $J$ Control Release. 2019;297:91-101. doi:10.1016/j.jconrel.2019.01.031

39. Delgado-Hernández R, Hernández-Balmaseda I, Rodeiro-Guerra I, et al. Anti-angiogenic effects of mangiferin and mechanism of action in metastatic melanoma. Melanoma Res. 2020;30(1):3951. doi:10.1097/CMR.0000000000000647

40. Jie J, Sha L, Ming L, Jizhou X. Antiviral effect of chinonin against herpes simples virus. J Huazhong Univ Sci Technol. 2004;24(5):521-524. doi:10.1007/BF02831126

41. Alexandra A-R, Andrew S. The science behind lutein. Toxicol Lett. 2004;150(1):57-83. doi:10.1016/j.toxlet.2003.10.031

42. Shao A, Hathcock JN. Risk assessment for the carotenoids lutein and lycopene. Regul Toxicol Pharmacol. 2006;45(3):289-298. doi:10.1016/j.yrtph.2006.05.007

43. Buscemi S, Corleo D, Di Pace F, Petroni ML, Satriano A, Marchesini G. The effect of lutein on eye and extra-eye health. Nutrients. 2018;10(9):1321. doi:10.3390/nu10091321

44. Balić A, Mokos M. Do we utilize our knowledge of the skin protective effects of carotenoids enough? Antioxidants. 2019;8 (8):259. doi:10.3390/antiox 8080259 
45. Souyoul SA, Saussy KP, Lupo MP. Nutraceuticals: a review. Dermatol Ther (Heidelb). 2018;8(1):5-16. doi:10.1007/s13555018-0221-x

46. Aziz E, Batool R, Akhtar W, et al. Xanthophyll: health benefits and therapeutic insights. Life Sci. 2020;240:117104. doi:10.1016/ j.lfs.2019.117104

47. Murillo AG, Hu S, Fernandez ML. Zeaxanthin: metabolism, properties, and antioxidant protection of eyes, heart, liver, and skin. Antioxidants. 2019;8(9):390. doi:10.3390/antiox 8090390

48. Heinen MM, Hughes MC, Ibiebele TI, Marks GC, Green AC, van der Pols JC. Intake of antioxidant nutrients and the risk of skin cancer. Eur J Cancer. 2007;43(18):2707-2716. doi:10.1016/j.ejca.2007.09.005

49. Panahi Y, Fazlolahzadeh O, Atkin SL, et al. Evidence of curcumin and curcumin analogue effects in skin diseases: a narrative review. J Cell Physiol. 2019;234(2):1165-1178. doi:10.1002/jcp.27096

50. Vaughn AR, Haas KN, Burney W, et al. Potential role of curcumin against biofilm-producing organisms on the skin: a review. Phytother Res. 2017;31(12):1807-1816. doi:10.1002/ptr.5912

51. Patel SS, Acharya A, Ray R, Agrawal R, Raghuwanshi R, Jain P. Cellular and molecular mechanisms of curcumin in prevention and treatment of disease. Crit Rev Food Sci Nutr. 2020;60 (6):887-939. doi:10.1080/10408398.2018.1552244

52. Aggarwal BB, Gupta SC, Sung B. Curcumin: an orally bioavailable blocker of TNF and other pro-inflammatory biomarkers. $\mathrm{Br} \mathrm{J}$ Pharmacol. 2013;169(8):1672-1692. doi:10.1111/bph.12131

53. Heng M, Song M, Harker J, Heng M. Drug-induced suppression of phosphorylase kinase activity correlates with resolution of psoriasis as assessed by clinical, histological and immunohistochemical parameters. Br J Dermatol. 2000;143(5):937-949. doi:10.1046/j.1365-2133.2000.03767.x

54. Gupta SC, Prasad S, Kim JH, et al. Multitargeting by curcumin as revealed by molecular interaction studies. Nat Prod Rep. 2011;28 (12):1937-1955. doi:10.1039/c1np00051a

55. Lai C-Y, Su Y-W, Lin K-I, Hsu L-C, Chuang T-H. Natural modulators of endosomal toll-like receptor-mediated psoriatic skin inflammation. J Immunol Res. 2017;2017:1-15. doi:10.1155/2017/7807313

56. Rawal RC, Shah BJ, Jayaraaman AM, Jaiswal V. Clinical evaluation of an Indian polyherbal topical formulation in the management of eczema. J Altern Complement Med. 2009;15(6):669-672. doi:10.1089/acm.2008.0508

57. Vaughn AR, Branum A, Sivamani RK. Effects of turmeric (Curcuma longa) on skin health: a systematic review of the clinical evidence. Phytother Res. 2016;30(8):1243-1264. doi: $10.1002 /$ ptr.5640

58. Lee H-S, Kim Y-D, Na B-R, et al. Phytocomponent p-Hydroxycinnamic acid inhibits T-cell activation by modulation of protein kinase $\mathrm{C}$ - $\theta$-dependent pathway. Int Immunopharmacol. 2012;12(1):131-138. doi:10.1016/j.intimp.2011.11.001

59. Kim J, Park S, Jeon B-S, et al. Therapeutic effect of topical application of curcumin during treatment of radiation burns in a mini-pig model. J Vet Sci. 2016;17(4):435. doi:10.4142/ jvs.2016.17.4.435

60. Sharma A, Mittal A, Puri V, Kumar P, Singh I. Curcumin-loaded, alginate-gelatin composite fibers for wound healing applications. 3 Biotech. 2020;10(11):1-13. doi:10.1007/s13205-020-02453-5

61. Mohanty C, Sahoo SK. Curcumin and its topical formulations for wound healing applications. Drug Discov Today. 2017;22 (10):1582-1592. doi:10.1016/j.drudis.2017.07.001

62. Phan -T-T, See P, Lee S-T, Chan S-Y. Protective effects of curcumin against oxidative damage on skin cells in vitro: its implication for wound healing. J Trauma Acute Care Surg. 2001;51(5):927-931. doi:10.1097/00005373-200111000-00017

63. Mohammadi Z, Sharif Zak M, Majdi H, et al. The effect of chrysin-curcumin-loaded nanofibres on the wound-healing process in male rats. Artif Cells Nanomed Biotechnol. 2019;47 (1):1642-1652. doi:10.1080/21691401.2019.1594855
64. Barchitta M, Maugeri A, Favara G, et al. Nutrition and wound healing: an overview focusing on the beneficial effects of curcumin. Int J Mol Sci. 2019;20(5):1119. doi:10.3390/ijms20051119

65. Sommerfeld B. Randomised, placebo-controlled, double-blind, split-face study on the clinical efficacy of Tricutan ${ }^{\circledR}$ on skin firmness. Phytomedicine. 2007;14(11):711-715. doi:10.1016/j. phymed.2007.09.015

66. Asada K, Ohara T, Muroyama K, Yamamoto Y, Murosaki S. Effects of hot water extract of Curcuma longa on human epidermal keratinocytes in vitro and skin conditions in healthy participants: a randomized, double-blind, placebo-controlled trial. J Cosmet Dermatol. 2019;18 (6):1866-1874. doi:10.1111/jocd.12890

67. Kim H, Park J, Tak K-H, Bu SY, Kim E. Chemopreventive effects of curcumin on chemically induced mouse skin carcinogenesis in BK5. insulin-like growth factor-1 transgenic mice. In Vitro Cell Dev Biol Anim. 2014;50(9):883-892. doi:10.1007/s11626-0149791-9

68. Lelli D, Pedone C, Sahebkar A. Curcumin and treatment of melanoma: the potential role of microRNAs. Biomed Pharmacother. 2017;88:832-834. doi:10.1016/j.biopha.2017.01.078

69. Wu J, Lu W-Y, Cui -L-L. Inhibitory effect of curcumin on invasion of skin squamous cell carcinoma A431 cells. Asian Pac J Cancer Prev. 2015;16(7):2813-2818. doi:10.7314/APJCP.2015.16.7.2813

70. Qiu Y, Yu T, Wang W, Pan K, Shi D, Sun H. Curcumin-induced melanoma cell death is associated with mitochondrial permeability transition pore (mPTP) opening. Biochem Biophys Res Commun. 2014;448(1):15-21. doi:10.1016/j.bbrc.2014.04.024

71. Tsai K-D, Lin J-C, Yang S-M, et al. Curcumin protects against UVB-induced skin cancers in SKH-1 hairless mouse: analysis of early molecular markers in carcinogenesis. Evid Based Complement Alternat Med. 2012;2012:1-11. doi:10.1155/2012/ 593952

72. Zorofchian Moghadamtousi S, Abdul Kadir H, Hassandarvish P, Tajik H, Abubakar S, Zandi K. A review on antibacterial, antiviral, and antifungal activity of curcumin. Biomed Res Int. 2014;2014:1-12. doi:10.1155/2014/186864

73. Mun S-H, Joung D-K, Kim Y-S, et al. Synergistic antibacterial effect of curcumin against methicillin-resistant Staphylococcus aureus. Phytomedicine. 2013;20(8-9):714-718. doi:10.1016/j. phymed.2013.02.006

74. Almeida PP, Pereira ÍS, Rodrigues KB, et al. Photodynamic therapy controls of Staphylococcus aureus intradermal infection in mice. Lasers Med Sci. 2017;32(6):1337-1342. doi:10.1007/ s10103-017-2247-1

75. Liu C-H, Huang H-Y. Antimicrobial activity of curcumin-loaded myristic acid microemulsions against Staphylococcus epidermidis. Chem Pharm Bull (Tokyo). 2012;60(9):1118-1124. doi:10.1248/cpb. c12-00220

76. Baltazar LM, Krausz AE, Souza ACO, et al. Trichophyton rubrum is inhibited by free and nanoparticle encapsulated curcumin by induction of nitrosative stress after photodynamic activation. PLoS One. 2015;10 (3):e0120179. doi:10.1371/journal.pone.0120179

77. Ruivo J, Francisco C, Oliveira R, Figueiras A. The main potentialities of resveratrol for drug delivery systems. Braz J Pharm Sci. 2015;51(3):499-513. doi:10.1590/S1984-8250201500030 0002

78. Wen S, Zhang J, Yang B, Elias PM, Man M-Q. Role of resveratrol in regulating cutaneous functions. Evid Based Complement Alternat Med. 2020;2020:1-20. doi:10.1155/2020/2416837

79. Salehi B, Mishra AP, Nigam M, et al. Resveratrol: a double-edged sword in health benefits. Biomedicines. 2018;6(3):91. doi:10.3390/biomedicines6030091

80. Ratz-łyko A, Arct J. Resveratrol as an active ingredient for cosmetic and dermatological applications: a review. J Cosmet Laser Ther. 2019;21(2):84-90. doi:10.1080/14764172.2018.1469767 
81. Boo YC. Human skin lightening efficacy of resveratrol and its analogs: from in vitro studies to cosmetic applications. Antioxidants. 2019;8(9):332. doi:10.3390/antiox8090332

82. Liang Q-X, Lin Y-H, Zhang C-H, et al. Resveratrol increases resistance of mouse oocytes to postovulatory aging in vivo. Aging (Albany NY). 2018;10(7):1586. doi:10.18632/aging.101494

83. Soleymani S, Iranpanah A, Najafi F, et al. Implications of grape extract and its nanoformulated bioactive agent resveratrol against skin disorders. Arch Dermatol Res. 2019;311(8):577-588. doi:10.1007/s00403-019-01930-z

84. Deloche C, Lavaud B, Zaouati DC, et al. Antiaging potential of resveratrol upon clinical and biomechanical properties of the skin. In: Journal of the American Academy of Dermatology. Vol. 70. 360 Park Avenue South, New York, NY 10010-1710 USA: Mosby-Elsevier; 2014:AB37-AB37.

85. Buonocore D, Lazzeretti A, Tocabens P, et al. Resveratrol-procyanidin blend: nutraceutical and antiaging efficacy evaluated in a placebocontrolled, double-blind study. Clin Cosmet Investig Dermatol. 2012;5:159. doi:10.2147/CCID.S36102

86. Aziz MH, Afaq F, Ahmad N. Prevention of ultraviolet-B radiation damage by resveratrol in mouse skin is mediated via modulation in survivin. Photochem Photobiol. 2005;81(1):25-31. doi:10.1562/2004-08-13-RA-274.1

87. Dybkowska E, Sadowska A, Swiderski F, Rakowska R, Wysocka $\mathrm{K}$. The occurrence of resveratrol in foodstuffs and its potential for supporting cancer prevention and treatment. A review. Rocz Panstw Zakl Hig. 2018;69(1):5-14.

88. Rauf A, Imran M, Butt MS, Nadeem M, Peters DG, Mubarak MS. Resveratrol as an anti-cancer agent: a review. Crit Rev Food Sci Nutr. 2018;58(9):1428-1447. doi:10.1080/10408398.2016.1263597

89. Reagan-Shaw S, Afaq F, Aziz MH, Ahmad N. Modulations of critical cell cycle regulatory events during chemoprevention of ultraviolet B-mediated responses by resveratrol in SKH-1 hairless mouse skin. Oncogene. 2004;23(30):5151-5160. doi:10.1038/sj. onc. 1207666

90. Lee SH, Koo BS, Park SY, Kim YM. Anti-angiogenic effects of resveratrol in combination with 5-fluorouracil on B16 murine melanoma cells. Mol Med Rep. 2015;12(2):2777-2783. doi: 10.3892/mmr.2015.3675

91. Yarla NS, Bishayee A, Sethi G, et al. Targeting arachidonic acid pathway by natural products for cancer prevention and therapy. In: Seminars in Cancer Biology. Vol. 40. Elsevier; 2016:48-81.

92. Annunziata G, Maisto M, Schisano C, et al. Resveratrol as a novel anti-herpes simplex virus nutraceutical agent: an overview. Viruses. 2018;10(9):473. doi:10.3390/v10090473

93. Docherty JJ, Smith JS, Fu MM, Stoner T, Booth T. Effect of topically applied resveratrol on cutaneous herpes simplex virus infections in hairless mice. Antiviral Res. 2004;61(1):19-26. doi:10.1016/j.antiviral.2003.07.001

94. Docherty JJ, Fu MM, Hah JM, Sweet TJ, Faith SA, Booth T. Effect of resveratrol on herpes simplex virus vaginal infection in the mouse. Antiviral Res. 2005;67(3):155-162. doi:10.1016/j. antiviral.2005.06.008

95. Faith SA, Sweet TJ, Bailey E, Booth T, Docherty JJ. Resveratrol suppresses nuclear factor- $\mathrm{KB}$ in herpes simplex virus infected cells. Antiviral Res. 2006;72(3):242-251. doi:10.1016/j.antiviral.20 06.06 .011

96. Leyton L, Hott M, Acuña F, et al. Nutraceutical activators of AMPK/Sirt1 axis inhibit viral production and protect neurons from neurodegenerative events triggered during HSV-1 infection. Virus Res. 2015;205:63-72. doi:10.1016/j.virusres.2015.05.015

97. Yang S-C, Tseng C-H, Wang P-W, et al. Pterostilbene, a methoxylated resveratrol derivative, efficiently eradicates planktonic, biofilm, and intracellular MRSA by topical application. Front Microbiol. 2017;8:1103. doi:10.3389/ fmicb.2017.01103
98. Soleymani S, Farzaei MH, Zargaran A, Niknam S, Rahimi R Promising plant-derived secondary metabolites for treatment of acne vulgaris: a mechanistic review. Arch Dermatol Res. 2020;312(1):5-23. doi:10.1007/s00403-019-01968-z

99. Docherty JJ, McEwen HA, Sweet TJ, Bailey E, Booth TD. Resveratrol inhibition of Propionibacterium acnes. J Antimicrob Chemother. 2007;59(6):1182-1184. doi:10.1093/jac/dkm099

100. Taylor EJ, Yu Y, Champer J, Kim J. Resveratrol demonstrates antimicrobial effects against Propionibacterium acnes in vitro. Dermatol Ther. 2014;4(2):249-257. doi:10.1007/s13555-014-0063-0

101. Kjær TN, Thorsen K, Jessen N, Stenderup K, Pedersen SB. Resveratrol ameliorates imiquimod-induced psoriasis-like skin inflammation in mice. PLoS One. 2015;10(5):e0126599. doi:10.1371/journal.pone.0126599

102. Hemmati AA. The topical effect of grape seed extract $2 \%$ cream on surgery wound healing. Glob J Health Sci. 2015;7(3):52.

103. Perez-Bernal A, Munoz-Perez MA, Camacho F. Management of facial hyperpigmentation. Am J Clin Dermatol. 2000;1(5):261268. doi:10.2165/00128071-200001050-00001

104. Yamakoshi J, Otsuka F, Sano A, et al. Lightening effect on ultraviolet-induced pigmentation of Guinea pig skin by oral administration of a proanthocyanidin-rich extract from grape seeds. Pigment Cell Res. 2003;16(6):629-638. doi:10.1046/ j.1600-0749.2003.00093.x

105. Moreira AM, Bravo BSF, da Fonseca Amorim AG, Luiz RR, Issa MCA. Double-blind comparative study of hydroquinone and ursine grape extract in the treatment of melasma. Surg Cosmet Dermatol. 2010;2(2):99-104.

106. Caruso F, Rossi M, Kaur S, et al. Antioxidant properties of embelin in cell culture. Electrochemistry and theoretical mechanism of scavenging. potential scavenging of superoxide radical through the membrane cell. Antioxidants. 2020;9(5):382. doi:10.3390/antiox9050382

107. Kundap UP, Bhuvanendran S, Kumari Y, Othman I, Shaikh M. Plant derived phytocompound, embelin in CNS disorders: a systematic review. Front Pharmacol. 2017;8:76. doi:10.3389/ fphar.2017.00076

108. Li Z, Chen S-J, Yu X-A, et al. Pharmacokinetic and bioavailability studies of embelin after intravenous and oral administration to rats. Evid Based Complement Alternat Med. 2019;2019. doi:10.1155/2019/9682495

109. Park N, Baek HS, Chun Y-J. Embelin-induced apoptosis of human prostate cancer cells is mediated through modulation of Akt and $\beta$-Catenin signaling. PLoS One. 2015;10(8):e0134760. doi:10.1371/journal.pone.0134760

110. Kumar GK, Dhamotharan R, Kulkarni NM, Mahat MYA, Gunasekaran J, Ashfaque M. Embelin reduces cutaneous TNF- $\alpha$ level and ameliorates skin edema in acute and chronic model of skin inflammation in mice. Eur J Pharmacol. 2011;662(1-3):6369. doi:10.1016/j.ejphar.2011.04.037

111. Swamy HK, Krishna V, Shankarmurthy K, et al. Wound healing activity of embelin isolated from the ethanol extract of leaves of Embelia ribes Burm. J Ethnopharmacol. 2007;109(3):529-534. doi:10.1016/j.jep.2006.09.003

112. Wang W, Wu C, Tian B, et al. The inhibition of RANKL-induced osteoclastogenesis through the suppression of p38 signaling pathway by naringenin and attenuation of titanium-particle-induced osteolysis. Int J Mol Sci. 2014;15(12):21913-21934. doi:10.3390/ ijms 151221913

113. Venkateswara PR, Kiran S, Rohini P, Bhagyasree P. Flavonoid: a review on Naringenin. J Pharmacogn Phytochem. 2017;6:27782783.

114. Kumar R, Bhan AT. Naringenin suppresses chemically induced skin cancer in two-stage skin carcinogenesis mouse model. Nutr Cancer. 2020;72(6):976-983. doi:10.1080/01635581.2019.1656756 
115. Salehi B, Fokou PVT, Sharifi-Rad M, et al. The therapeutic potential of naringenin: a review of clinical trials. Pharmaceuticals. 2019;12(1):11. doi:10.3390/ph12010011

116. Kumar R, Tiku A. Galangin induces cell death by modulating the expression of glyoxalase-1 and Nrf-2 in HeLa cells. Chem Biol Interact. 2018;279:1-9. doi:10.1016/j.cbi.2017.11.001

117. Anand K, Sarkar A, Kumar A, Ambasta RK, Kumar P. Combinatorial antitumor effect of naringenin and curcumin elicit angioinhibitory activities in vivo. Nutr Cancer. 2012;64(5):714 724. doi:10.1080/01635581.2012.686648

118. Ahamad MS, Siddiqui S, Jafri A, Ahmad S, Afzal M, Arshad M. Induction of apoptosis and antiproliferative activity of naringenin in human epidermoid carcinoma cell through ROS generation and cell cycle arrest. PLoS One. 2014;9(10):e110003. doi:10.1371/ journal.pone. 0110003

119. García-Bores A, Espinosa-González A, Reyna-Campos A, et al. Lippia graveolens photochemopreventive effect against UVB radiation-induced skin carcinogenesis. $J$ Photochem Photobiol B. 2017;167:72-81. doi:10.1016/j.jphotobiol.2016.12.014

120. Rittié L, Fisher GJ. Natural and sun-induced aging of human skin. Cold Spring Harb Perspect Med. 2015;5(1):a015370. doi:10.1101/cshperspect.a015370

121. Jung SK, Ha SJ, Jung $\mathrm{CH}$, et al. Naringenin targets ERK 2 and suppresses UVB-induced photoaging. J Cell Mol Med. 2016;20 (5):909-919. doi:10.1111/jcmm.12780

122. Prasanth MI, Gayathri S, Bhaskar JP, Krishnan V, Balamurugan K. Analyzing the synergistic effects of antioxidants in combating photoaging using model nematode, Caenorhabditis elegans. Photochem Photobiol. 2020;96(1):139-147. doi:10.1111/php.13167

123. El-Mahdy MA, Zhu Q, Wang QE, et al. Naringenin protects $\mathrm{HaCaT}$ human keratinocytes against UVB-induced apoptosis and enhances the removal of cyclobutane pyrimidine dimers from the genome. Photochem Photobiol. 2008;84(2):307-316. doi:10.1111/j.1751-1097.2007.00255.x

124. Kim T-H, Kim G-D, Ahn H-J, Cho -J-J, Park YS, Park C-S. The inhibitory effect of naringenin on atopic dermatitis induced by DNFB in NC/Nga mice. Life Sci. 2013;93(15):516-524. doi:10.1016/j.1fs.2013.07.027

125. Nagula RL, Wairkar S. Cellulose microsponges based gel of naringenin for atopic dermatitis: design, optimization, in vitro and in vivo investigation. Int J Biol Macromol. 2020;164:717725. doi:10.1016/j.ijbiomac.2020.07.168

126. Trombino S, Servidio C, Laganà AS, Conforti F, Marrelli M, Cassano R. Viscosified solid lipidic nanoparticles based on naringenin and linolenic acid for the release of cyclosporine $\mathrm{A}$ on the skin. Molecules. 2020;25(15):3535. doi:10.3390/molecules25153535

127. Gaggeri R, Rossi D, Daglia M, et al. An eco-friendly enantioselective access to (R)-naringenin as inhibitor of proinflammatory cytokine release. Chem Biodivers. 2013;10(8):1531-1538. doi:10.1002/cbdv.201200227

128. Alalaiwe A, Lin C-F, Hsiao C-Y, et al. Development of flavanone and its derivatives as topical agents against psoriasis: the prediction of therapeutic efficiency through skin permeation evaluation and cell-based assay. Int J Pharm. 2020;581:119256. doi:10.1016/ j.ijpharm.2020.119256

129. Escribano-Ferrer E, Queralt Regué J, Garcia-Sala X, Boix Montañés A, Lamuela-Raventos RM. In vivo anti-inflammatory and antiallergic activity of pure naringenin, naringenin chalcone, and quercetin in mice. $J$ Nat Prod. 2019;82(2):177-182. doi:10.1021/acs.jnatprod.8b00366

130. Yamamoto T, Yoshimura M, Yamaguchi F, et al. Anti-allergic activity of naringenin chalcone from a tomato skin extract. Biosci Biotechnol Biochem. 2004;68(8):1706-1711. doi:10.1271/ bbb.68.1706
131. Yoshimura M, Sano A, Kamei J-I, Obata A. Identification and quantification of metabolites of orally administered naringenin chalcone in rats. J Agric Food Chem. 2009;57(14):6432-6437. doi: $10.1021 / \mathrm{j} f 901137 \mathrm{x}$

132. Salih EY, Fyhrquist P, Abdalla A, et al. LC-MS/MS tandem mass spectrometry for analysis of phenolic compounds and pentacyclic triterpenes in antifungal extracts of Terminalia brownii (Fresen). Antibiotics. 2017;6(4):37. doi:10.3390/ antibiotics 6040037

133. Orhan D, Özçelik B, Özgen S, Ergun F. Antibacterial, antifungal, and antiviral activities of some flavonoids. Microbiol Res. 2010;165(6):496-504. doi:10.1016/j.micres.2009.09.002

134. Al-Roujayee AS. Naringenin improves the healing process of thermally-induced skin damage in rats. $J$ Int Med Res. 2017;45 (2):570-582. doi:10.1177/0300060517692483

135. Memariani H, Memariani M, Ghasemian A. An overview on antibiofilm properties of quercetin against bacterial pathogens. World J Microbiol Biotechnol. 2019;35(9):1-16. doi:10.1007/s11274019-2719-5

136. Yang D, Wang T, Long M, Li P. Quercetin: its main pharmacological activity and potential application in clinical medicine. Oxid Med Cell Longev. 2020;2020:1-13. doi:10.1155/2020/ 8825387

137. Basu A, Das AS, Majumder M, Mukhopadhyay R. Antiatherogenic roles of dietary flavonoids chrysin, quercetin, and luteolin. $J$ Cardiovasc Pharmacol. 2016;68(1):89-96. doi:10.1097/FJC.0000000000000380

138. Ulusoy HG, Sanlier N. A minireview of quercetin: from its metabolism to possible mechanisms of its biological activities. Crit Rev Food Sci Nutr. 2020;60(19):3290-3303. doi:10.1080/ 10408398.2019.1683810

139. Shin EJ, Lee JS, Hong S, Lim T-G, Byun S. Quercetin directly targets JAK2 and PKC $\delta$ and prevents UV-induced photoaging in human skin. Int $J$ Mol Sci. 2019;20(21):5262. doi:10.3390/ ijms 20215262

140. Chondrogianni N, Kapeta S, Chinou I, Vassilatou K, Papassideri I, Gonos ES. Anti-ageing and rejuvenating effects of quercetin. Exp Gerontol. 2010;45(10):763-771. doi:10.1016/j.exger.2010.07.001

141. Pawlikowska-Pawlega B, Gawron A. Effect of quercetin on the growth of mouse fibroblast cells in vitro. Pol $J$ Pharmacol. 1995;47(6):531-535.

142. Sajadimajd S, Bahramsoltani R, Iranpanah A, et al. Advances on natural polyphenols as anticancer agents for skin cancer. Pharmacol Res. 2020;151:104584. doi:10.1016/j.phrs.2019.104584

143. Shaik Y, Caraffa A, Ronconi G, Lessiani G, Conti P. Impact of polyphenols on mast cells with special emphasis on the effect of quercetin and luteolin. Cent Eur J Immunol. 2018;43(4):476. doi:10.5114/ceji.2018.81347

144. Caltagirone S, Rossi C, Poggi A, et al. Flavonoids apigenin and quercetin inhibit melanoma growth and metastatic potential. Int $J$ Cancer. 2000;87(4):595-600. doi:10.1002/1097-0215(20000815) 87:4<595::AID-IJC21>3.0.CO;2-5

145. Vargas AJ, Sittadjody S, Thangasamy T, Mendoza EE, Limesand KH, Burd R. Exploiting tyrosinase expression and activity in melanocytic tumors: quercetin and the central role of p53. Integr Cancer Ther. 2011;10(4):328-340. doi:10.1177/1534735410391661

146. Brown J, Wang J, Kasman L, Jiang X, Haley-Zitlin V. Activities of muscadine grape skin and quercetin against Helicobacter pylori infection in mice. J Appl Microbiol. 2011;110(1):139-146. doi:10.1111/j.1365-2672.2010.04870.x

147. Amin MU, Khurram M, Khattak B, Khan J. Antibiotic additive and synergistic action of rutin, morin and quercetin against methicillin resistant Staphylococcus aureus. BMC Complement Altern Med. 2015;15(1):1-12. doi:10.1186/s12906-015-0580-0 
148. Karuppagounder V, Arumugam S, Thandavarayan RA, Sreedhar R, Giridharan VV, Watanabe K. Molecular targets of quercetin with antiinflammatory properties in atopic dermatitis. Drug Discov Today. 2016;21(4):632-639. doi:10.1016/j.drudis.2016.02.011

149. Matsushima M, Takagi K, Ogawa M, et al. Heme oxygenase-1 mediates the anti-allergic actions of quercetin in rodent mast cells. Inflamm Res. 2009;58(10):705-715. doi:10.1007/s00011-0090039-1

150. Jung MK, Hur DY, Song SB, Park Y, Kim TS. Tannic acid and quercetin display a therapeutic effect in atopic dermatitis via suppression of angiogenesis and TARC expression in $\mathrm{Nc} / \mathrm{Nga}$ mice. J Invest Dermatol. 2010;130(5):1459-1463. doi:10.1038/ jid.2009.401

151. Weng Z, Zhang B, Asadi S, et al. Quercetin is more effective than cromolyn in blocking human mast cell cytokine release and inhibits contact dermatitis and photosensitivity in humans. PLoS One. 2012;7(3):e33805. doi:10.1371/journal.pone.0033805

152. Hatahet T, Morille M, Hommoss A, Devoisselle J, Müller R, Bégu S. Quercetin topical application, from conventional dosage forms to nanodosage forms. Eur $J$ Pharm Biopharm. 2016;108:41-53. doi:10.1016/j.ejpb.2016.08.011

153. Gomathi K, Gopinath D, Ahmed MR, Jayakumar R. Quercetin incorporated collagen matrices for dermal wound healing processes in rat. Biomaterials. 2003;24(16):2767-2772. doi:10.1016/S0142-9612(03)00059-0

154. Unahabhokha T, Sucontphunt A, Nimmannit U, Chanvorachote P, Yongsanguanchai N, Pongrakhananon V. Molecular signalings in keloid disease and current therapeutic approaches from natural based compounds. Pharm Biol. 2015;53(3):457-463. doi:10.3109/13880209.2014.918157

155. Story EN, Kopec RE, Schwartz SJ, Harris GK. An update on the health effects of tomato lycopene. Annu Rev Food Sci Technol. 2010;1:189-210. doi:10.1146/annurev.food.102308.124120

156. Camara M, de Cortes Sánchez-Mata M, Fernández-Ruiz V, Cámara RM, Manzoor S, Caceres JO. Lycopene: a review of chemical and biological activity related to beneficial health effects. Stud Nat Prod Chem. 2013;40:383-426.

157. Choksi PM, Joshi VY. A review on lycopene-extraction, purification, stability and applications. Int J Food Prop. 2007;10 (2):289-298. doi:10.1080/10942910601052699

158. Olempska-Beer Z Lycopene (Synthetic) chemical and technical assessment (CTA). Submitted to the Joint Expert Committee on Food Additives (JECFA) Rome; 2006.

159. Przybylska S. Lycopene-a bioactive carotenoid offering multiple health benefits: a review. Int J Food Sci Technol. 2020;55(1):1132. doi:10.1111/ijfs. 14260

160. Heinrich U, Tronnier H, Stahl W, Bejot M, Maurette J-M. Antioxidant supplements improve parameters related to skin structure in humans. Skin Pharmacol Physiol. 2006;19(4):224231. doi: $10.1159 / 000093118$

161. Darvin M, Patzelt A, Gehse S, et al. Cutaneous concentration of lycopene correlates significantly with the roughness of the skin. Eur J Pharm Biopharm. 2008;69(3):943-947. doi:10.1016/j. ejpb.2008.01.034

162. Segger D, Schönlau F. Supplementation with Evelle ${ }^{\circledR}$ improves skin smoothness and elasticity in a double-blind, placebo-controlled study with 62 women. J Dermatol Treat. 2004;15(4):222226. doi:10.1080/09546630410033772

163. Meinke MC, Darvin ME, Vollert H, Lademann J. Bioavailability of natural carotenoids in human skin compared to blood. Eur J Pharm Biopharm. 2010;76(2):269-274. doi:10.1016/j.ejpb.2010.06.004

164. Marchena AM, Franco L, Romero AM, Barriga C, Rodríguez AB. Lycopene and melatonin: antioxidant compounds in cosmetic formulations. Skin Pharmacol Physiol. 2020;33(5):237-243. doi:10.1159/000508673
165. Fazekas Z, Gao D, Saladi RN, Lu Y, Lebwohl M, Wei H. Protective effects of lycopene against ultraviolet B-induced photodamage. Nutr Cancer. 2003;47(2):181-187. doi:10.1207/ s15327914nc4702_11

166. Basu A, Imrhan V. Tomatoes versus lycopene in oxidative stress and carcinogenesis: conclusions from clinical trials. Eur J Clin Nutr. 2007;61(3):295-303. doi:10.1038/sj.ejcn.1602510

167. Cooperstone JL, Tober KL, Riedl KM, et al. Tomatoes protect against development of UV-induced keratinocyte carcinoma via metabolomic alterations. Sci Rep. 2017;7(1):1-9. doi:10.1038/ s41598-017-05568-7

168. Kopec RE, Schick J, Tober KL, et al. Sex differences in skin carotenoid deposition and acute UVB-induced skin damage in SKH-1 hairless mice after consumption of tangerine tomatoes. Mol Nutr Food Res. 2015;59(12):2491-2501. doi:10.1002/ mnfr.201500317

169. Hwang E-S, Bowen PE. Can the consumption of tomatoes or lycopene reduce cancer risk? Integr Cancer Ther. 2002;1 (2):121-132. doi:10.1177/153473540200100203

170. Stahl W, Heinrich U, Aust O, Tronnier H, Sies H. Lycopene-rich products and dietary photoprotection. Photochem Photobiol Sci. 2006;5(2):238-242. doi:10.1039/B505312A

171. Mesa-Arango AC, FlórezMuñoz SV, Sanclemente G. Mechanisms of skin aging. Latreia. 2017;30(2):160-170. doi:10.17533/udea.iatreia. v30n2a05

172. Sies H, Stahl W. Non-nutritive bioactive food constituents of plants: lycopene, lutein and zeaxanthin. Int $J$ Vitam Nutr Res. 2003;73(2):95-100. doi:10.1024/0300-9831.73.2.95

173. Grether-Beck S, Marini A, Jaenicke T, Stahl W, Krutmann J. Molecular evidence that oral supplementation with lycopene or lutein protects human skin against ultraviolet radiation: results from a double-blinded, placebo-controlled, crossover study. $\mathrm{Br} J$ Dermatol. 2017;176(5):1231-1240. doi:10.1111/bjd.15080

174. Shih C-M, Hsieh C-K, Huang C-Y, et al. Lycopene inhibit IMQinduced psoriasis-like inflammation by inhibiting ICAM-1 production in mice. Polymers. 2020;12(7):1521. doi:10.3390/polym12071521

175. Rühl R. Non-pro-vitamin A and pro-vitamin A carotenoids in atopy development. Int Arch Allergy Immunol. 2013;161(2):99115. doi:10.1159/000345958

176. Han X, Zhang Y, Liang Y, et al. 6-Gingerol, an active pungent component of ginger, inhibits L-type $\mathrm{Ca} 2+$ current, contractility, and $\mathrm{Ca} 2+$ transients in isolated rat ventricular myocytes. Food Sci Nutr. 2019;7(4):1344-1352. doi:10.1002/fsn3.968

177. Information NCfB. PubChem Compound Summary for CID 442793 , Gingerol. [updated cited]. Avaiable from: https://pubchem.ncbi.nlm. nih.gov/compound/Gingerol. Accessed December 17, 2021.

178. Wang S, Zhang C, Yang G, Yang Y. Biological properties of 6gingerol: a brief review. Nat Prod Commun. 2014;9 (7):1934578X1400900736. doi:10.1177/1934578X1400900736

179. Qiu J-X, Zhou Z-W, He Z-X, Zhang X, Zhou S-F, Zhu S. Estimation of the binding modes with important human cytochrome P450 enzymes, drug interaction potential, pharmacokinetics, and hepatotoxicity of ginger components using molecular docking, computational, and pharmacokinetic modeling studies. Drug Des Devel Ther. 2015;9:841. doi:10.2147/ DDDT.S74669

180. Sugimoto K, Takeuchi H, Nakagawa K, Matsuoka Y. Hyperthermic effect of Ginger (Zingiber officinale) extract-containing beverage on peripheral skin surface temperature in women. Evid Based Complement Alternat Med. 2018;2018:1-8. doi: $10.1155 / 2018 / 3207623$

181. Liu Y, Liu J, Zhang Y. Research progress on chemical constituents of Zingiber officinale Roscoe. Biomed Res Int. 2019;2019:121. doi: $10.1155 / 2019 / 5370823$ 
182. Kim J-K, Kim Y, Na K-M, Surh Y-J, Kim T-Y. [6]-Gingerol prevents UVB-induced ROS production and COX-2 expression in vitro and in vivo. Free Radic Res. 2007;41(5):603-614. doi:10.1080/10715760701209896

183. Huang H-C, Chiu S-H, Chang T-M. Inhibitory effect of [6]gingerol on melanogenesis in B16F10 melanoma cells and a possible mechanism of action. Biosci Biotechnol Biochem. 2011;75(6):1067-1072. doi:10.1271/bbb.100851

184. Kim SO, Kundu JK, Shin YK, et al. [6]-Gingerol inhibits COX-2 expression by blocking the activation of p38 MAP kinase and NF- $\kappa$ B in phorbol ester-stimulated mouse skin. Oncogene. 2005;24(15):2558-2567. doi:10.1038/sj.onc. 1208446

185. Ali F, Rahul F, Naz F, Jyoti S, Siddique YH. Health functionality of apigenin: a review. Int J Food Prop. 2017;20:1197-1238. doi:10.1080/10942912.2016.1207188

186. Salehi B, Venditti A, Sharifi-Rad M, et al. The therapeutic potential of apigenin. Int $J$ Mol Sci. 2019;20(6):1305. doi:10.3390/ ijms 20061305

187. Wang M, Firrman J, Liu L, Yam K. A review on flavonoid apigenin: dietary intake, ADME, antimicrobial effects, and interactions with human gut microbiota. Biomed Res Int. 2019;2019. doi:10.1155/2019/7010467

188. Imran M, Aslam Gondal T, Atif M, et al. Apigenin as an anticancer agent. Phytother Res. 2020;34(8):1812-1828. doi:10.1002/ ptr.6647

189. Bridgeman BB, Wang P, Ye B, Pelling JC, Volpert OV, Tong X. Inhibition of mTOR by apigenin in UVB-irradiated keratinocytes: a new implication of skin cancer prevention. Cell Signal. 2016;28 (5):460-468. doi:10.1016/j.cellsig.2016.02.008

190. Kiraly AJ, Soliman E, Jenkins A, Van Dross RT. Apigenin inhibits COX-2, PGE2, and EP1 and also initiates terminal differentiation in the epidermis of tumor bearing mice. Prostaglandins Leukot Essent Fatty Acids. 2016;104:44-53. doi:10.1016/j. plefa.2015.11.006

191. Paredes-Gonzalez X, Fuentes F, Su Z-Y, Kong A-NT. Apigenin reactivates $\mathrm{Nrf2}$ anti-oxidative stress signaling in mouse skin epidermal JB6 P+ cells through epigenetics modifications. AAPS J. 2014;16(4):727-735. doi:10.1208/s12248-014-9613-8

192. Mirzoeva S, Tong X, Bridgeman BB, Plebanek MP, Volpert OV. Apigenin inhibits UVB-induced skin carcinogenesis: the role of thrombospondin-1 as an anti-inflammatory factor. Neoplasia. 2018;20(9):930-942. doi:10.1016/j.neo.2018.07.005

193. Hou M, Sun R, Hupe M, et al. Topical apigenin improves epidermal permeability barrier homoeostasis in normal murine skin by divergent mechanisms. Exp Dermatol. 2013;22(3):210-215. doi:10.1111/exd.12102

194. Zari ST, Zari TA. A review of four common medicinal plants used to treat eczema. J Med Plants Res. 2015;9(24):702-711. doi:10.5897/JMPR2015.5831

195. Man M-Q, Hupe M, Sun R, Man G, Mauro TM, Elias PM. Topical apigenin alleviates cutaneous inflammation in murine models. Evid Based Complement Alternat Med. 2012;2012:1-7. doi:10.1155/2012/912028

196. Arterbery V, Gupta S. Apigenin as an anti-aging skin treatment. $J$ Clin Cosmet Dermatol. 2018;2(2):1-8.

197. Taghipour YD, Hajialyani M, Naseri R, et al. Nanoformulations of natural products for management of metabolic syndrome. Int $J$ Nanomedicine. 2019;14:5303. doi:10.2147/IJN.S213831

198. Xie J, Huang S, Huang H, et al. Advances in the application of natural products and the novel drug delivery systems for psoriasis. Front Pharmacol. 2021;12:552. doi:10.3389/fphar.2021.644952

199. Yallapu MM, Nagesh PKB, Jaggi M, Chauhan SC. Therapeutic applications of curcumin nanoformulations. AAPS J. 2015;17 (6):1341-1356. doi:10.1208/s12248-015-9811-z
200. Bhia M, Motallebi M, Abadi B, et al. Naringenin nano-delivery systems and their therapeutic applications. Pharmaceutics. 2021;13(2):291. doi:10.3390/pharmaceutics13020291

201. Jain S, Khare P, Date T, et al. Mechanistic insights into high permeation vesicle-mediated synergistic enhancement of transdermal drug permeation. Nanomedicine. 2019;14(16):2227-2241. doi:10.2217/nnm-2018-0519

202. Prausnitz MR, Langer R. Transdermal drug delivery. Nat Biotechnol. 2008;26(11):1261-1268. doi:10.1038/nbt.1504

203. Sabri AH, Kim Y, Marlow M, et al. Intradermal and transdermal drug delivery using microneedles-Fabrication, performance evaluation and application to lymphatic delivery. Adv Drug Deliv Rev. 2020;153:195-215. doi:10.1016/j.addr.2019.10.004

204. Zsikó S, Csányi E, Kovács A, Budai-Szücs M, Gácsi A, Berkó S. Methods to evaluate skin penetration in vitro. Sci Pharm. 2019;87 (3):19. doi:10.3390/scipharm87030019

205. Polat BE, Deen WM, Langer R, Blankschtein D. A physical mechanism to explain the delivery of chemical penetration enhancers into skin during transdermal sonophoresis-Insight into the observed synergism. J Control Release. 2012;158(2):250-260. doi:10.1016/j.jconrel.2011.11.008

206. Abd E, Yousef SA, Pastore MN, et al. Skin models for the testing of transdermal drugs. Clin Pharmacol. 2016;8:163. doi:10.2147/ CPAA.S64788

207. Gerber M, Breytenbach JC, Du Plessis J. Transdermal penetration of zalcitabine, lamivudine and synthesised $\mathrm{N}$-acyl lamivudine esters. Int $J$ Pharm. 2008;351(1-2):186-193. doi:10.1016/j. ijpharm.2007.09.040

208. Lipinski CA, Lombardo F, Dominy BW, Feeney PJ. Experimental and computational approaches to estimate solubility and permeability in drug discovery and development settings. Adv Drug Deliv Rev. 1997;23(1-3):3-25. doi:10.1016/S0169-409X(96)00423-1

209. Prausnitz MR, Mitragotri S, Langer R. Current status and future potential of transdermal drug delivery. Nat Rev Drug Discov. 2004;3(2):115-124. doi:10.1038/nrd1304

210. Choudhury H, Gorain B, Pandey M, et al. Recent update on nanoemulgel as topical drug delivery system. J Pharm Sci. 2017;106(7):1736-1751. doi:10.1016/j.xphs.2017.03.042

211. Huang X, Peng X, Wang Y, et al. A reexamination of active and passive tumor targeting by using rod-shaped gold nanocrystals and covalently conjugated peptide ligands. ACS Nano. 2010;4 (10):5887-5896. doi:10.1021/nn102055s

212. DeLouise LA. Applications of nanotechnology in dermatology. $J$ Investig Dermatol. 2012;132(3):964-975. doi:10.1038/jid.2011.425

213. Jeevanandam J, San Chan Y, Danquah MK. Nano-formulations of drugs: recent developments, impact and challenges. Biochimie. 2016;128:99-112. doi:10.1016/j.biochi.2016.07.008

214. Sahni JK, Baboota S, Ali J. Promising role of nanopharmaceuticals in drug delivery. Pharma Times. 2011;43(10):16-18.

215. Diab R, Jaafar-Maalej C, Fessi H, Maincent P. Engineered nanoparticulate drug delivery systems: the next frontier for oral administration? AAPS J. 2012;14(4):688-702. doi:10.1208/s12248-012-9377-y

216. Kalani M, Yunus R. Application of supercritical antisolvent method in drug encapsulation: a review. Int J Nanomedicine. 2011;6:1429. doi:10.2147/IJN.S19021

217. Kaul S, Gulati N, Verma D, Mukherjee S, Nagaich U. Role of nanotechnology in cosmeceuticals: a review of recent advances. $J$ Pharm. 2018;2018:1-19. doi:10.1155/2018/3420204

218. Khogta S, Patel J, Barve K, Londhe V. Herbal nano-formulations for topical delivery. J Herb Med. 2020;20:100300. doi:10.1016/j. hermed.2019.100300

219. Kaur R, Sharma A, Puri V, Singh I. Preparation and characterization of biocomposite films of carrageenan/locust bean gum/montmorillonite for transdermal delivery of curcumin. BioImpacts. 2019;9(1):37. doi:10.15171/bi.2019.05 
220. Ramakrishnan P, Loh WM, Gopinath SC, et al. Selective phytochemicals targeting pancreatic stellate cells as new anti-fibrotic agents for chronic pancreatitis and pancreatic cancer. Acta Pharm Sin B. 2020;10(3):399-413. doi:10.1016/j.apsb.2019.11.008

221. Lum PT, Sekar M, Gan SH, Bonam SR, Shaikh MF. Protective effect of natural products against Huntington's disease: an overview of scientific evidence and understanding their mechanism of action. ACS Chem Neurosci. 2021;12(3):391-418. doi:10.1021/ acschemneuro.0c00824

222. Lum PT, Sekar M, Gan SH, Pandy V, Bonam SR. Protective effect of mangiferin on memory impairment: a systematic review. Saudi J Biol Sci. 2020;28(1):917-927. doi:10.1016/j.sjbs.2020.11.037

223. Bonam SR, Wu YS, Tunki L, et al. What has come out from phytomedicines and herbal edibles for the treatment of cancer? ChemMedChem. 2018;13(18):1854-1872. doi:10.1002/cmdc.20 1800343

224. Pires JR, Nogueira MRS, Nunes AJF, et al. Deposition of immune complexes in gingival tissues in the presence of periodontitis and systemic lupus erythematosus. Front Immunol. 2021;12:663. doi:10.3389/fimmu.2021.591236

225. Careta MF, Romiti R. Localized scleroderma: clinical spectrum and therapeutic update. An Bras Dermatol. 2015;90:62-73. doi:10.1590/abd1806-4841.20152890

226. Sapkota B, Al Khalili Y. Mixed connective tissue disease. In: StatPearls. Treasure Island (FL): StatPearls Publishing. Copyright (C) 2021, StatPearls Publishing LLC:; 2021.

227. Cheeti A, Brent LH, Panginikkod S. Autoimmune myopathies. In: StatPearls. Treasure Island (FL): StatPearls Publishing. Copyright (C) 2021, StatPearls Publishing LLC.; 2021.

228. Koler RA, Montemarano A. Dermatomyositis. Am Fam Physician. 2001;64(9):1565.

229. Siiskonen H, Harvima I. Mast cells and sensory nerves contribute to neurogenic inflammation and pruritus in chronic skin inflammation. Front Cell Neurosci. 2019;13:422. doi:10.3389/ fncel.2019.00422

230. Umehara Y, Kiatsurayanon C, Trujillo-Paez JV, et al. Intractable itch in atopic dermatitis: causes and treatments. Biomedicines. 2021;9(3):229. doi:10.3390/biomedicines9030229

231. Corsini E, Engin AB, Neagu M, et al. Chemical-induced contact allergy: from mechanistic understanding to risk prevention. Arch Toxicol. 2018;92(10):3031-3050. doi:10.1007/s00204-018-2283-z

232. Kaplan DH, Igyártó BZ, Gaspari AA. Early immune events in the induction of allergic contact dermatitis. Nat Rev Immunol. 2012;12(2):114-124. doi:10.1038/nri3150

233. Pratt CH, King LE, Messenger AG, Christiano AM, Sundberg JP. Alopecia areata. Nat Rev Dis Primers. 2017;3(1):1-17. doi:10.1038/nrdp.2017.11

234. Folgori L, Scarselli A, Angelino G, et al. Cutaneous granulomatosis and combined immunodeficiency revealing AtaxiaTelangiectasia: a case report. Ital J Pediatr. 2010;36(1):1-4. doi:10.1186/1824-7288-36-29

235. Goldman MP. Pathophysiology of telangiectasias. In: Sclerotherapy (Sixth Edition); 2017.

236. Beenhouwer DO. Molecular basis of diseases of immunity. In: Molecular Pathology. Elsevier; 2018.

237. Song E, Jaishankar GB, Saleh H, Jithpratuck W, Sahni R, Krishnaswamy G. Chronic granulomatous disease: a review of the infectious and inflammatory complications. Clin Mol Allergy. 2011;9(1):1-14. doi:10.1186/1476-7961-9-10

238. Freeman AF, Holland SM. The hyper-IgE syndromes. Immunol Allergy Clin North Am. 2008;28(2):277-291. doi:10.1016/j. iac.2008.01.005

239. Freeman AF, Olivier KN. Hyper-IgE syndromes and the lung Clin Chest Med. 2016;37(3):557-567. doi:10.1016/j. ccm.2016.04.016
240. Snyder PW. Chapter 5 - Diseases of Immunity1. In: Zachary JF, editor. Pathologic Basis of Veterinary Disease (Sixth Edition). Mosby; 2017.

241. Justiz Vaillant AA, Ahmad F. Leukocyte adhesion deficiency. In: StatPearls. Treasure Island (FL): StatPearls Publishing. Copyright (C) 2021, StatPearls Publishing LLC.; 2021.

242. Fischer A. Severe combined immunodeficiencies (SCID). Clin Exp Immunol. 2000;122(2):143. doi:10.1046/j.1365-2249.2000.01359.x

243. Tasher D, Dalal I. The genetic basis of severe combined immunodeficiency and its variants. Appl Clin Genet. 2012;5:67. doi:10.2147/TACG.S18693

244. Badolato R, Donadieu J, Group WR. How I treat warts, hypogammaglobulinemia, infections, and myelokathexis syndrome. Blood. 2017;130(23):2491-2498.

245. Baharin MF, Dhaliwal JS, Sarachandran SV, Idris SZ, Yeoh SL. A rare case of Wiskott-Aldrich syndrome with normal platelet size: a case report. J Med Case Rep. 2016;10(1):1-4. doi:10.1186/ s13256-016-0944-1

246. Malik MA, Masab M. Wiskott-Aldrich syndrome. In: StatPearls. Treasure Island (FL): StatPearls Publishing. Copyright (C) 2021, StatPearls Publishing LLC.; 2021.

247. Errichetti E, Stinco G. Dermoscopy in general dermatology: a practical overview. Dermatol Ther. 2016;6(4):471-507. doi:10.1007/s13555-016-0141-6

248. Langley R, Krueger G, Griffiths C. Psoriasis: epidemiology, clinical features, and quality of life. Ann Rheum Dis. 2005;64 (supp12):ii18-ii23. doi:10.1136/ard.2004.033217

249. Armstrong AW. Psoriasis. JAMA Dermatol. 2017;153(9):956. doi:10.1001/jamadermatol.2017.2103

250. Arnold DL, Krishnamurthy K. Lichen planus. In: StatPearls. Treasure Island (FL): StatPearls Publishing. Copyright (C) 2021, StatPearls Publishing LLC.; 2021.

251. Villarreal CDV, Alanis JCS, Pérez JCJ, Candiani JO. Cutaneous graft-versus-host disease after hematopoietic stem cell transplanta review. An Bras Dermatol. 2016;91:336-343. doi:10.1590/ abd1806-4841.20164180

252. Plaza JA, Prieto VG. Inflammatory skin conditions. In: Modern Surgical Pathology. Elsevier Inc.; 2009.

253. Harris BW, Badri T, Schlessinger J. Solar urticaria. In: StatPearls. Treasure Island (FL): StatPearls Publishing. Copyright (C) 2021, StatPearls Publishing LLC.; 2021.

254. Smith E, Kiss F, Porter RM, Anstey AV. A review of UVAmediated photosensitivity disorders. Photochem Photobiol Sci. 2002;1(11):199-206

255. Foti C, Bonamonte D, Cassano N, Vena G, Angelini G. Photoallergic contact dermatitis. G Ital Dermatol Venereol. 2009; 144(5):515-525.

256. Bergqvist C, Ezzedine K. Vitiligo: a review. Dermatology. 2020;236(6):571-592. doi:10.1159/000506103

257. Marks JG, Miller JJ. CHAPTER 17 - Purpura. In: Marks JG, Miller JJ, editors. Lookingbill \& Marks' Principles of Dermatology (Fourth Edition). Edinburgh: W.B. Saunders; 2006.

258. Reamy BV, Williams PM, Lindsay TJ. Henoch-Schönlein purpura. Am Fam Physician. 2009;80(7):697-704.

259. Azanza JJC, Sarmiento PMC, Lia NL, Alexander SA, Modi V. Leukocytoclastic vasculitis: an early skin biopsy makes a difference. Cureus. 2020;12(5):e7912.

260. Baigrie D, Bansal P, Goyal A, Crane JS. Leukocytoclastic vasculitis. In: StatPearls. Treasure Island (FL): StatPearls Publishing. Copyright (C) 2021, StatPearls Publishing LLC.; 2021.

261. Hunder G. Vasculitis: diagnosis and therapy. Am J Med. 1996;100 (2):37S-45S. doi:10.1016/S0002-9343(97)89545-9

262. Deacock S. An approach to the patient with urticaria. Clin Exp Immunol. 2008;153(2):151-161. doi:10.1111/j.1365-2249.200 8.03693.x 
263. Engin B, Oba MÇ, Serdaroğlu S. Urticaria and Angioedema. In: A Comprehensive Review of Urticaria and Angioedema. 2017:11.

264. Ely JW, Stone MS. The generalized rash: part I. Differential diagnosis. Am Fam Physician. 2010;81(6):726-734.

265. Hafsi W, Badri T. Erythema Multiforme. In: StatPearls. Treasure Island (FL): StatPearls Publishing. Copyright (C) 2021, StatPearls Publishing LLC.; 2021.

266. Paulino L, Hamblin DJ, Osondu N, Amini R. Variants of erythema multiforme: a case report and literature review. Cureus. 2018;10(10). doi:10.7759/cureus.3459

267. Klimas N, Quintanilla-Dieck J, Vandergriff T. Stevens-Johnson syndrome and toxic epidermal necrolysis. In: Cutaneous Drug Eruptions. Springer; 2015.

268. Mawson AR, Eriator I, Karre S. Stevens-Johnson syndrome and toxic epidermal necrolysis (SJS/TEN): could retinoids play a causative role? Med Sci Monit. 2015;21:133. doi:10.12659/ MSM.891043

269. Azizi G, Arshi S, Nabavi M, Shabestari MS, Suri D, Gupta S. Autoinflammatory disorders. In: Inborn Errors of Immunity. Elsevier; 2021.

270. Alsharief AN, Laxer RM, Wang Q, et al. Monogenic autoinflammatory diseases in children: single center experience with clinical, genetic, and imaging review. Insights Imaging. 2020;11 (1):1-24. doi:10.1186/s13244-020-00889-0

271. Huttenlocher A, Frieden I, Emery H. Neonatal onset multisystem inflammatory disease. J Rheumatol. 1995;22(6):1171-1173.

272. Kutukculer N, Puel A, Eren Akarcan S, et al. Deficiency of interleukin-1 receptor antagonist: a case with late onset severe inflammatory arthritis, nail psoriasis with onychomycosis and well responsive to Adalimumab therapy. Case Rep Immunol. 2019;2019:1-6. doi:10.1155/2019/1902817

273. Schnellbacher C, Ciocca G, Menendez R, et al. Deficiency of interleukin-1 receptor antagonist responsive to anakinra. Pediatr Dermatol. 2013;30(6):758-760. doi:10.1111/j.1525-1470.2012.01725.x
274. Kasperkiewicz M, Ellebrecht CT, Takahashi H, et al. Pemphigus. Nat Rev Dis Primers. 2017;3(1):1-18.

275. James KA, Culton DA, Diaz LA. Diagnosis and clinical features of pemphigus foliaceus. Dermatol Clin. 2011;29(3):405-412. doi:10.1016/j.det.2011.03.012

276. Bakker CV, Terra JB, Pas HH, Jonkman MF. Bullous pemphigoid as pruritus in the elderly: a common presentation. JAMA Dermatol. 2013;149(8):950-953. doi:10.1001/jamadermatol.20 13.756

277. Yatim A, Bohelay G, Grootenboer-Mignot S, et al. Paraneoplastic pemphigus revealed by anti-programmed death-1 pembrolizumab therapy for cutaneous squamous cell carcinoma complicating hidradenitis suppurativa. Front Med. 2019;6:249. doi:10.3389/ fmed.2019.00249

278. Gupta R, Woodley DT, Chen M. Epidermolysis bullosa acquisita. Clin Dermatol. 2012;30(1):60-69. doi:10.1016/j.clinderma tol.2011.03.011

279. Criado PR, Criado RFJ, Aoki V, et al. Dermatitis herpetiformis: relevance of the physical examination to diagnosis suspicion. Can Fam Physician. 2012;58(8):843-847.

280. Chen S, Mattei P, Fischer M, Gay JD, Milner SM, Price LA. Linear IgA bullous dermatosis. Eplasty. 2013;13:ic49.

281. Şentürk Ş, Dilek N, Tekin YB, Çolak S, Gündoğdu B, Güven ESG. Pemphigoid gestationis in a third trimester pregnancy. Case Rep Obstet Gynecol. 2014;2014. doi:10.1155/2014/127628

282. Snarskaya ES, Olisova OY, Makatsariya AD, et al. Skin pathologies in pregnancy. $J$ Perinat Med. 2019;47(4):371-380. doi:10.1515/jpm-2018-0338

283. Lee SH, Koo BS, Park SY, Kim YM. Anti-angiogenic effects of resveratrol in combination with 5-fluorouracil on B16 murine melanoma cells. Mol Med Rep. 2015;12(2):2777-2783. doi:10.3892/mmr.2015.3675

\section{Publish your work in this journal}

Drug Design, Development and Therapy is an international, peerreviewed open-access journal that spans the spectrum of drug design and development through to clinical applications. Clinical outcomes, patient safety, and programs for the development and effective, safe, and sustained use of medicines are a feature of the journal, which has also been accepted for indexing on PubMed Central. The manuscrip management system is completely online and includes a very quick and fair peer-review system, which is all easy to use. Visit http://www. dovepress.com/testimonials.php to read real quotes from published authors. 